\title{
Copper-Catalyzed Aza-Michael Addition of
}

\author{
Aromatic Amines or Aromatic Aza-Heterocycles \\ to $\alpha, \beta$-Unsaturated Olefins
}

Seongcheol Kim, Seongil Kang, Gihyeon Kim and Yunmi Lee*

Department of Chemistry, Kwangwoon University, Seoul 01897, Republic of Korea

Supplementary Information 
- ${ }^{1} \mathrm{H}$ NMR and ${ }^{13} \mathrm{C}$ NMR spectra for all products:

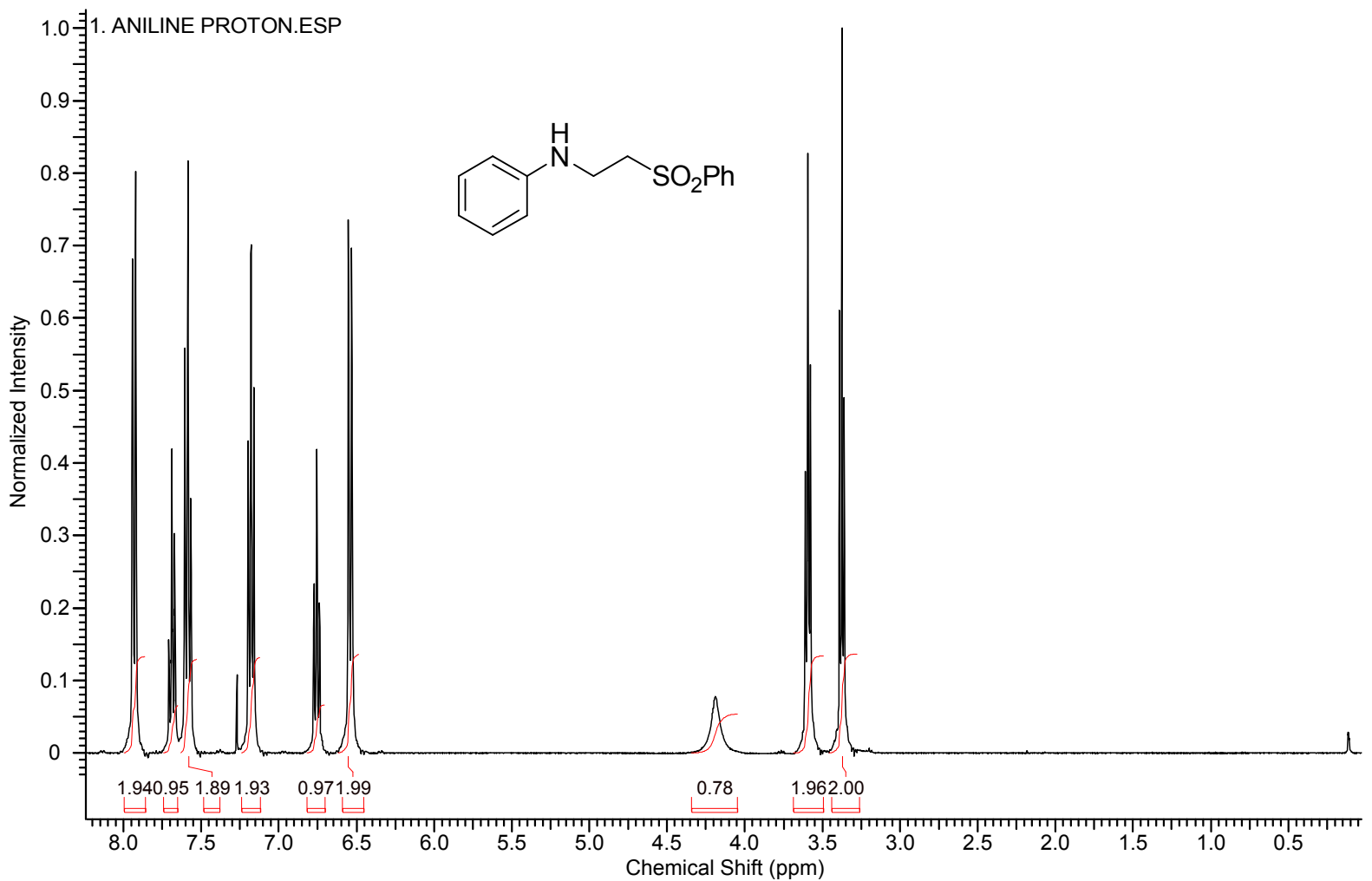

Figure S1. ${ }^{1} \mathrm{H}$ NMR spectrum of the compound 3a

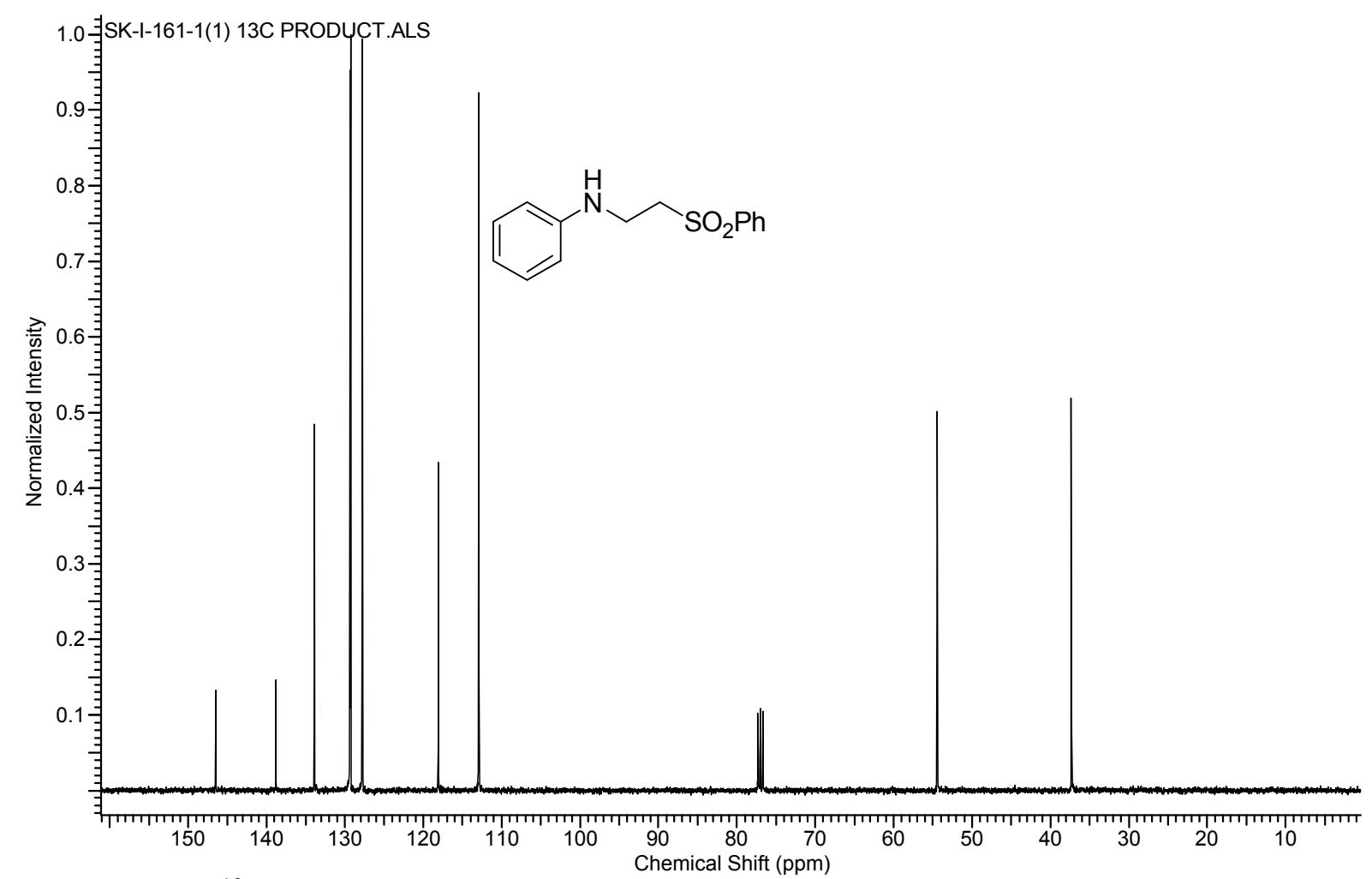

Figure S2. ${ }^{13} \mathrm{C}$ NMR spectrum of the compound 3a 


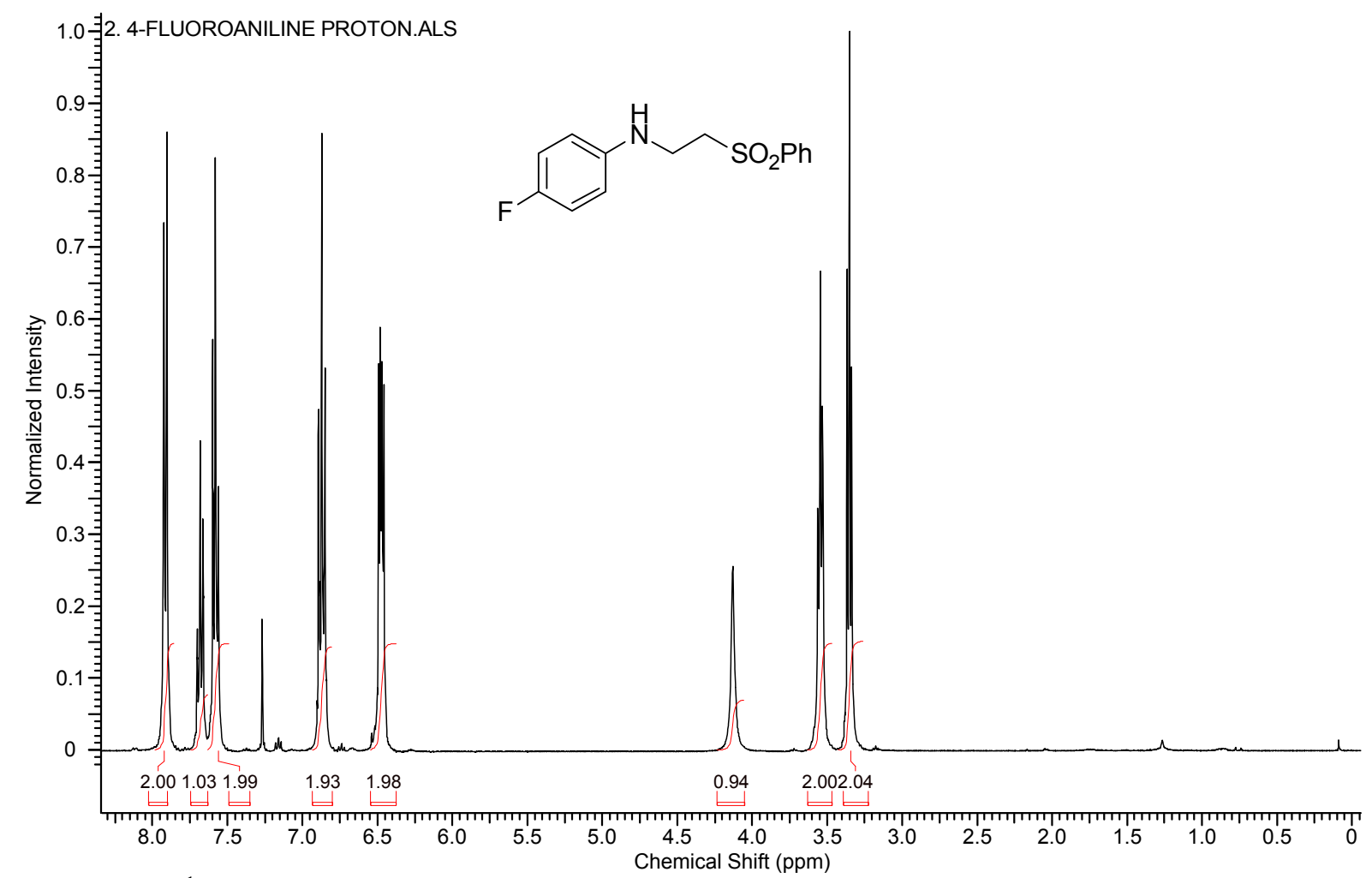

Figure S3. ${ }^{1} \mathrm{H}$ NMR spectrum of the compound $\mathbf{3 b}$

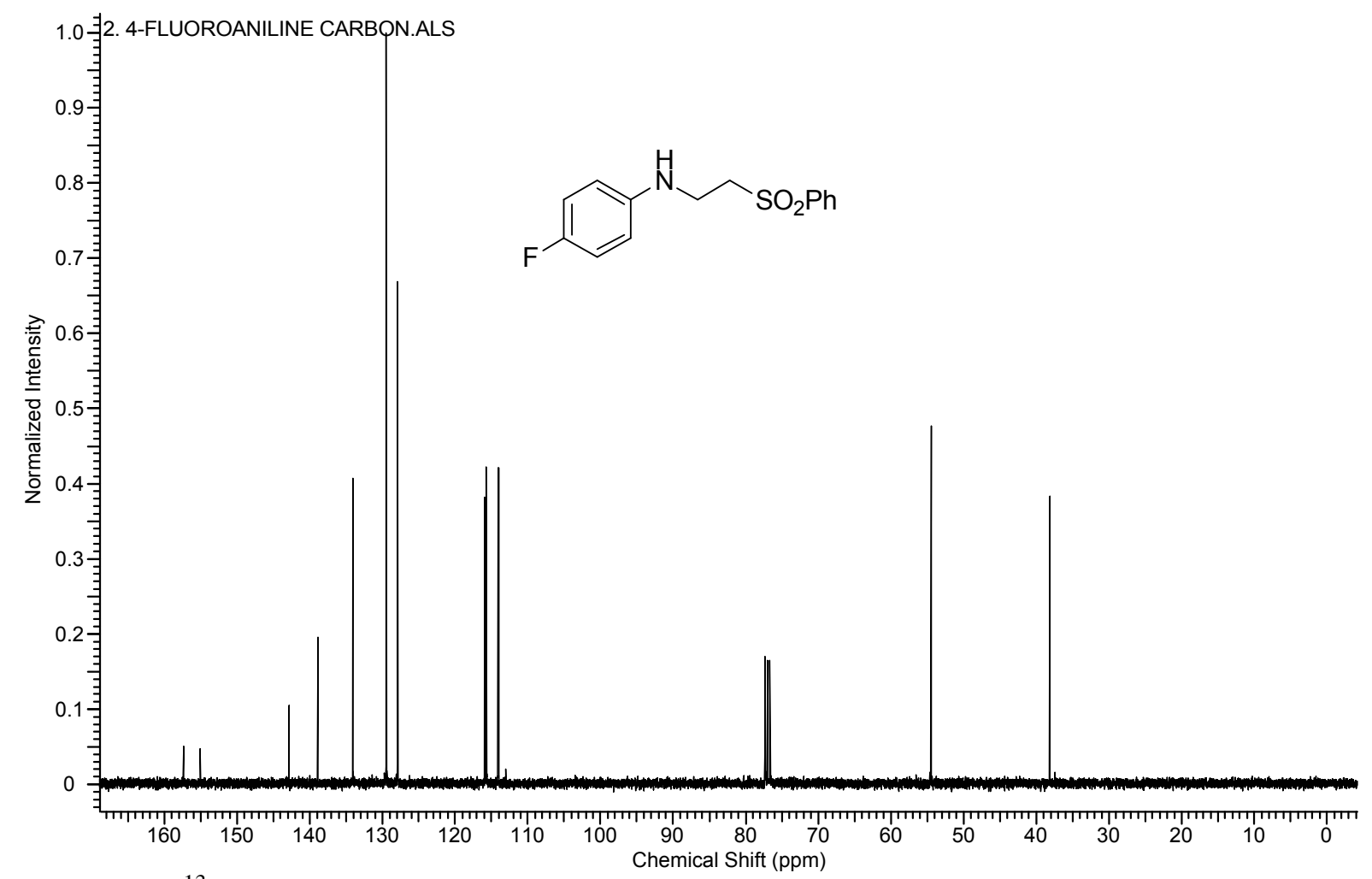

Figure S4. ${ }^{13} \mathrm{C}$ NMR spectrum of the compound $\mathbf{3 b}$ 


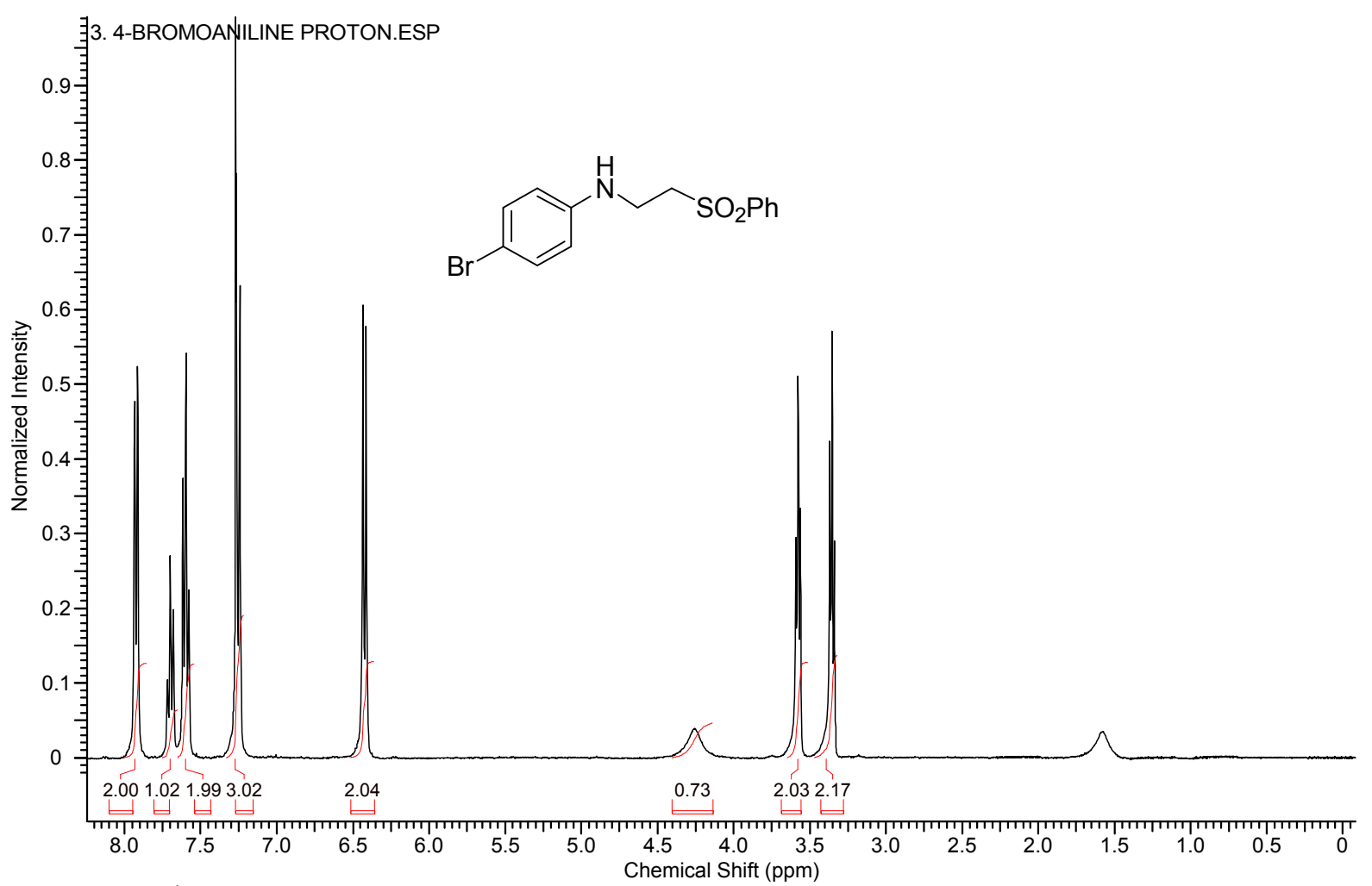

Figure S5. ${ }^{1} \mathrm{H}$ NMR spectrum of the compound 3c

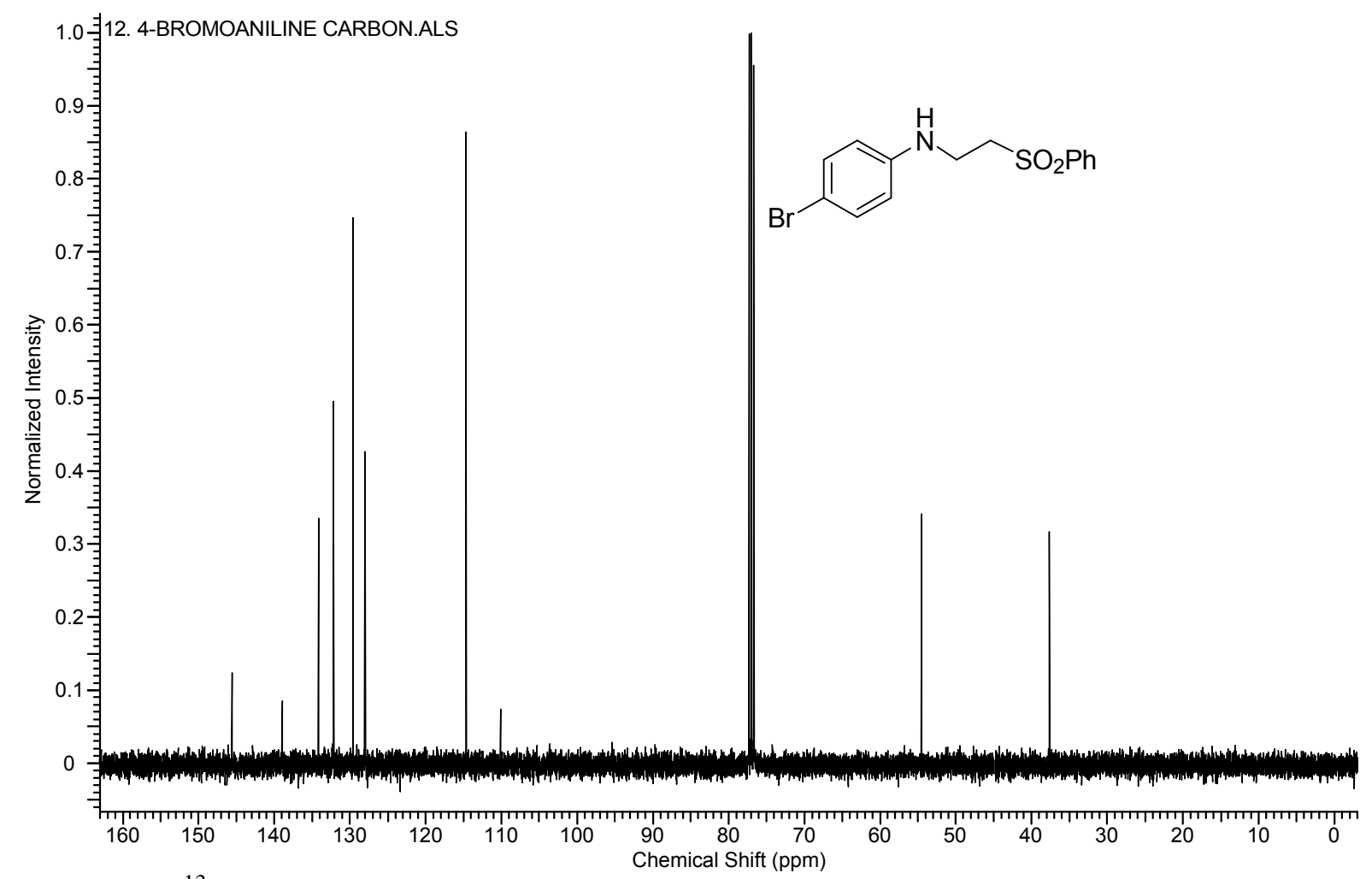

Figure S6. ${ }^{13} \mathrm{C}$ NMR spectrum of the compound 3c 


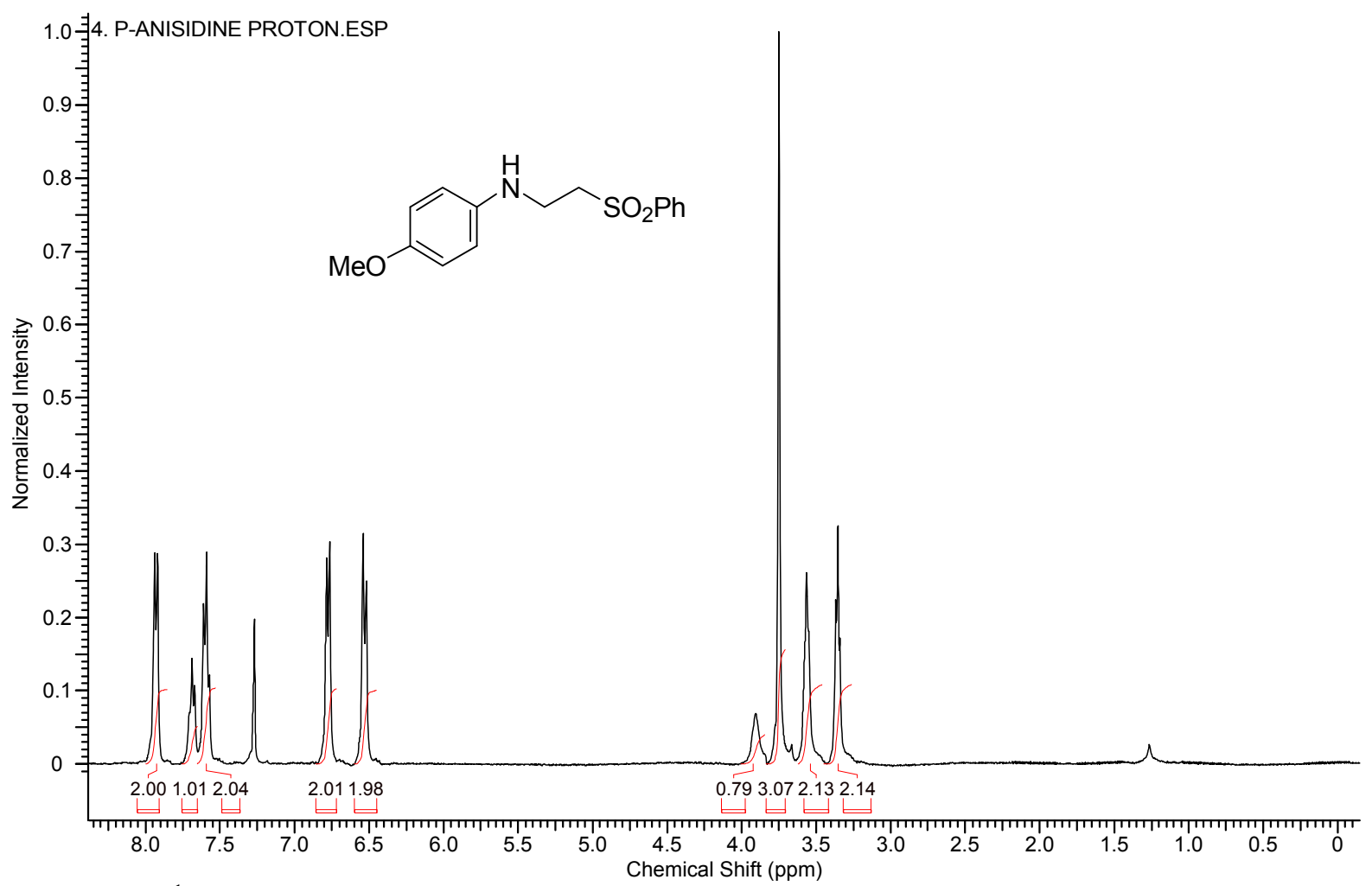

Figure S7. ${ }^{1} \mathrm{H}$ NMR spectrum of the compound 3d

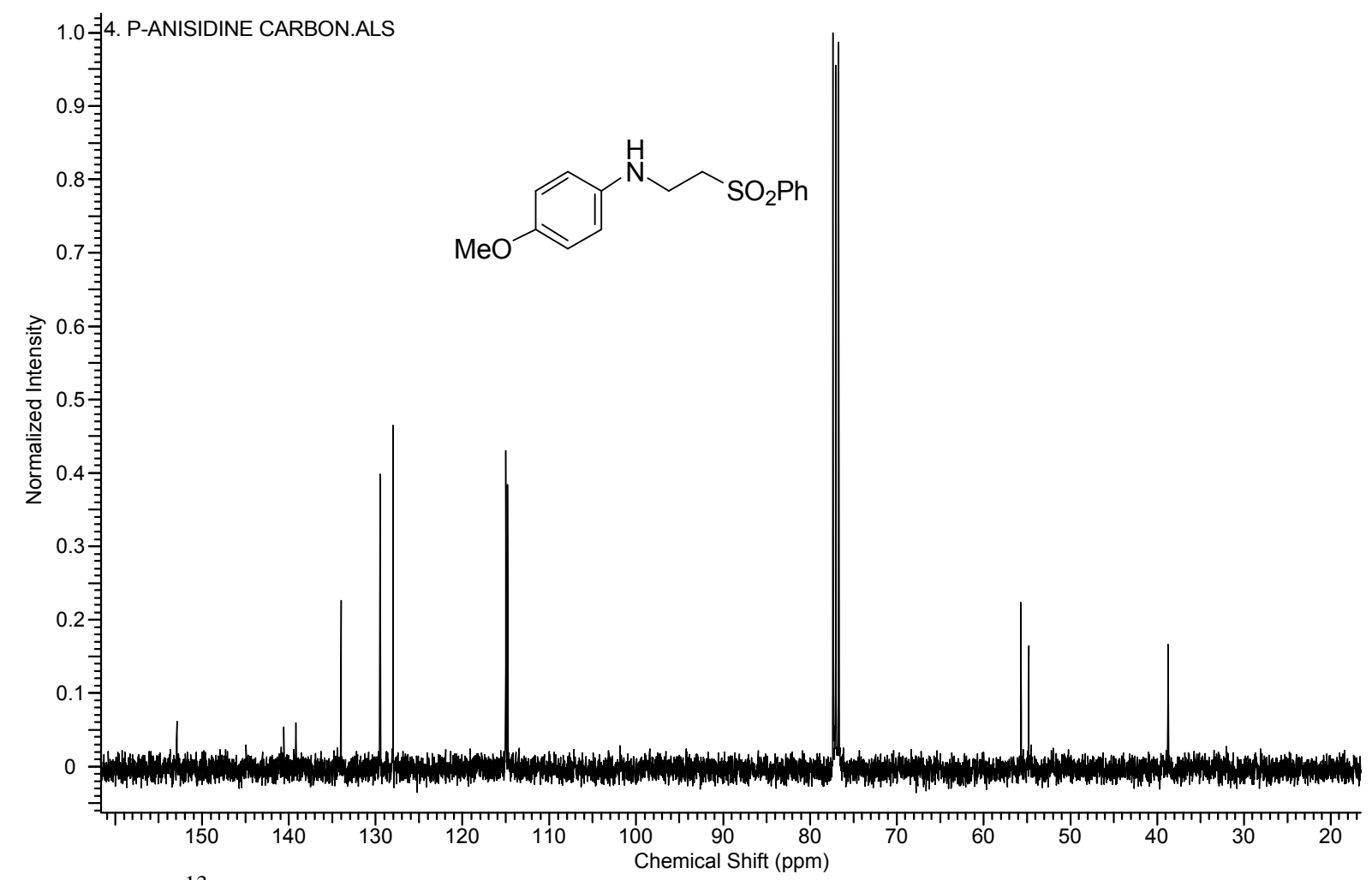

Figure S8. ${ }^{13} \mathrm{C}$ NMR spectrum of the compound 3d 


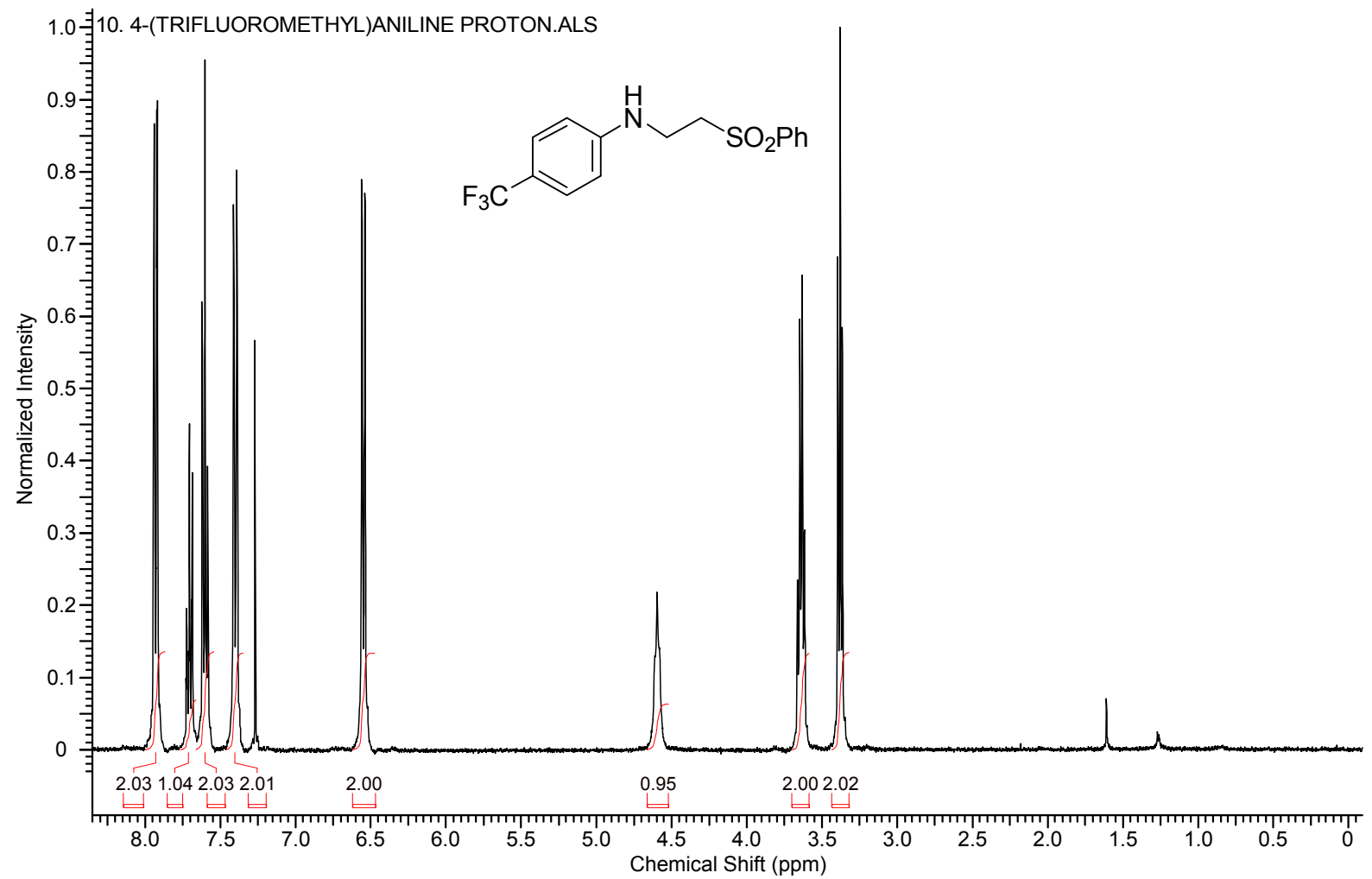

Figure S9. ${ }^{1} \mathrm{H}$ NMR spectrum of the compound $3 \mathbf{e}$

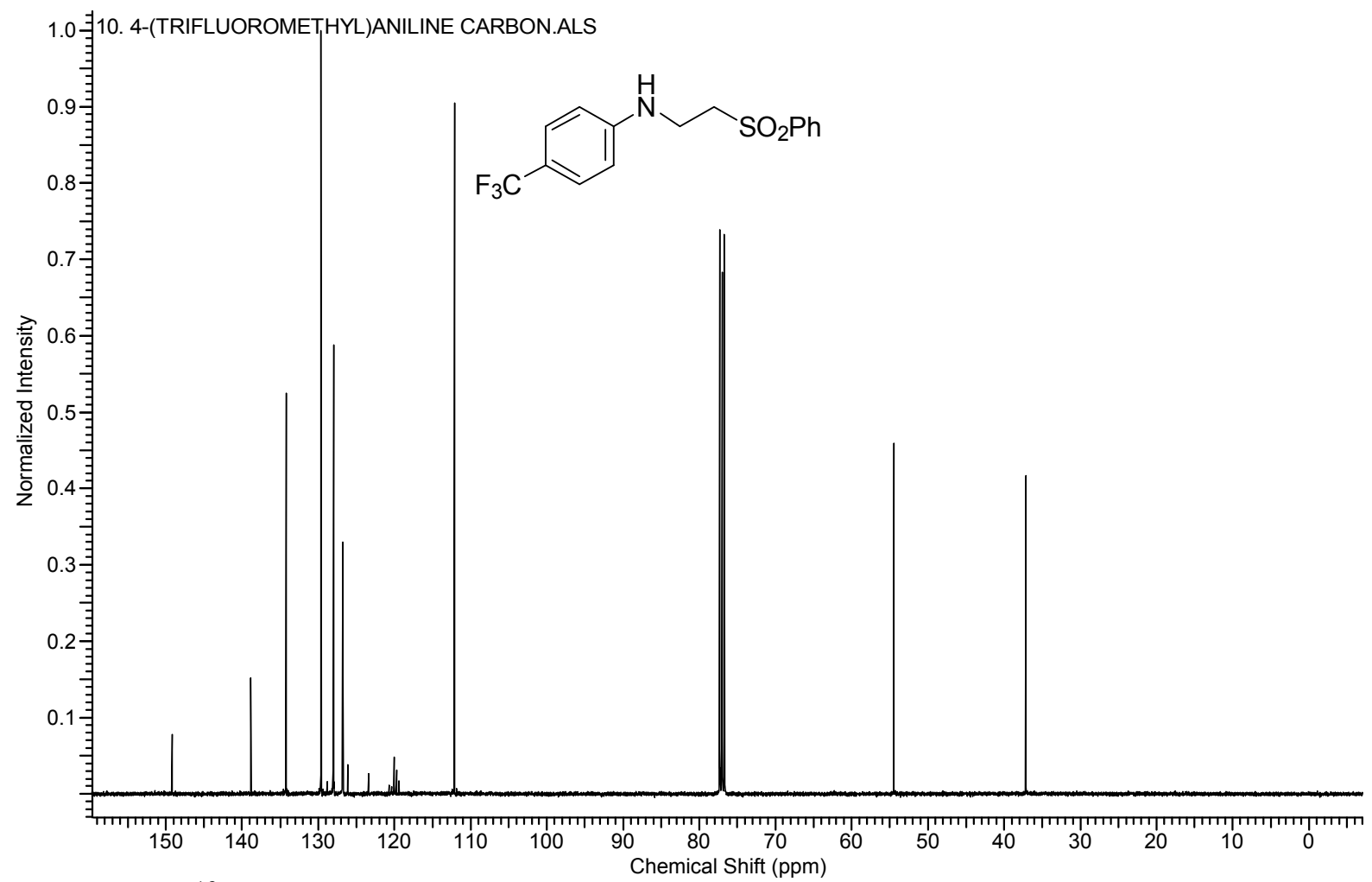

Figure S10. ${ }^{13} \mathrm{C}$ NMR spectrum of the compound $3 \mathrm{e}$

6 


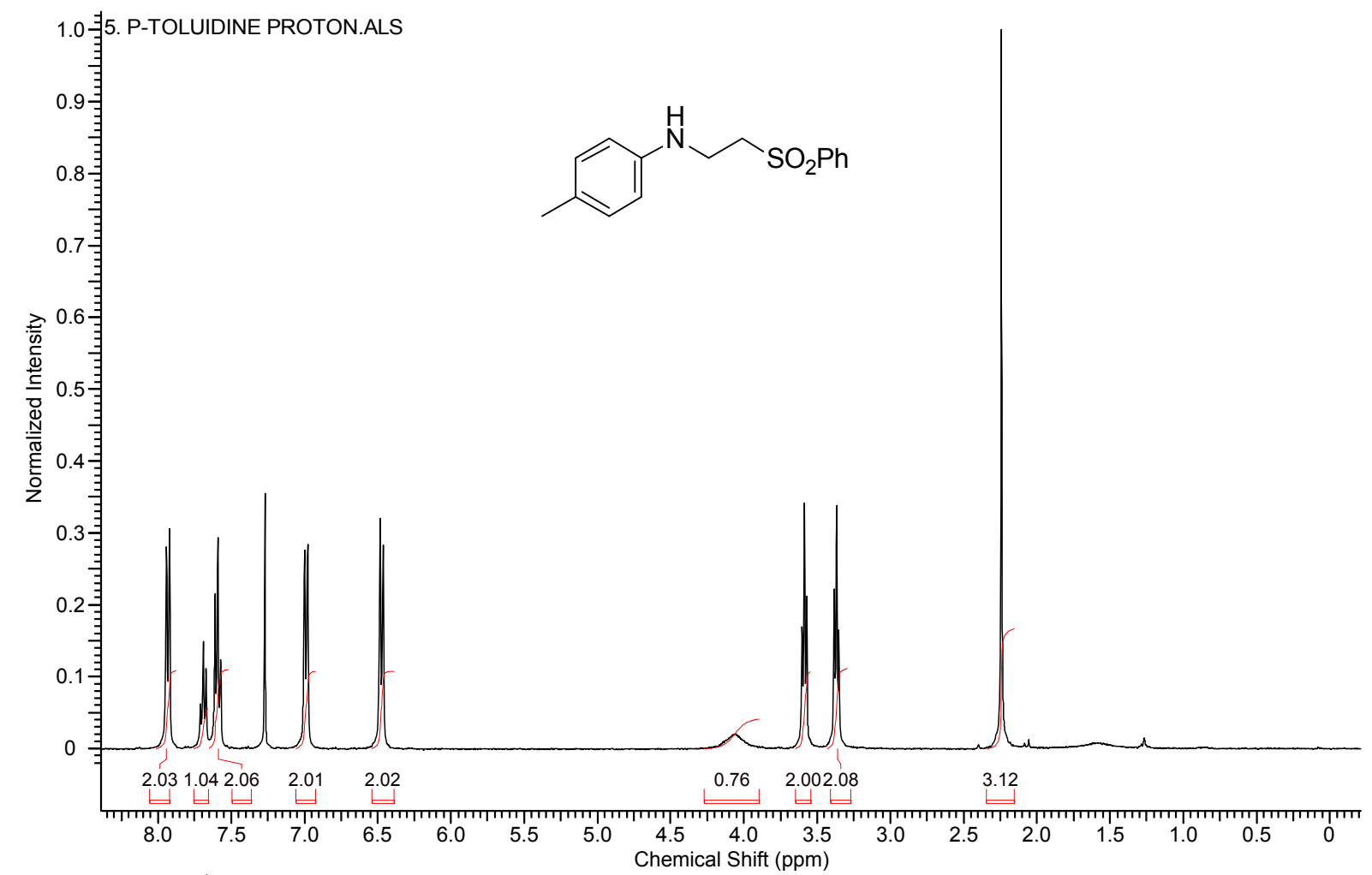

Figure S11. ${ }^{1} \mathrm{H}$ NMR spectrum of the compound $\mathbf{3 f}$

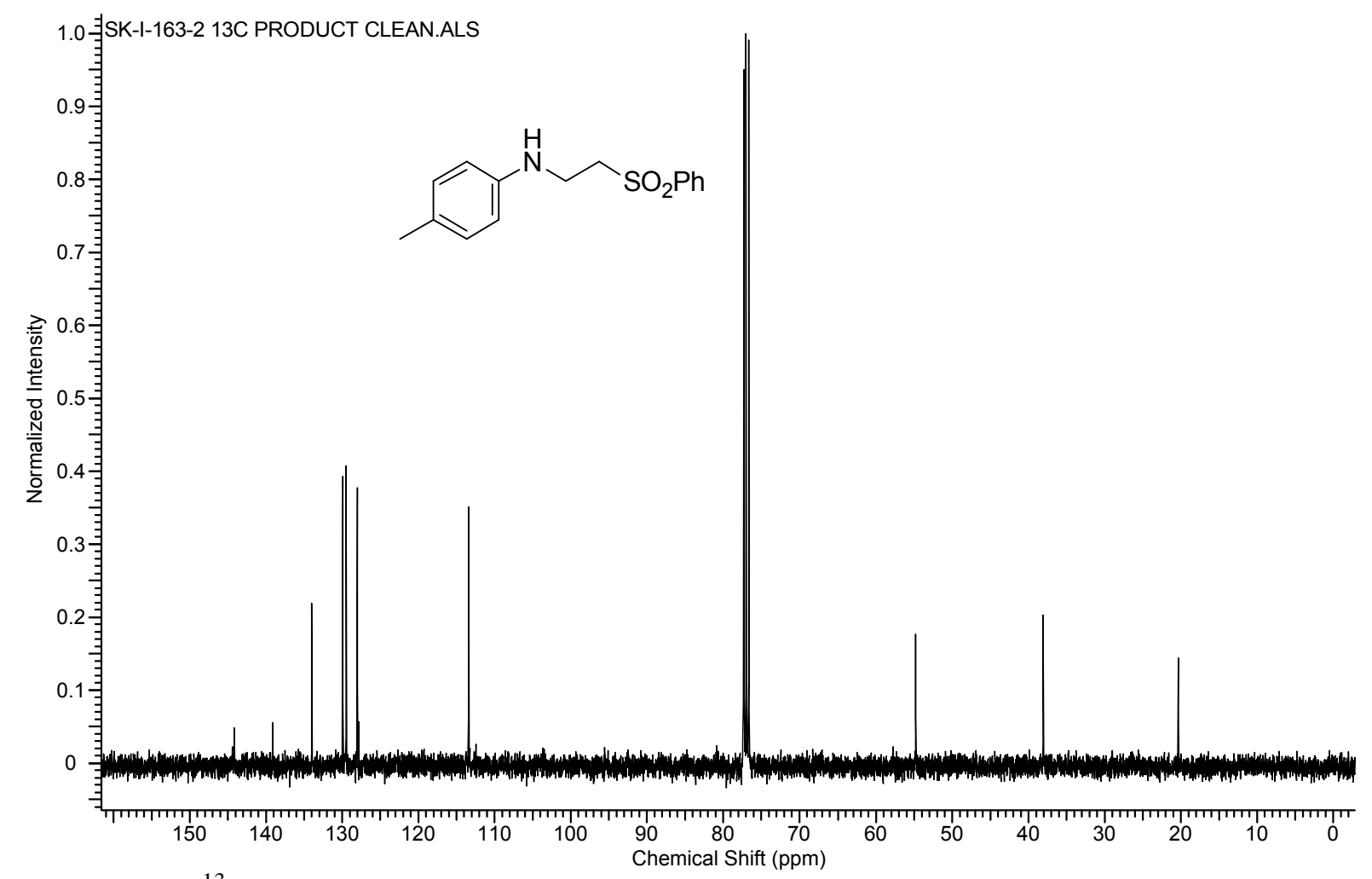

Figure S12. ${ }^{13} \mathrm{C}$ NMR spectrum of the compound $\mathbf{3 f}$ 


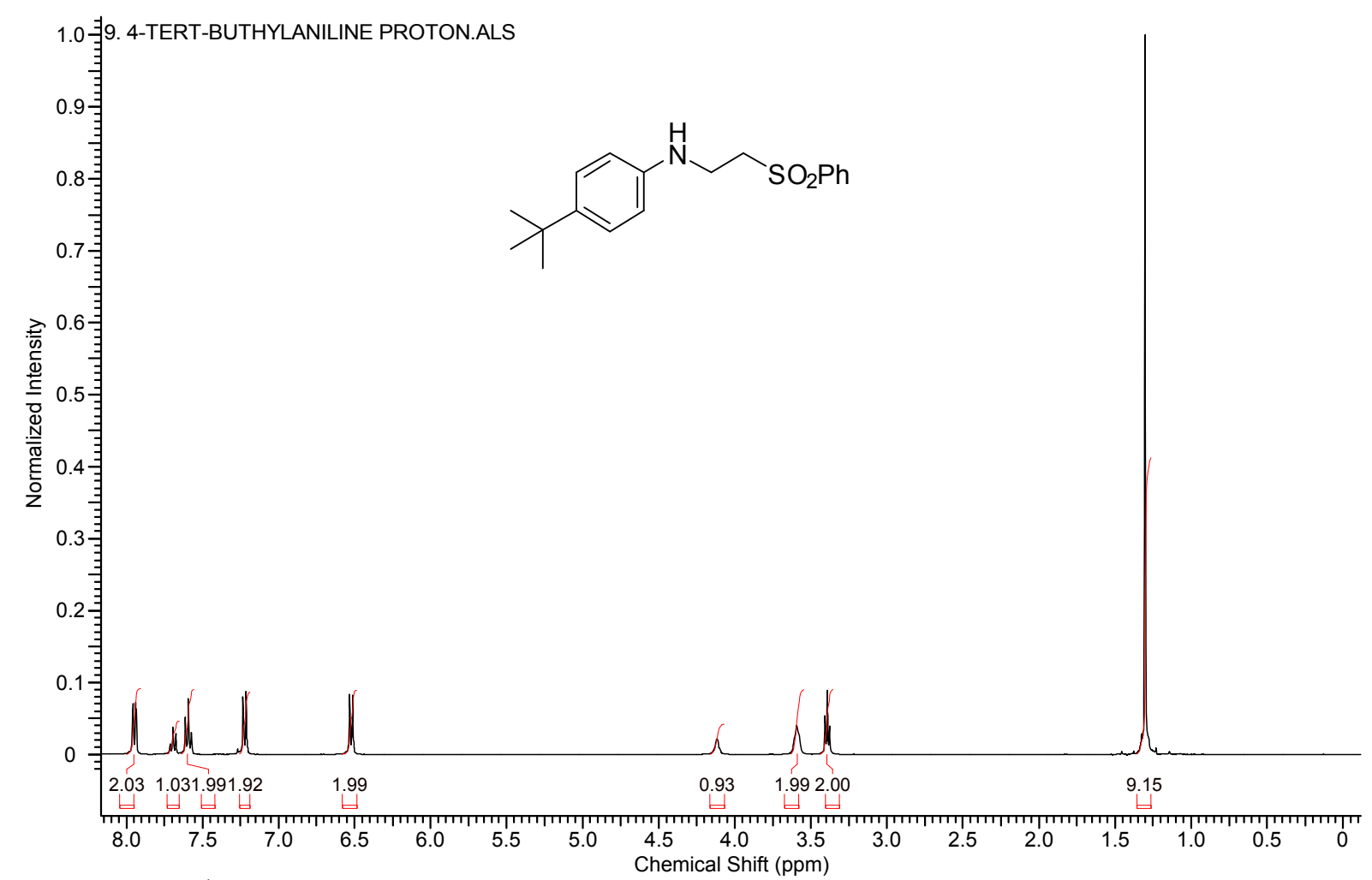

Figure S13. ${ }^{1} \mathrm{H}$ NMR spectrum of the compound $\mathbf{3 g}$

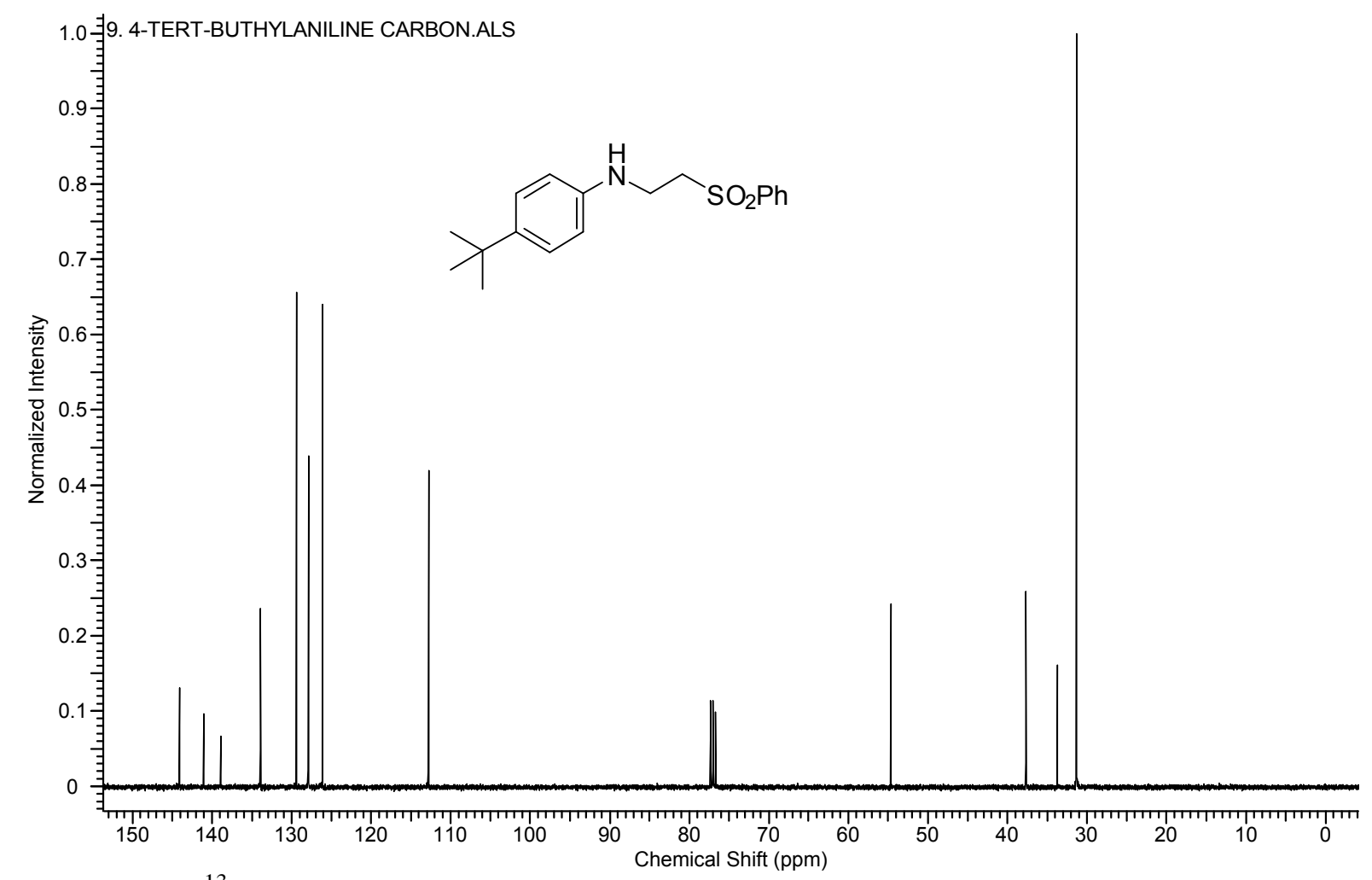

Figure S14. ${ }^{13} \mathrm{C}$ NMR spectrum of the compound $\mathbf{3 g}$ 


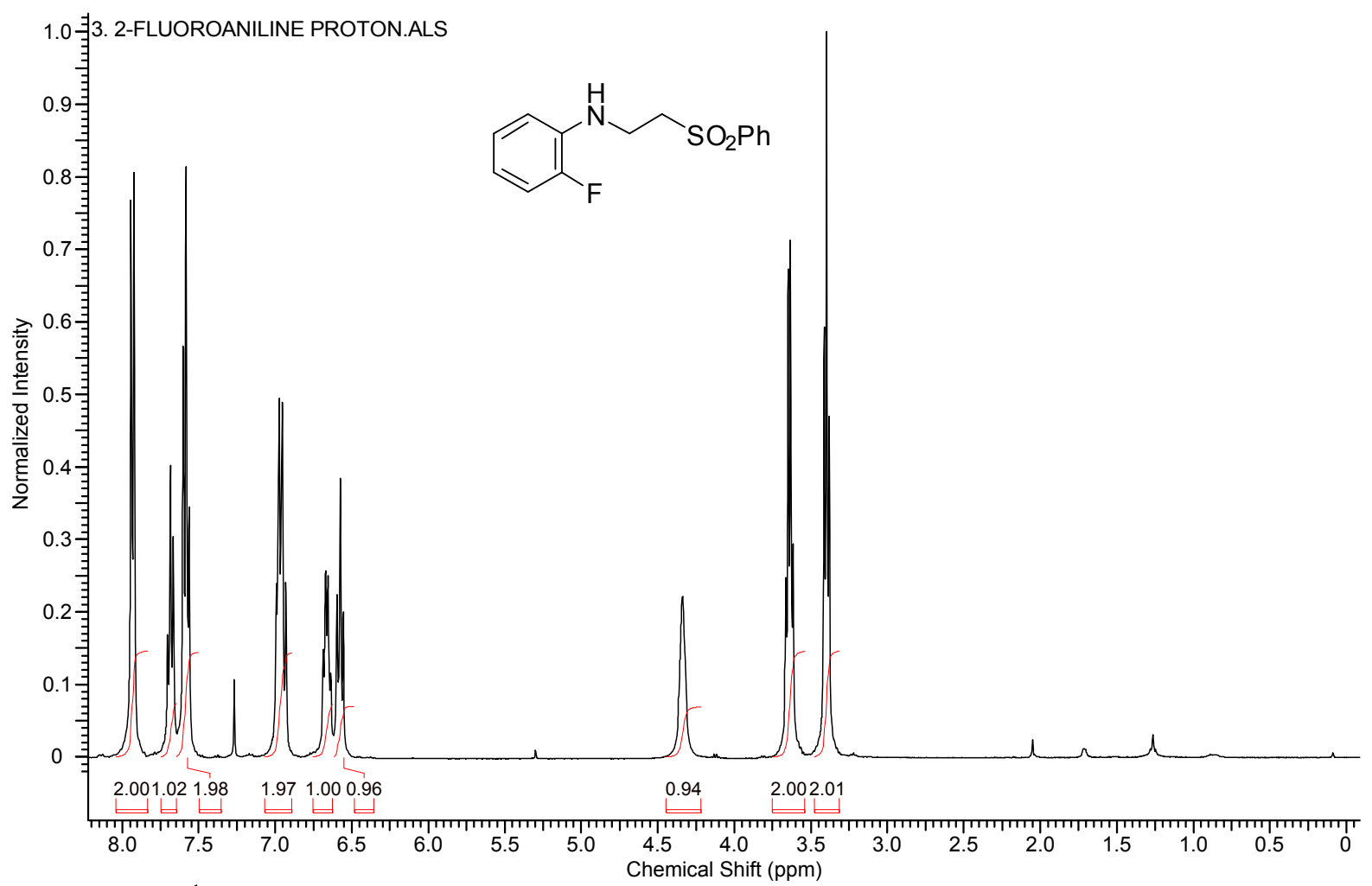

Figure S15. ${ }^{1} \mathrm{H}$ NMR spectrum of the compound $\mathbf{3 h}$

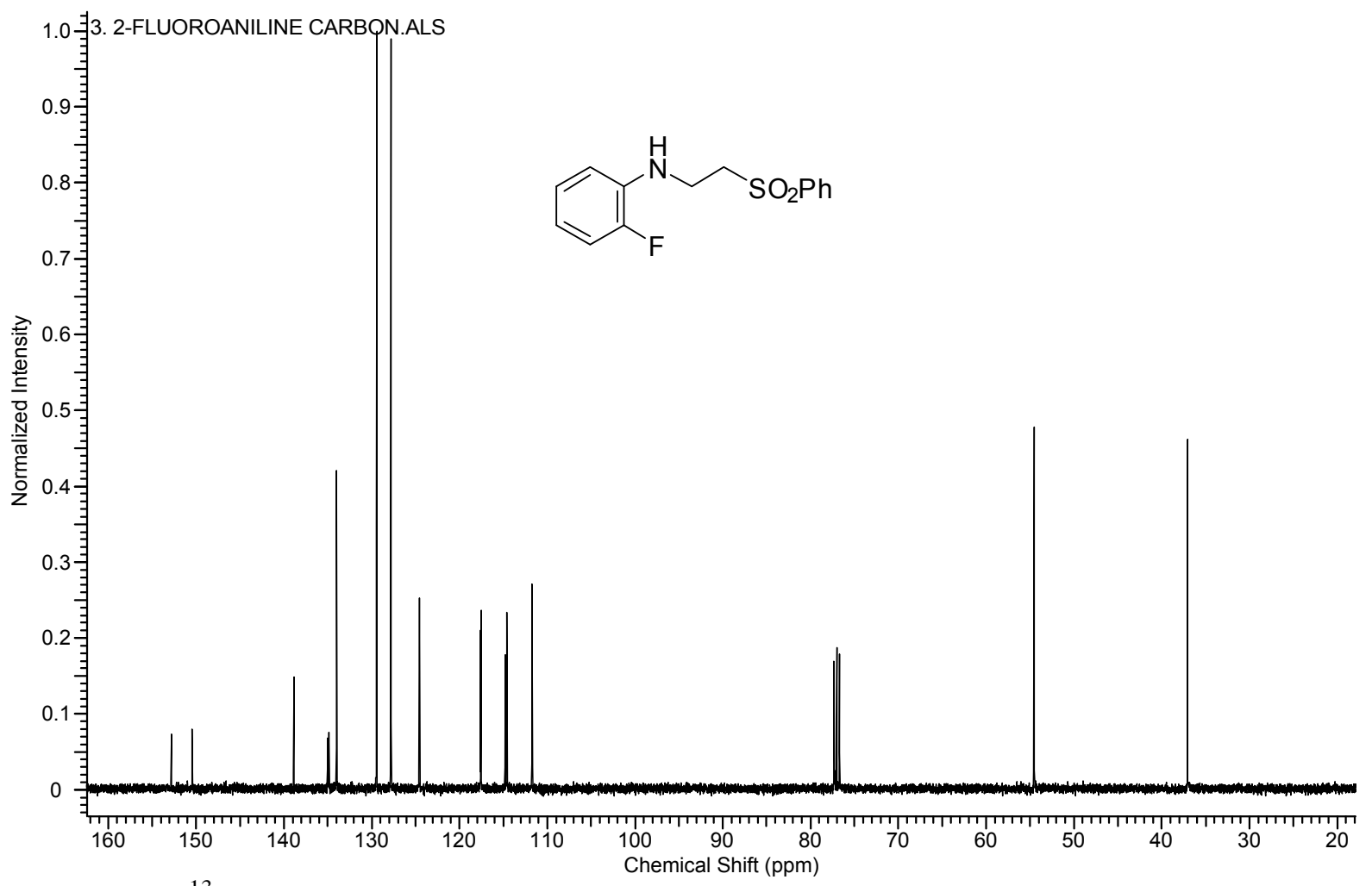

Figure S16. ${ }^{13} \mathrm{C}$ NMR spectrum of the compound $\mathbf{3 h}$ 


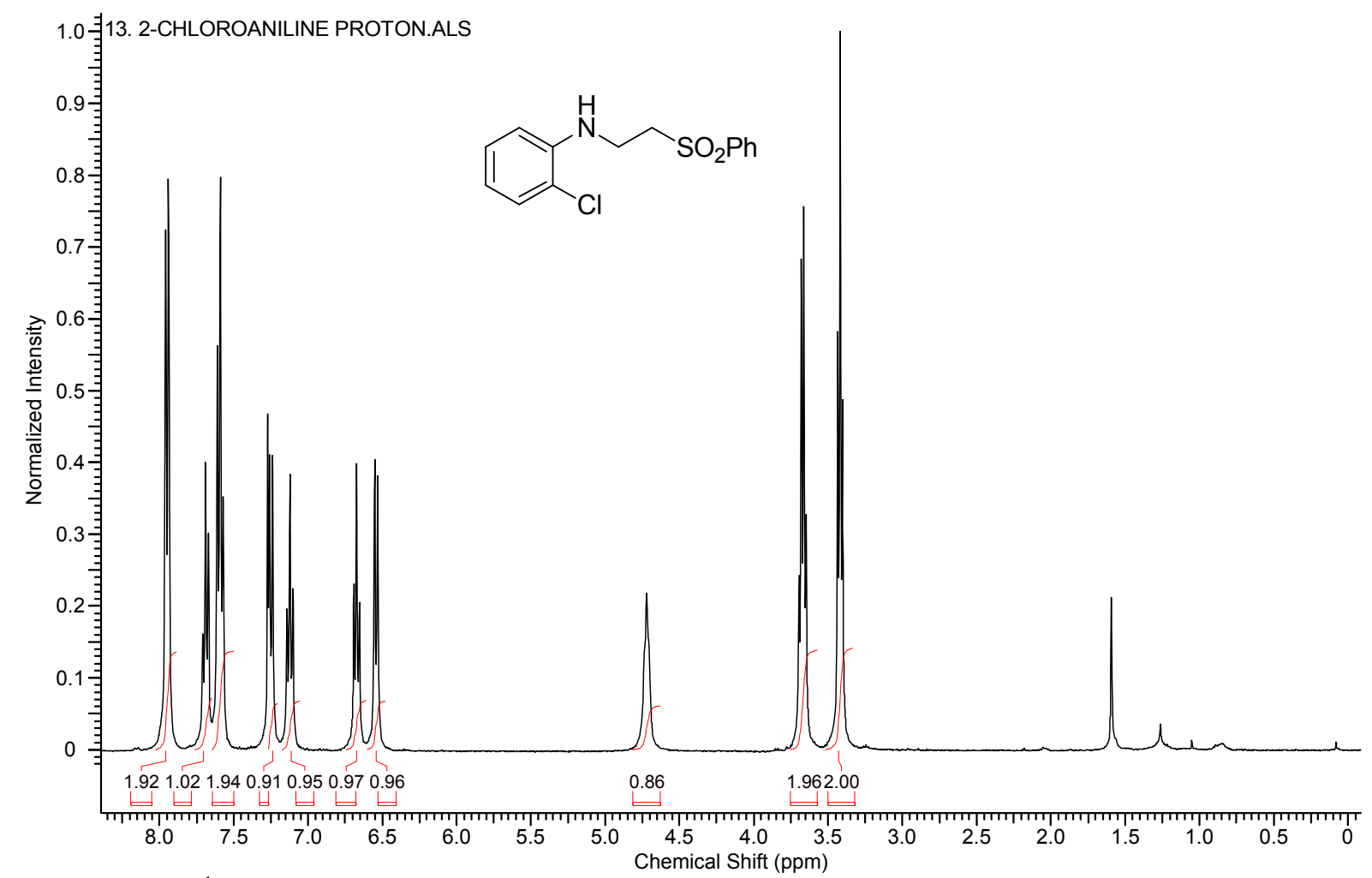

Figure S17. ${ }^{1} \mathrm{H}$ NMR spectrum of the compound $\mathbf{3 i}$

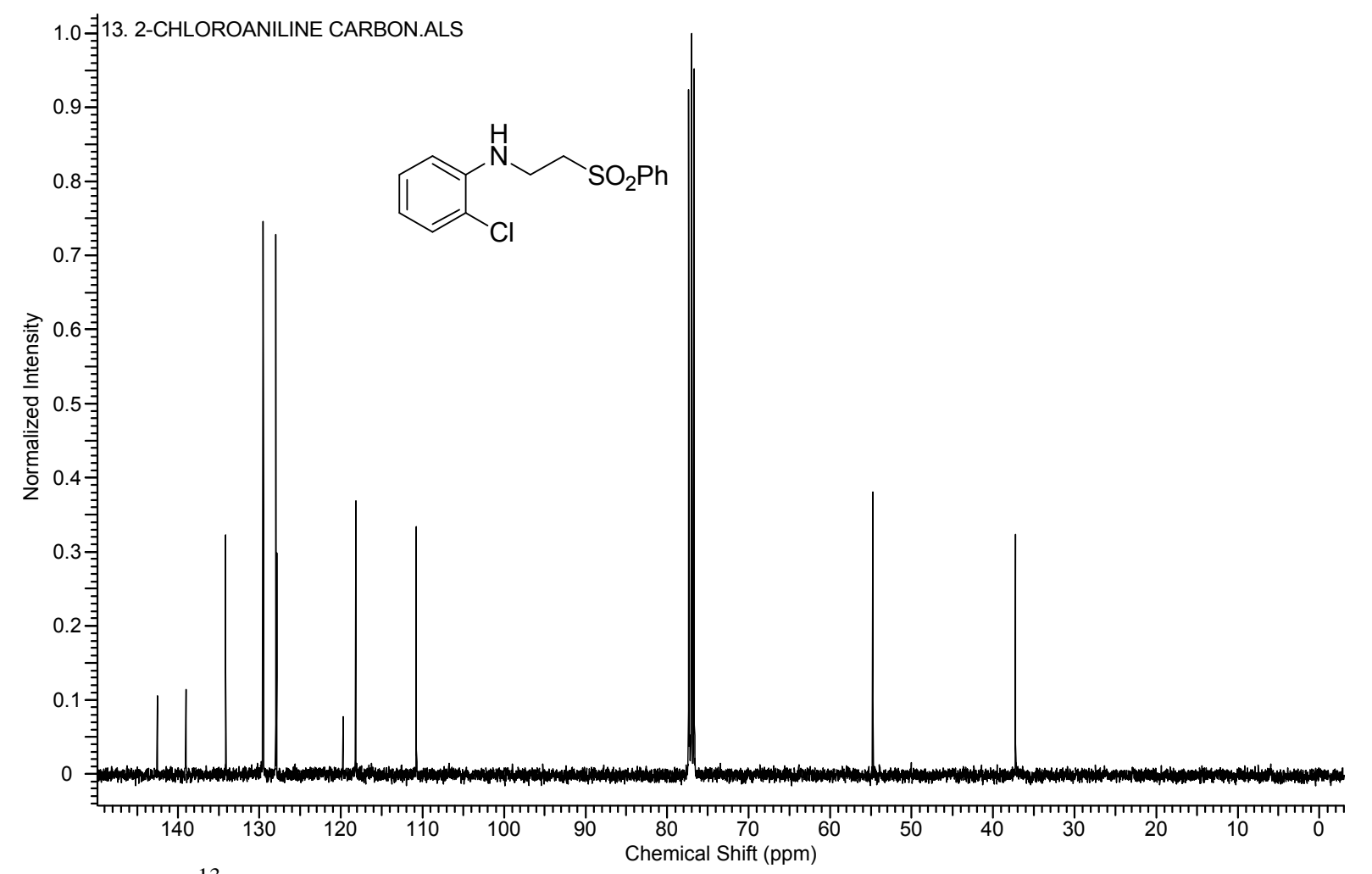

Figure S18. ${ }^{13} \mathrm{C}$ NMR spectrum of the compound $\mathbf{3 i}$ 


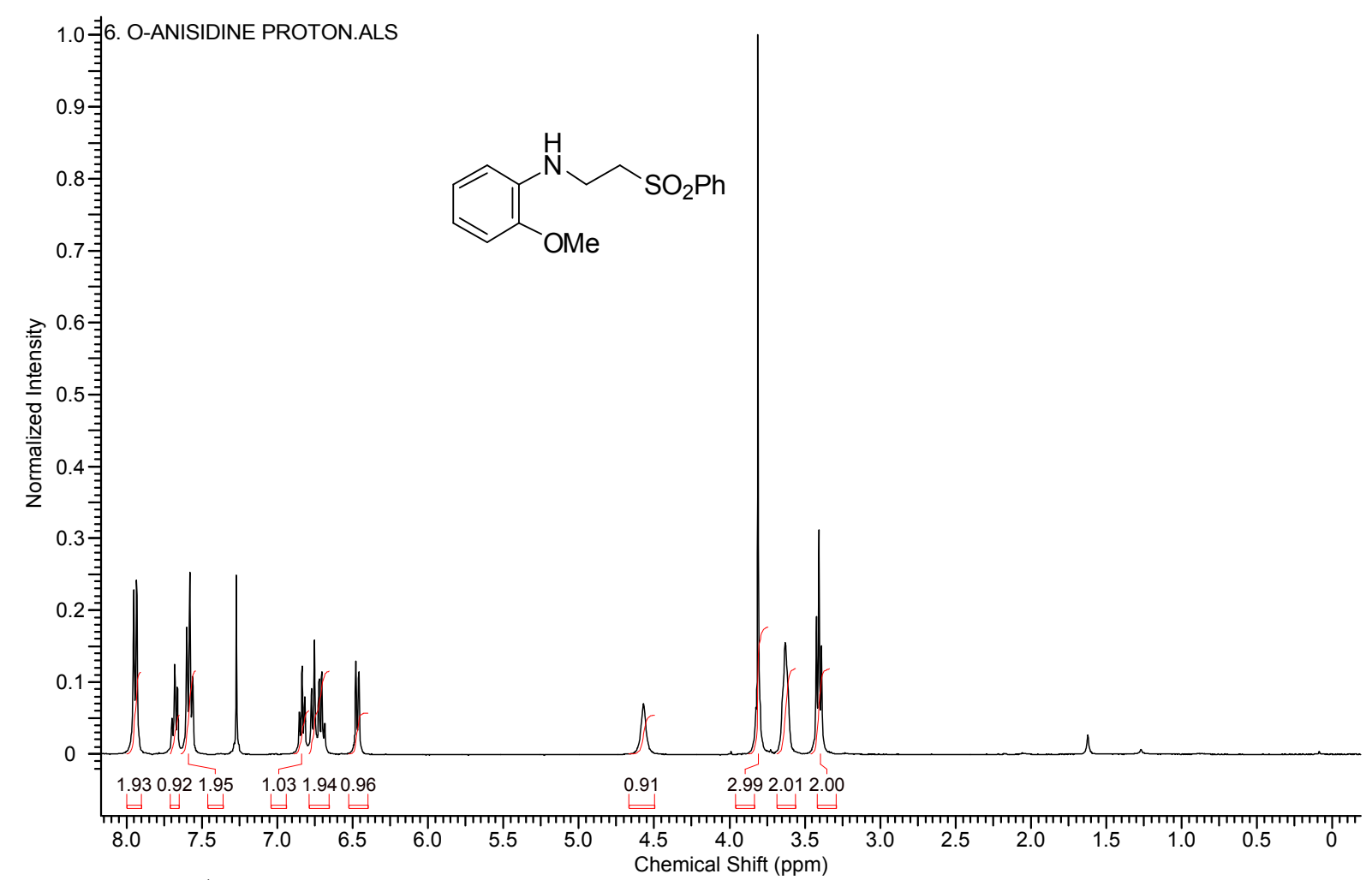

Figure S19. ${ }^{1} \mathrm{H}$ NMR spectrum of the compound $\mathbf{3 j}$

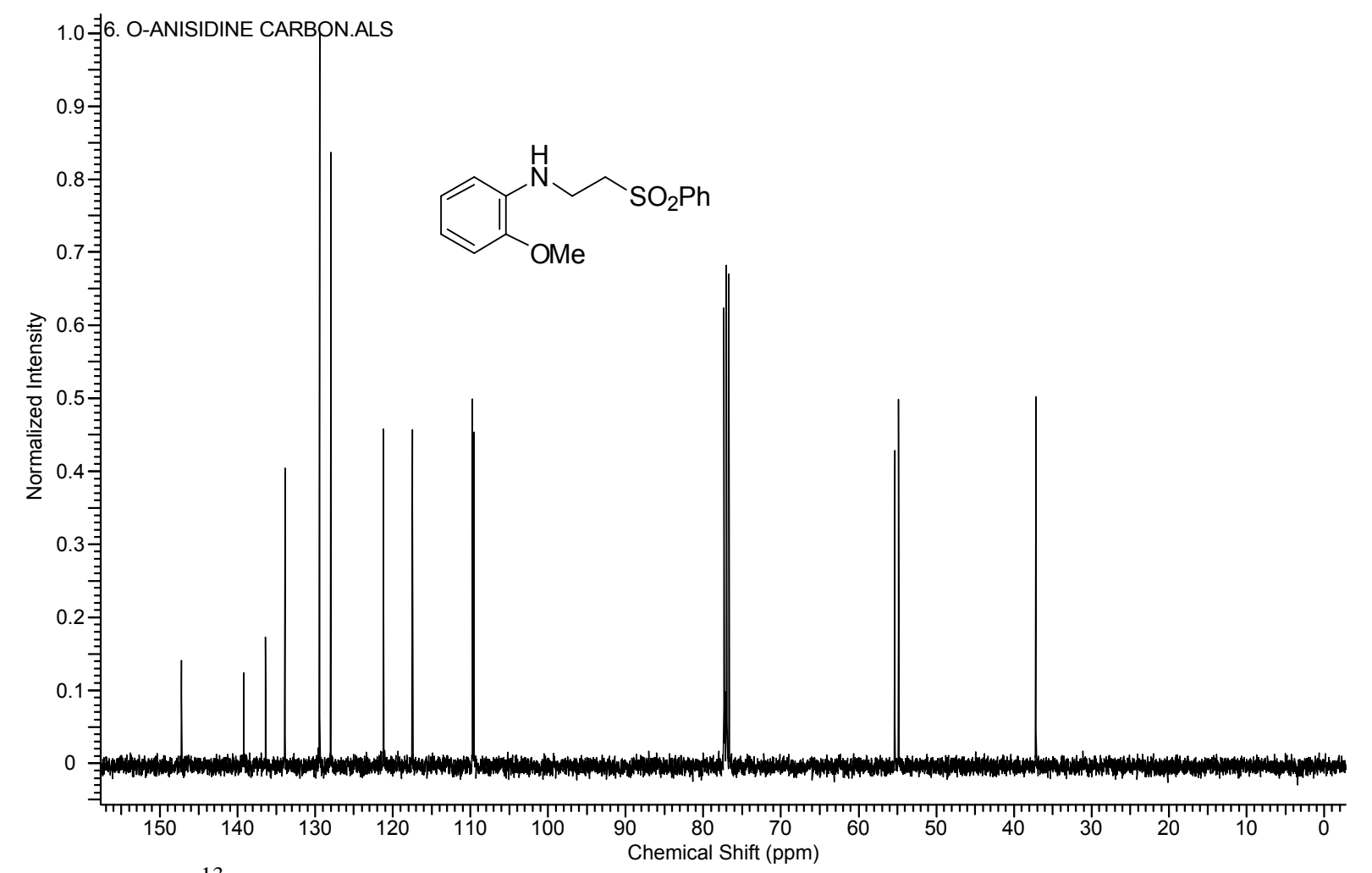

Figure S20. ${ }^{13} \mathrm{C}$ NMR spectrum of the compound $\mathbf{3 j}$ 


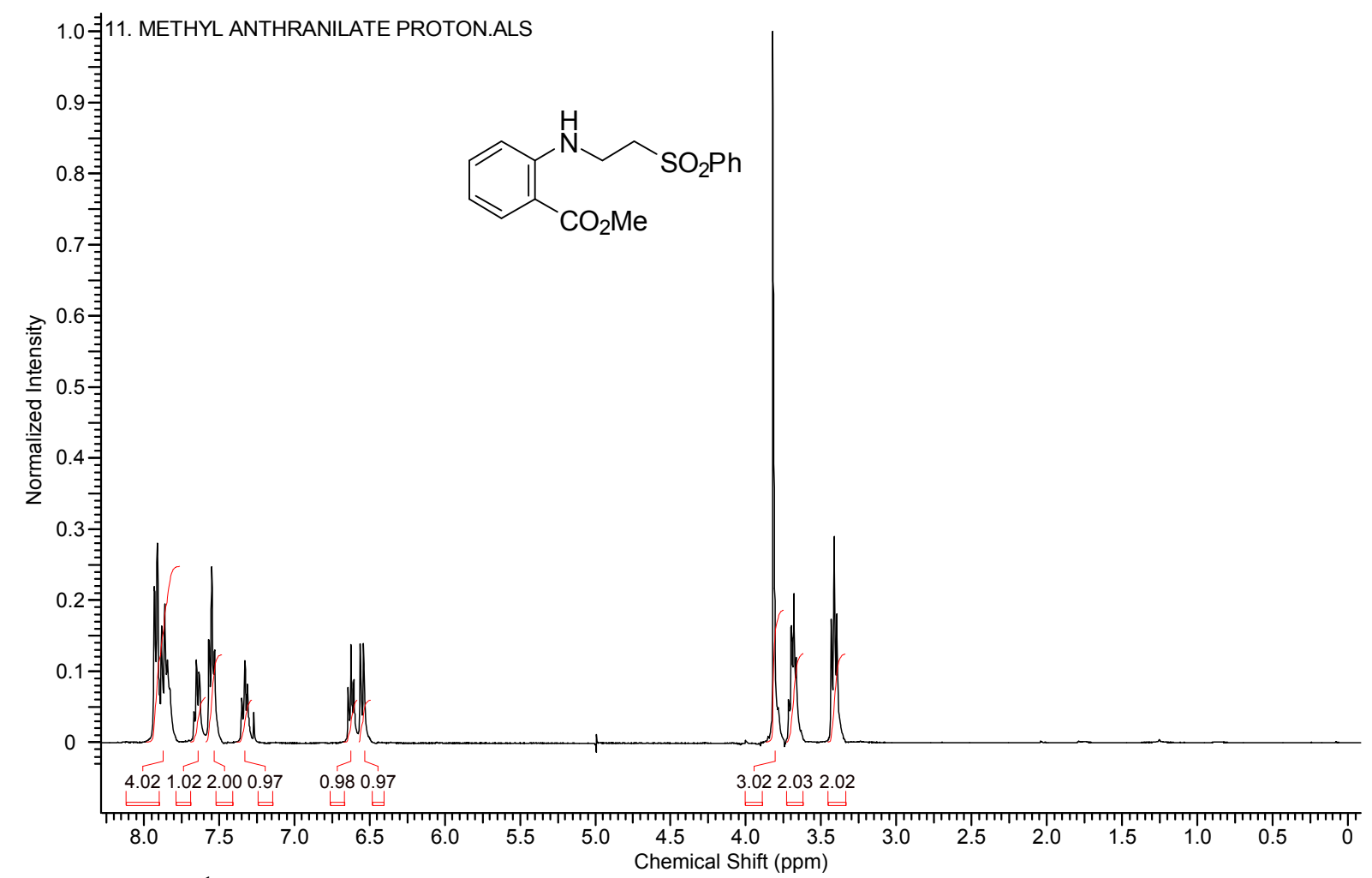

Figure S21. ${ }^{1} \mathrm{H}$ NMR spectrum of the compound $\mathbf{3 k}$

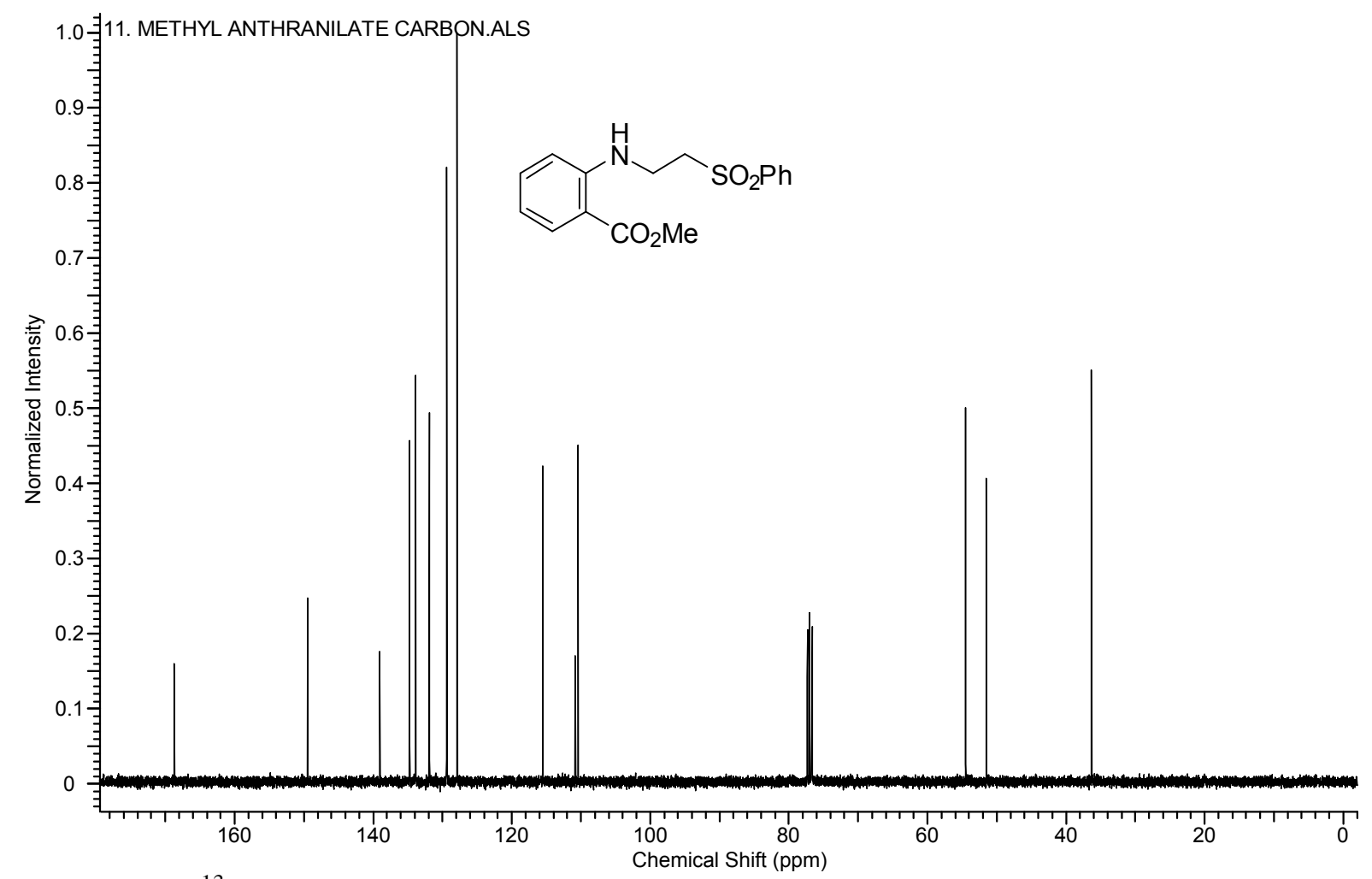

Figure S22. ${ }^{13} \mathrm{C}$ NMR spectrum of the compound $\mathbf{3 k}$ 


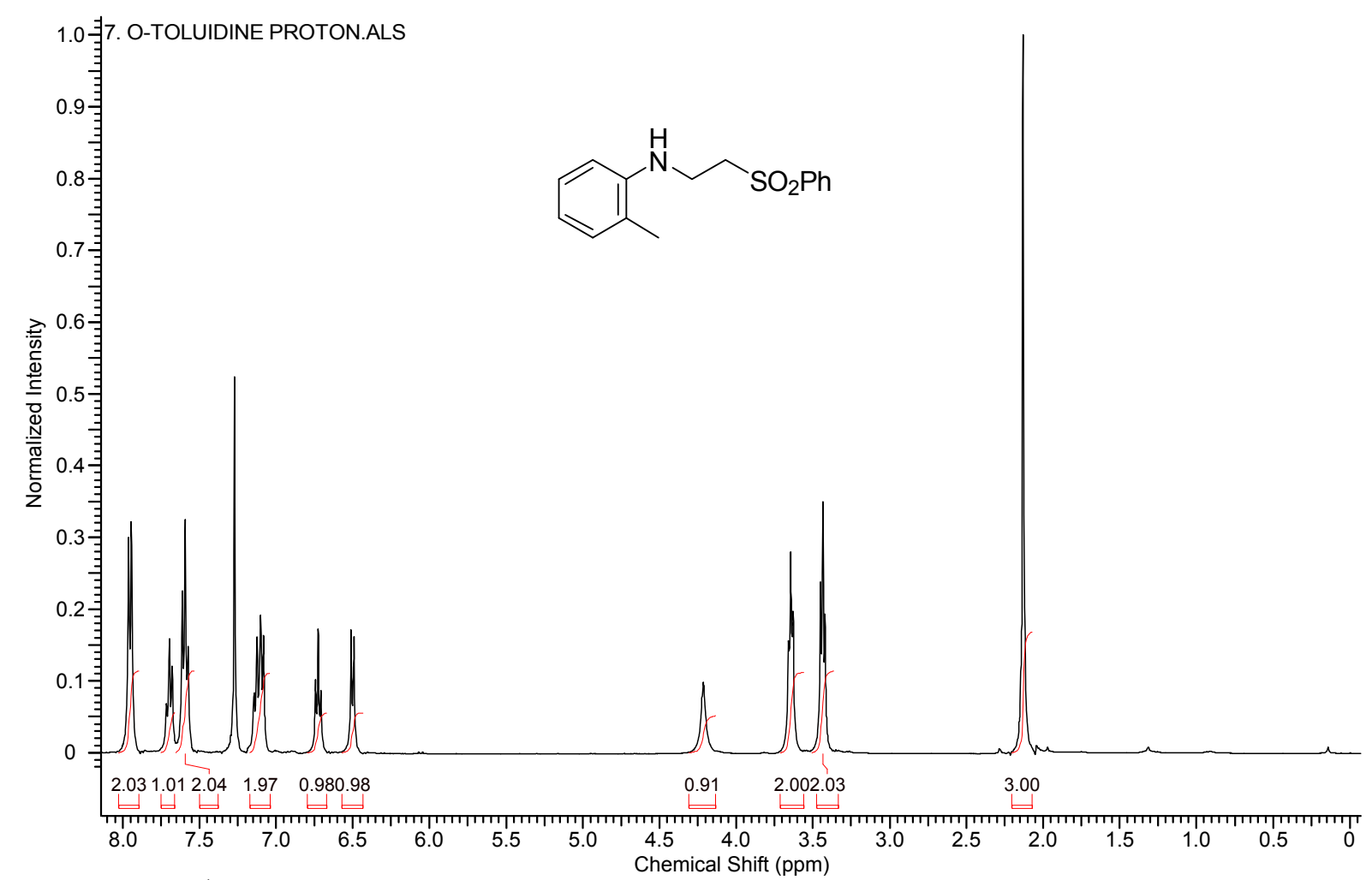

Figure S23. ${ }^{1} \mathrm{H}$ NMR spectrum of the compound 31

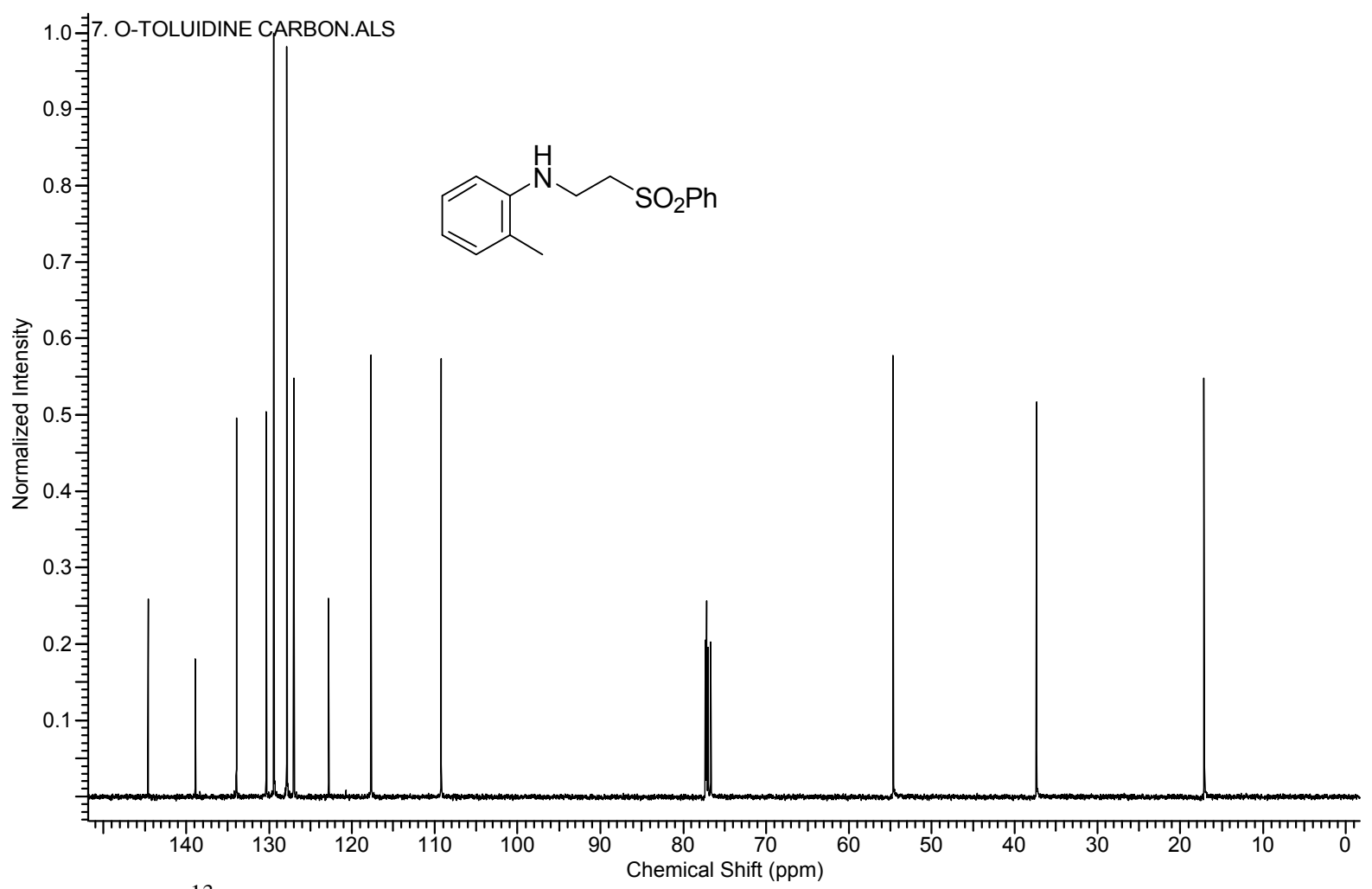

Figure S24. ${ }^{13} \mathrm{C}$ NMR spectrum of the compound 31 


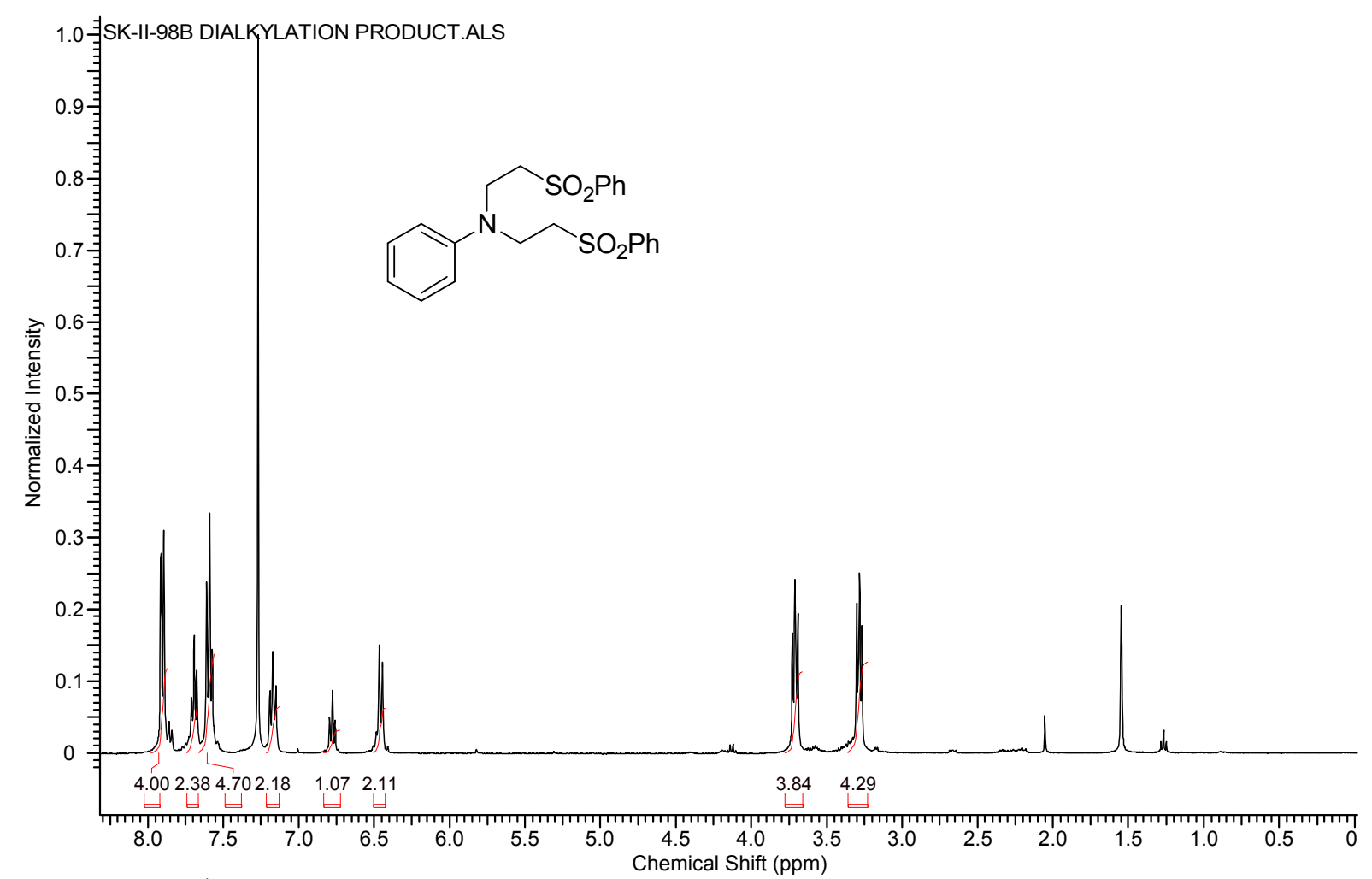

Figure S25. ${ }^{1} \mathrm{H}$ NMR spectrum of the compound $\mathbf{4 a}$

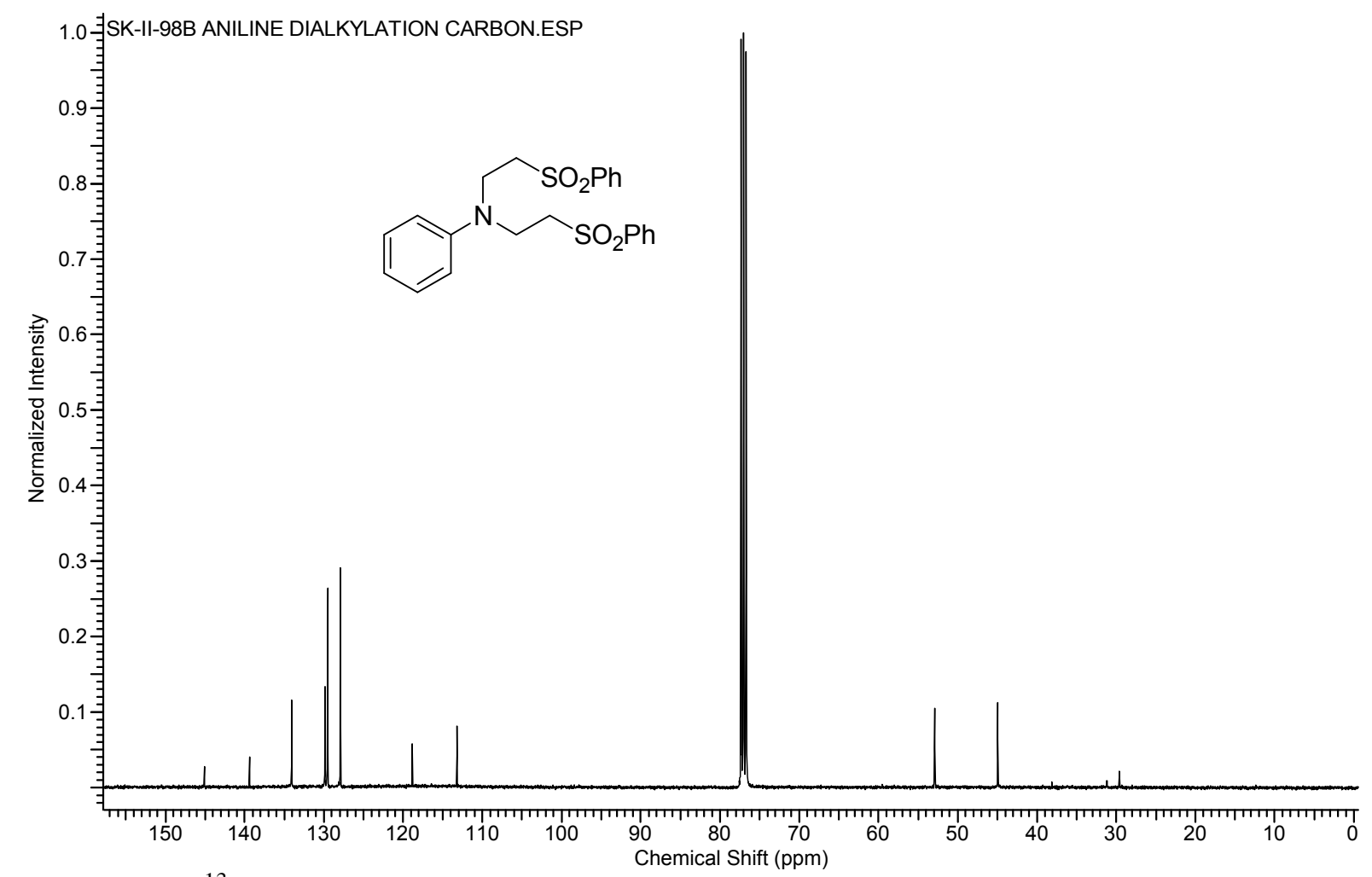

Figure S26. ${ }^{13} \mathrm{C}$ NMR spectrum of the compound $4 \mathbf{a}$ 


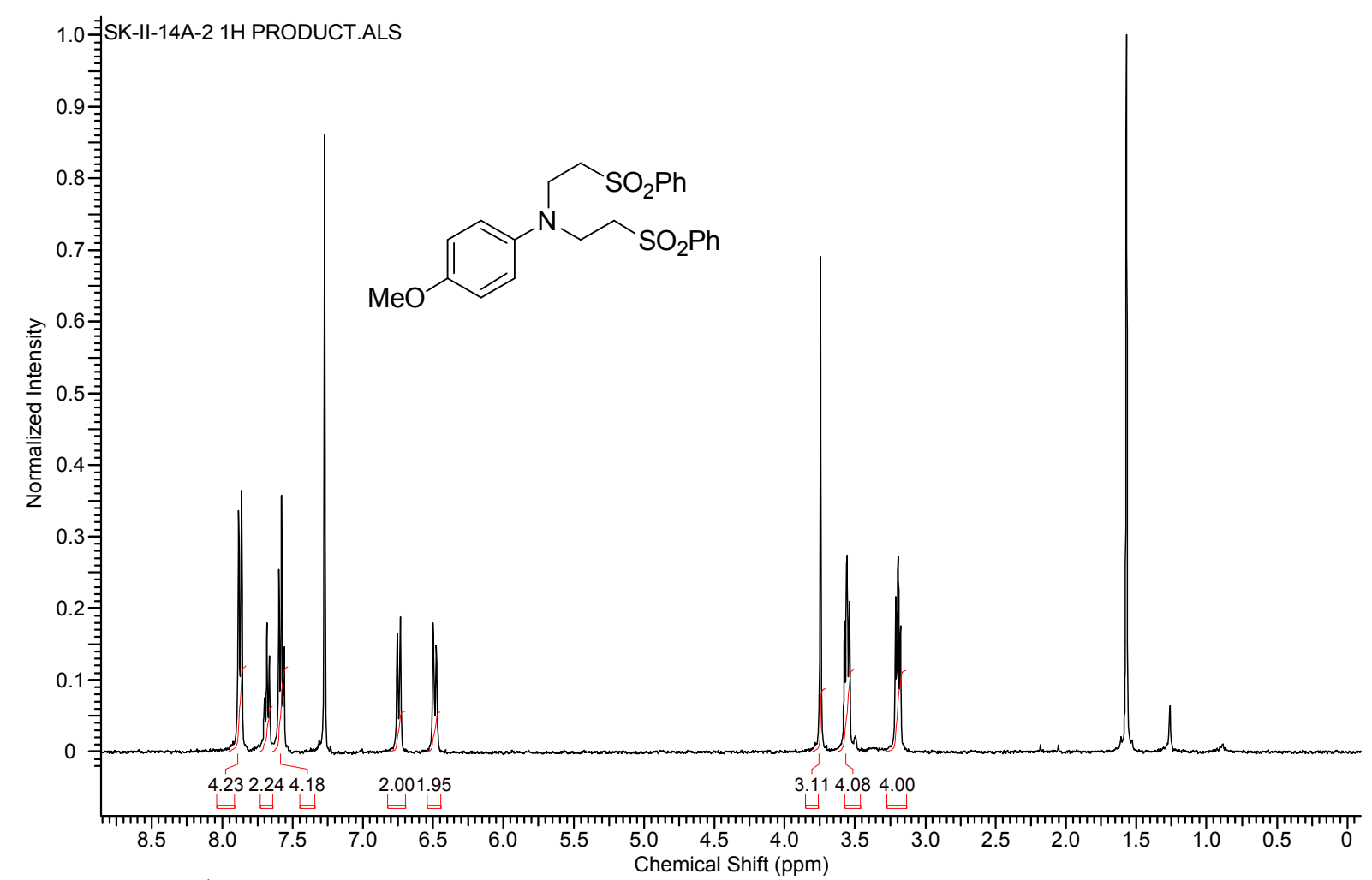

Figure S27. ${ }^{1} \mathrm{H}$ NMR spectrum of the compound $\mathbf{4 b}$

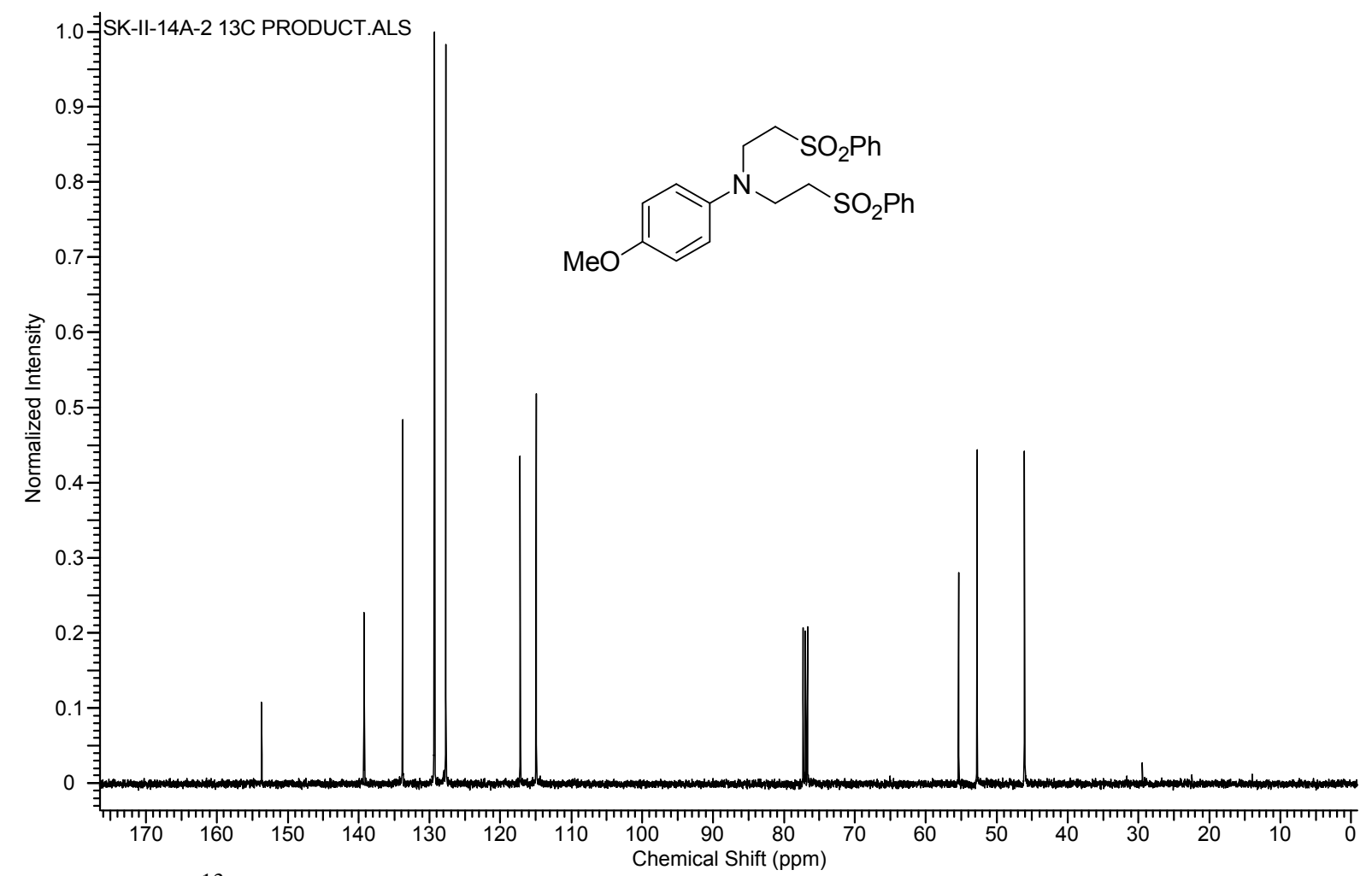

Figure S28. ${ }^{13} \mathrm{C}$ NMR spectrum of the compound $\mathbf{4 b}$ 


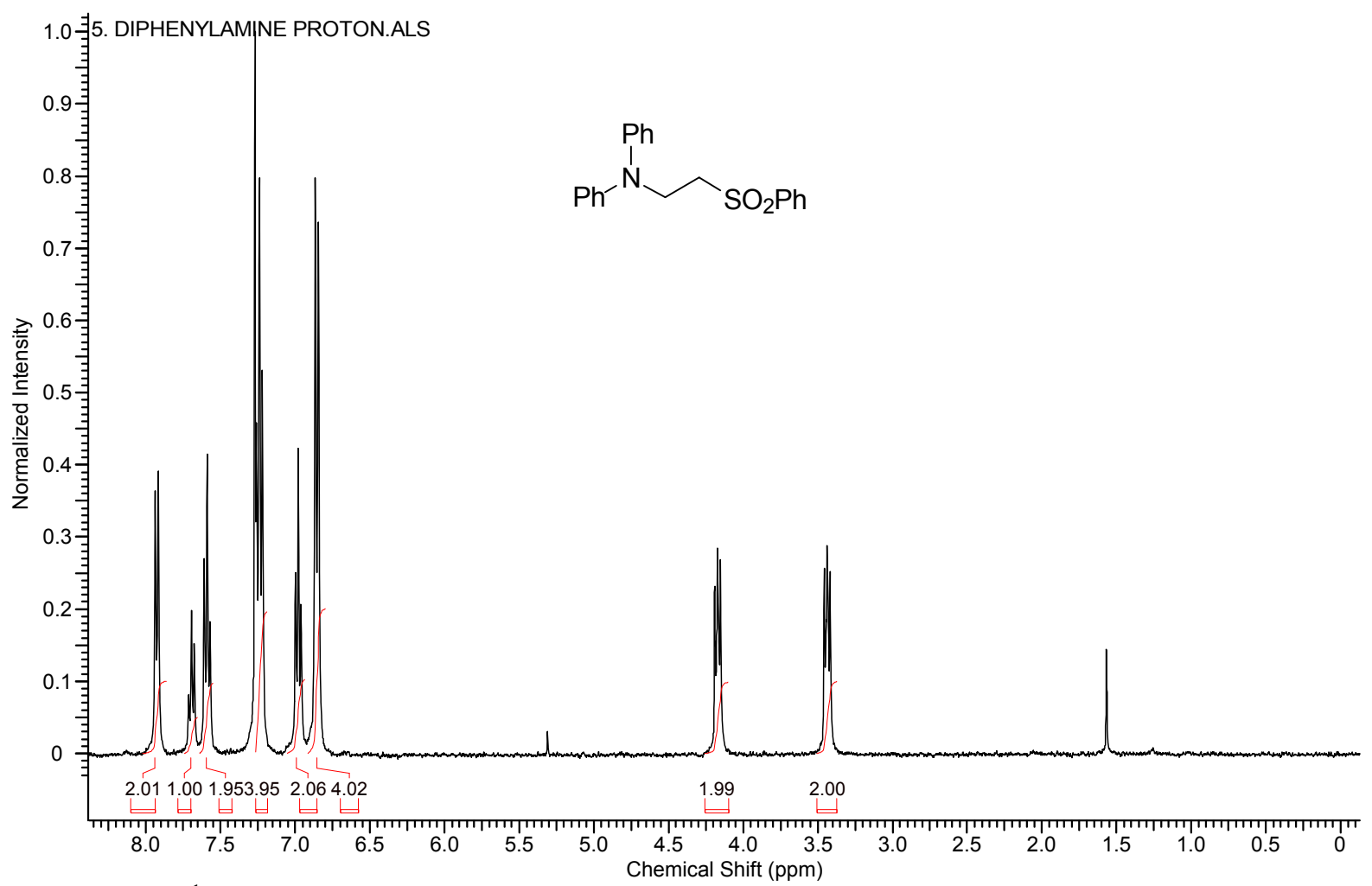

Figure S29. ${ }^{1} \mathrm{H}$ NMR spectrum of the compound $\mathbf{6 a}$

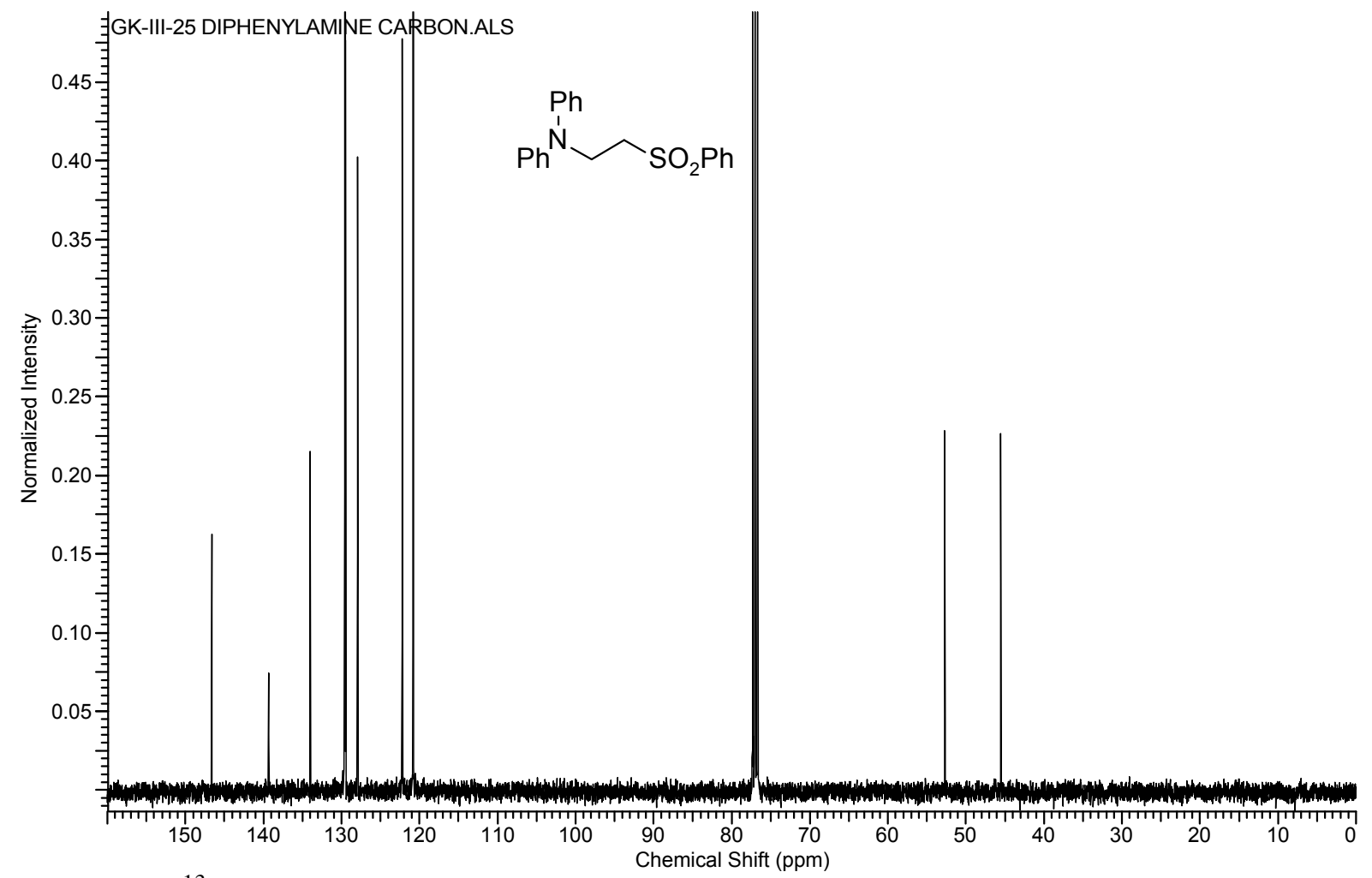

Figure S30. ${ }^{13} \mathrm{C}$ NMR spectrum of the compound $\mathbf{6 a}$ 


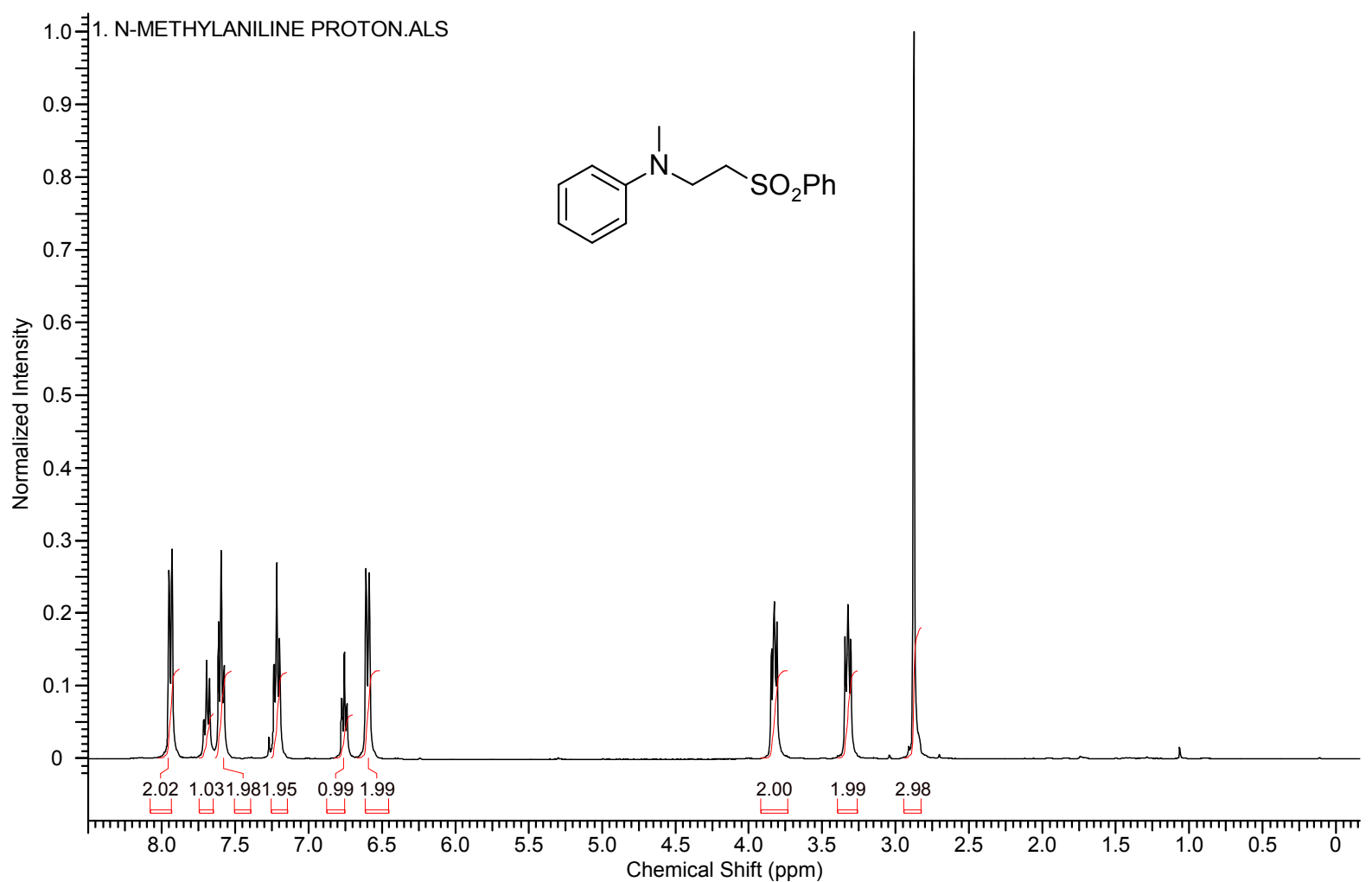

Figure S31. ${ }^{1} \mathrm{H}$ NMR spectrum of the compound $\mathbf{6 b}$

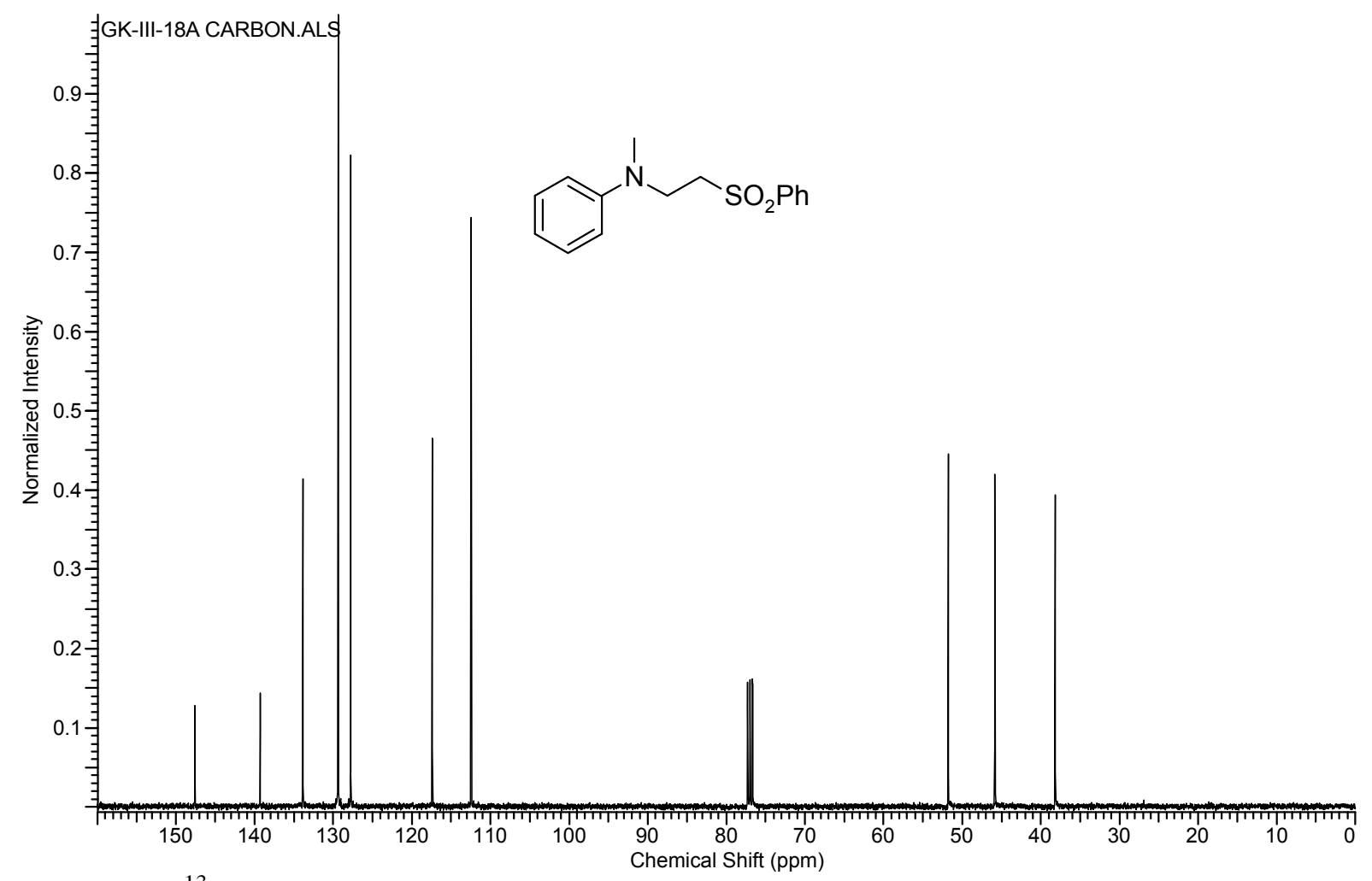

Figure S32. ${ }^{13} \mathrm{C}$ NMR spectrum of the compound $\mathbf{6 b}$ 


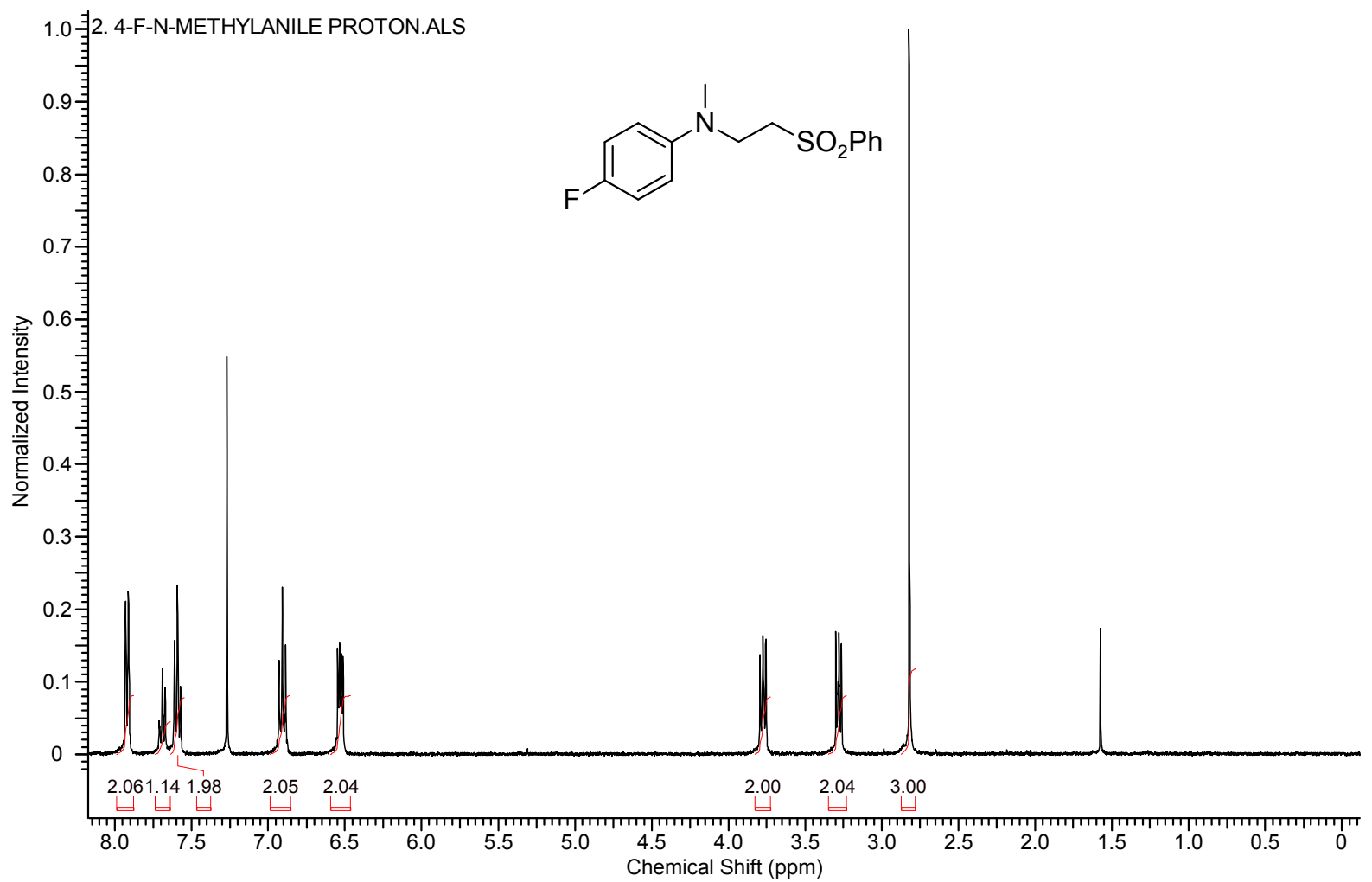

Figure S33. ${ }^{1} \mathrm{H}$ NMR spectrum of the compound $\mathbf{6 c}$

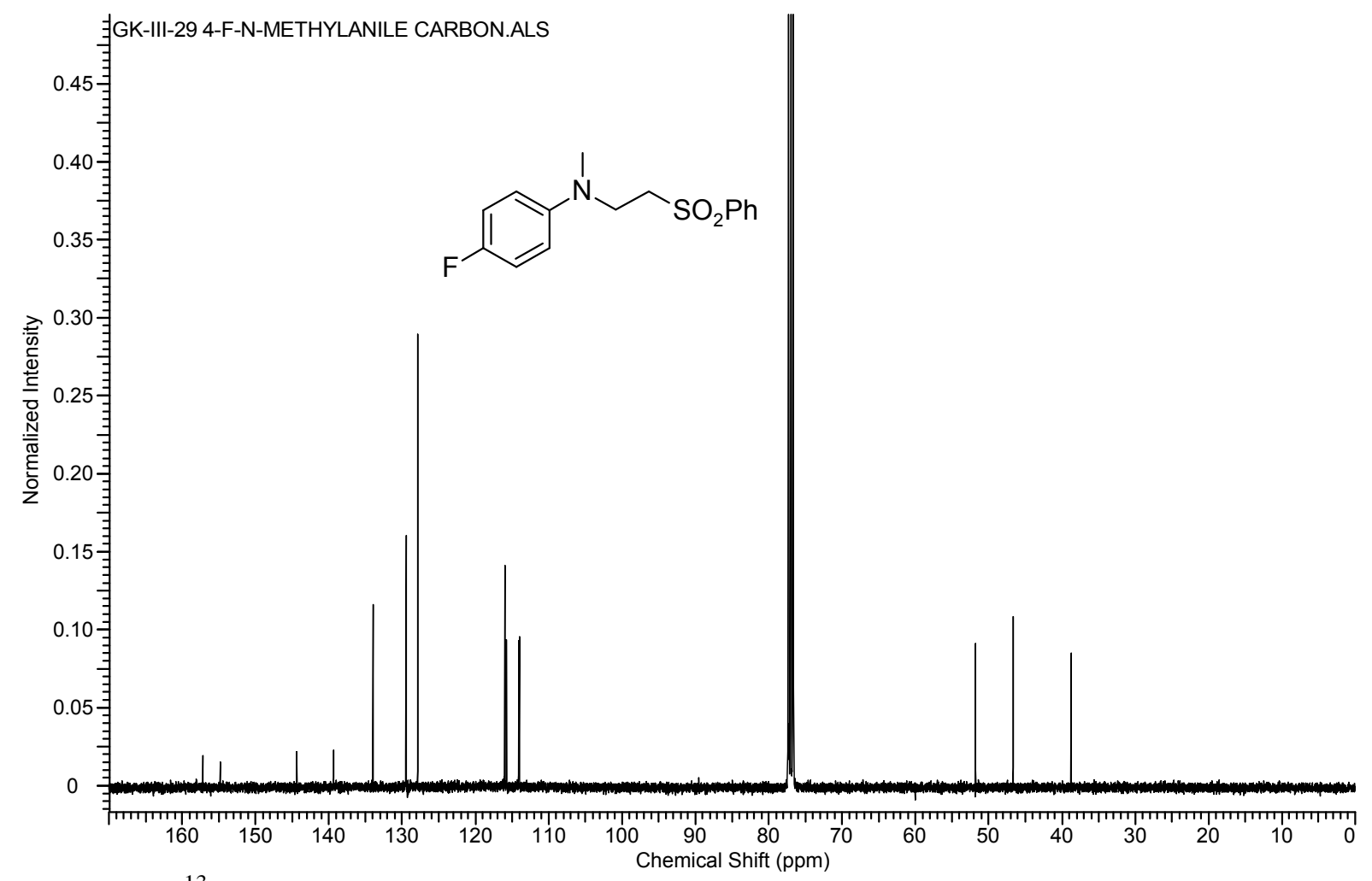

Figure S34. ${ }^{13} \mathrm{C}$ NMR spectrum of the compound $\mathbf{6 c}$ 


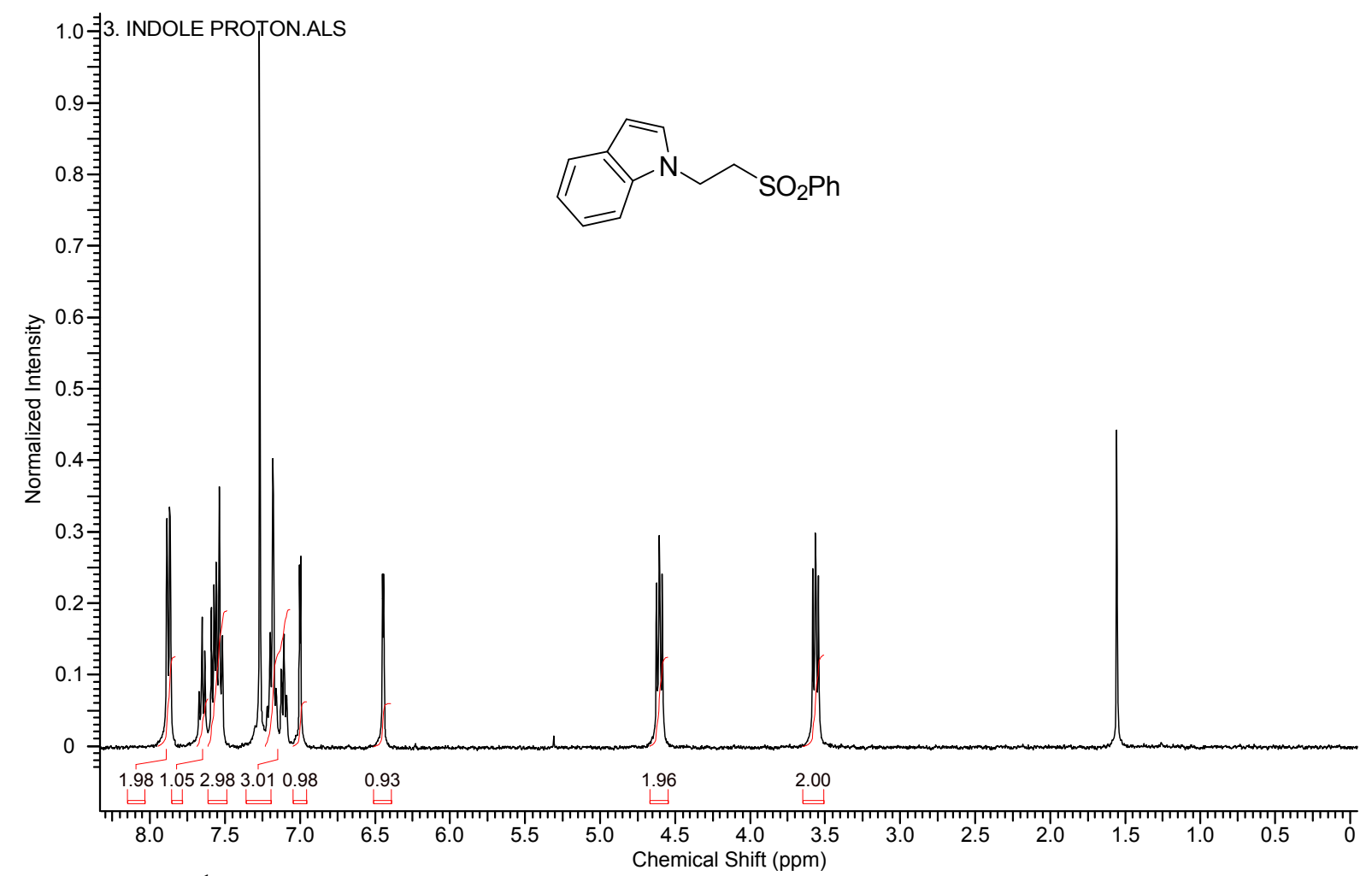

Figure S35. ${ }^{1} \mathrm{H}$ NMR spectrum of the compound $\mathbf{6 d}$

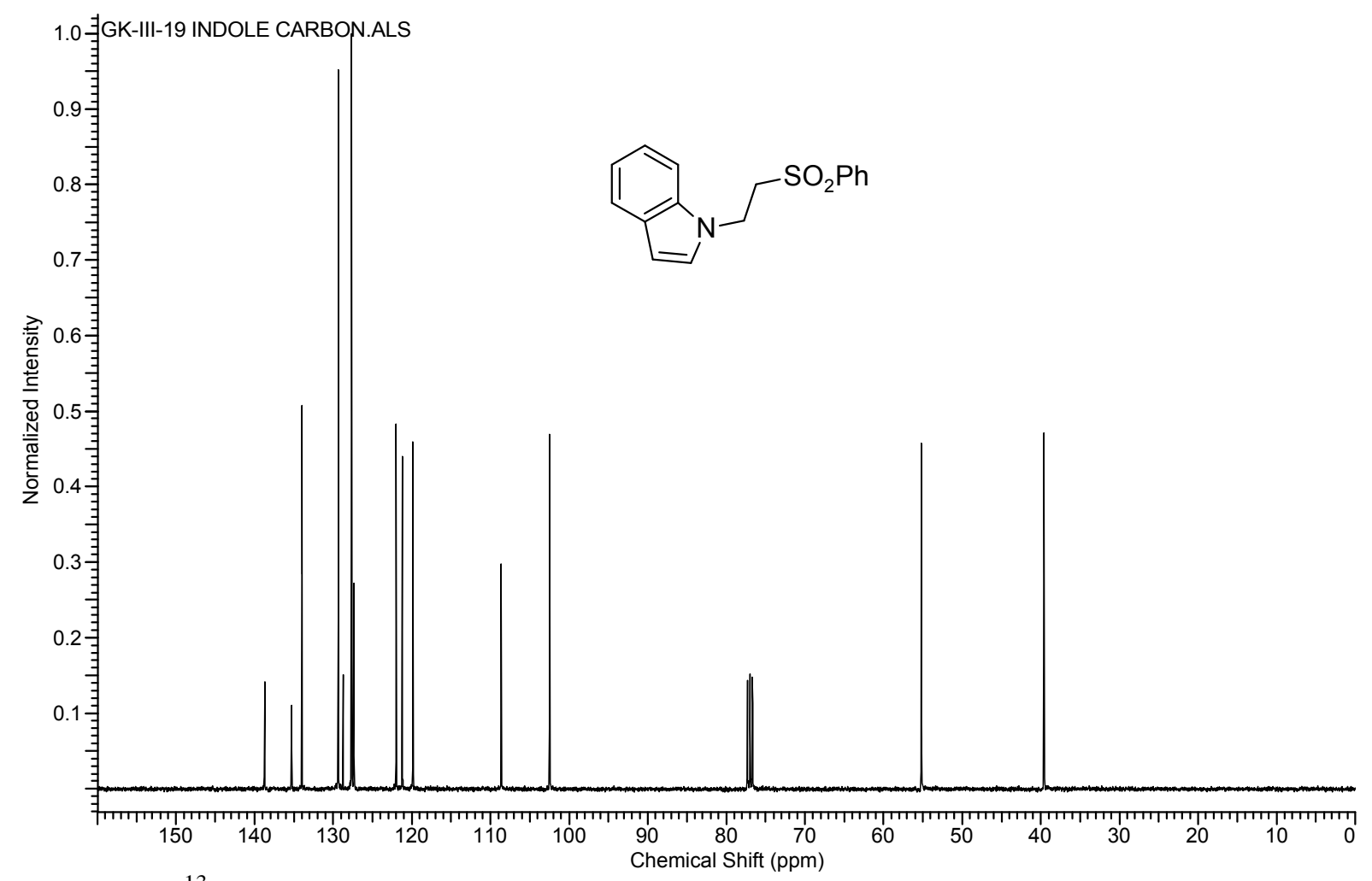

Figure S36. ${ }^{13} \mathrm{C}$ NMR spectrum of the compound $\mathbf{6 d}$ 


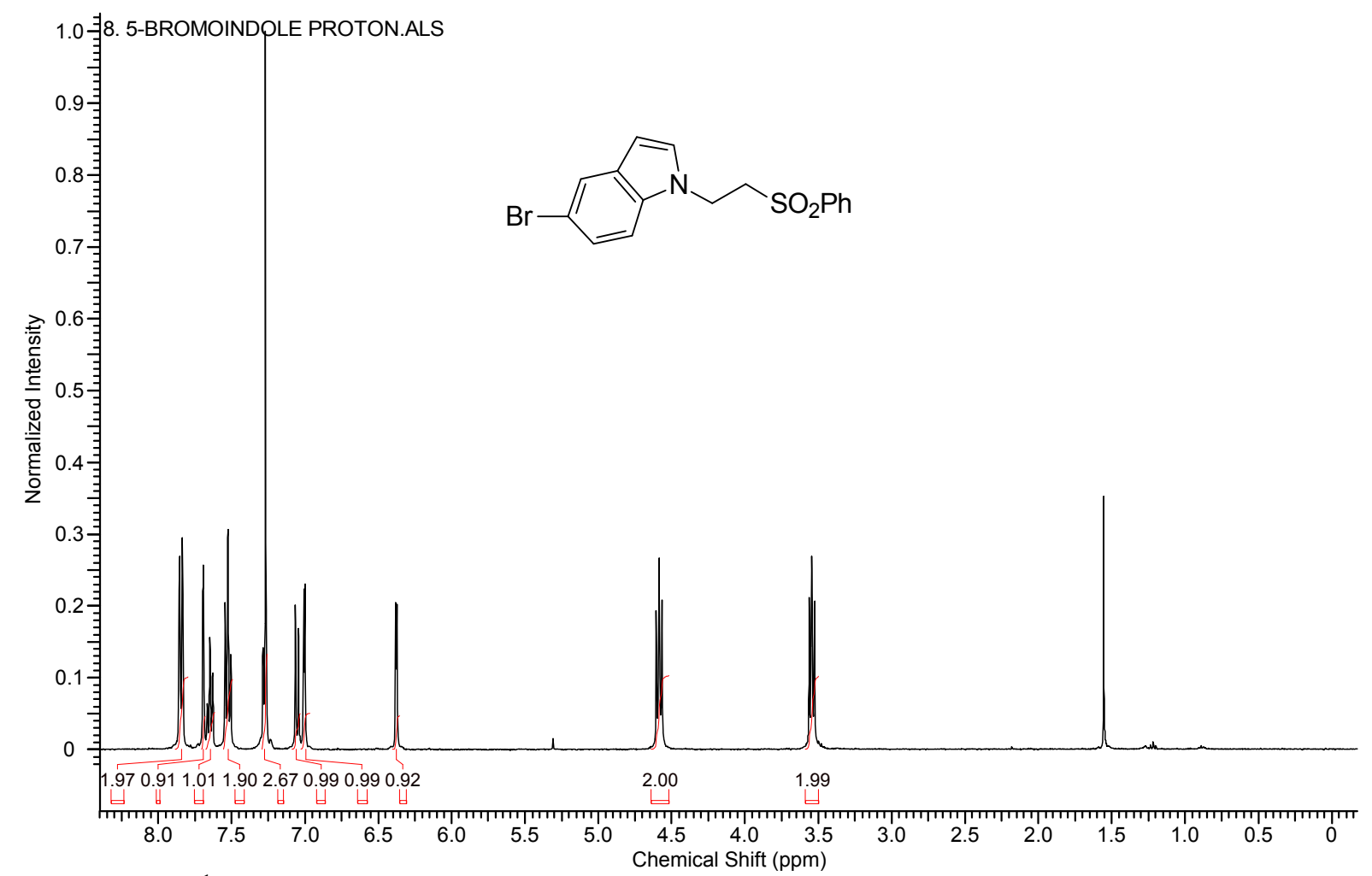

Figure S37. ${ }^{1} \mathrm{H}$ NMR spectrum of the compound $\mathbf{6 e}$

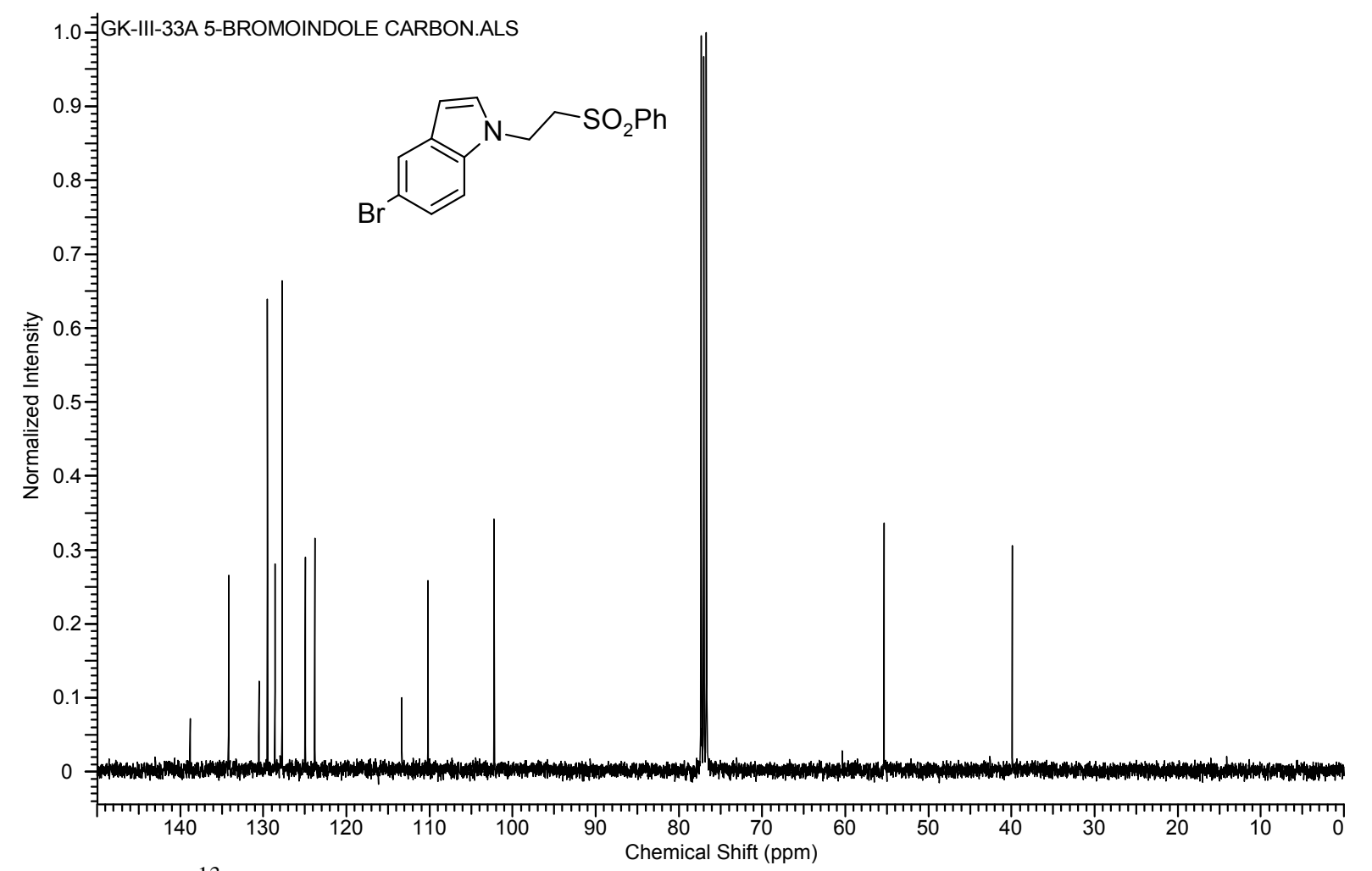

Figure S38. ${ }^{13} \mathrm{C}$ NMR spectrum of the compound $\mathbf{6 e}$ 


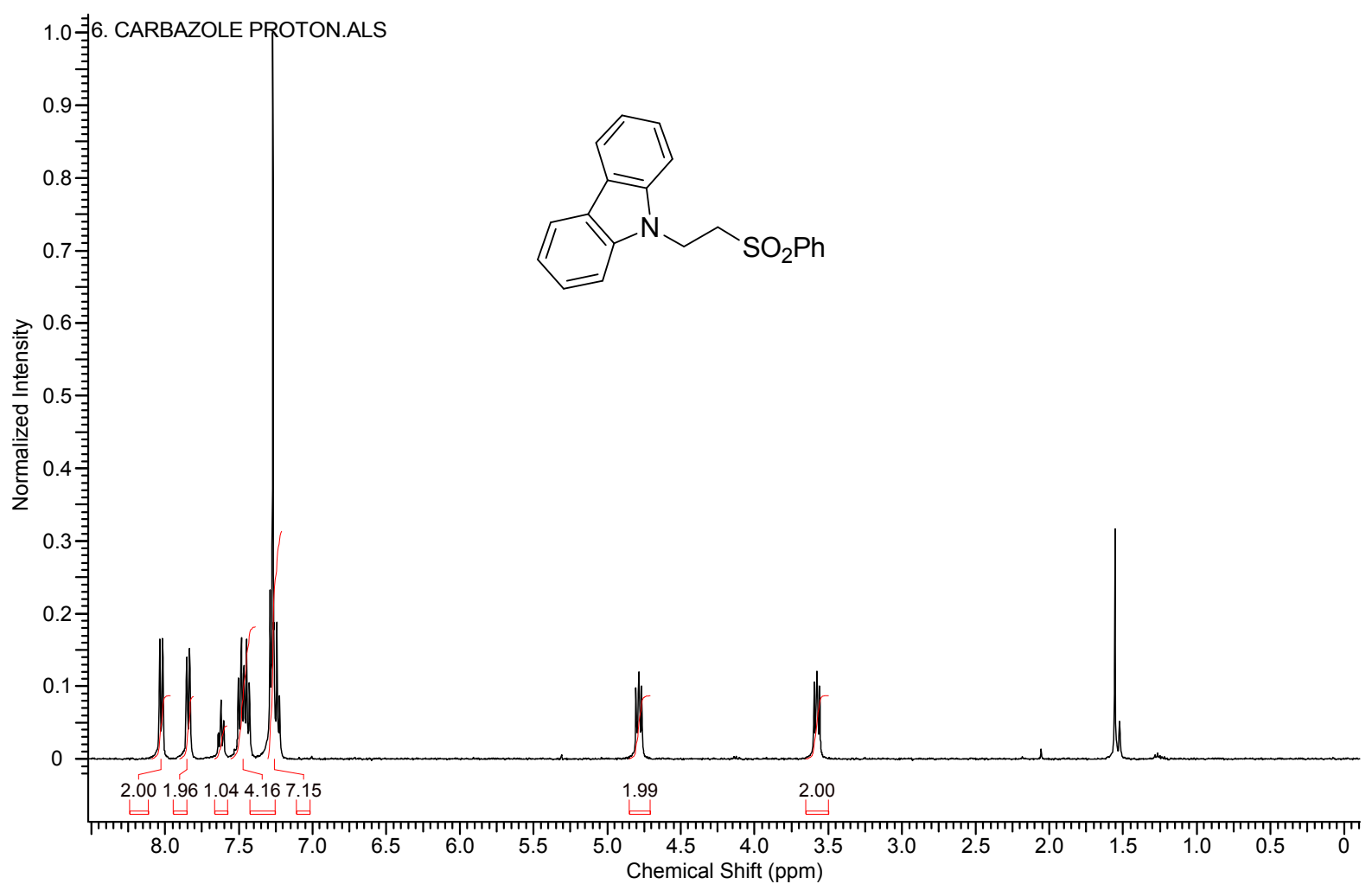

Figure S39. ${ }^{1} \mathrm{H}$ NMR spectrum of the compound $\mathbf{6 f}$

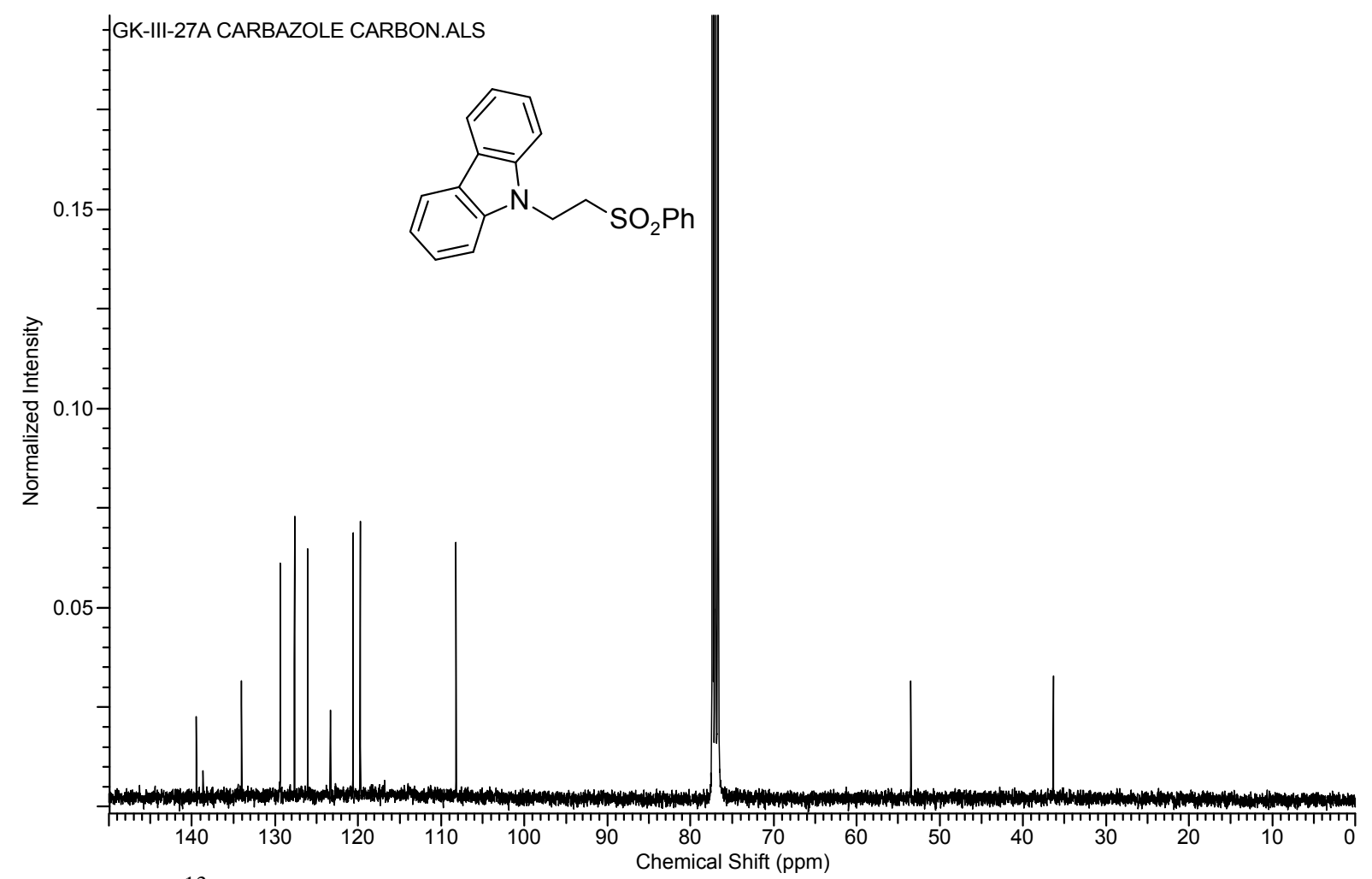

Figure S40. ${ }^{13} \mathrm{C}$ NMR spectrum of the compound $\mathbf{6 f}$ 


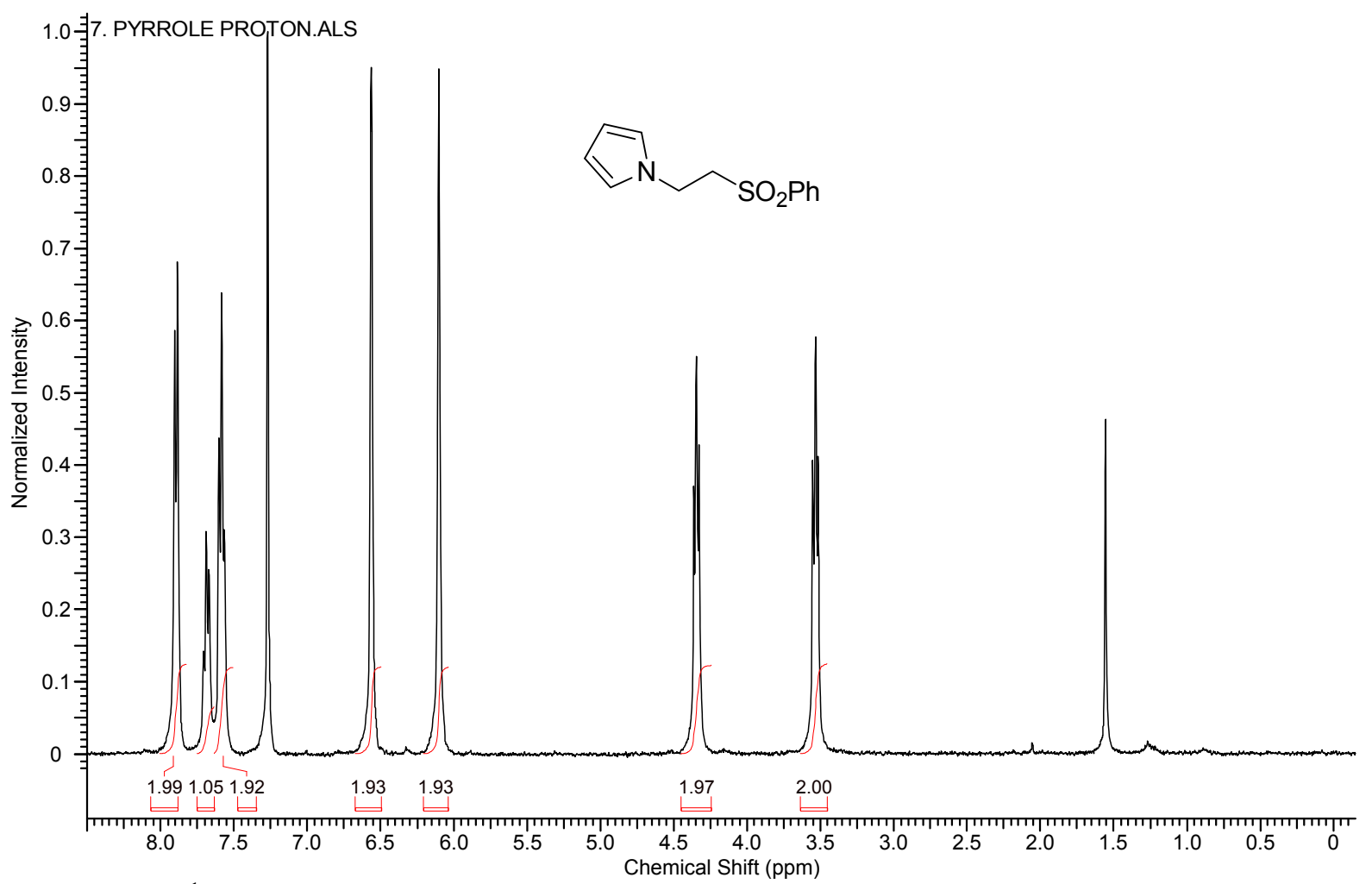

Figure S41. ${ }^{1} \mathrm{H}$ NMR spectrum of the compound $\mathbf{6 g}$

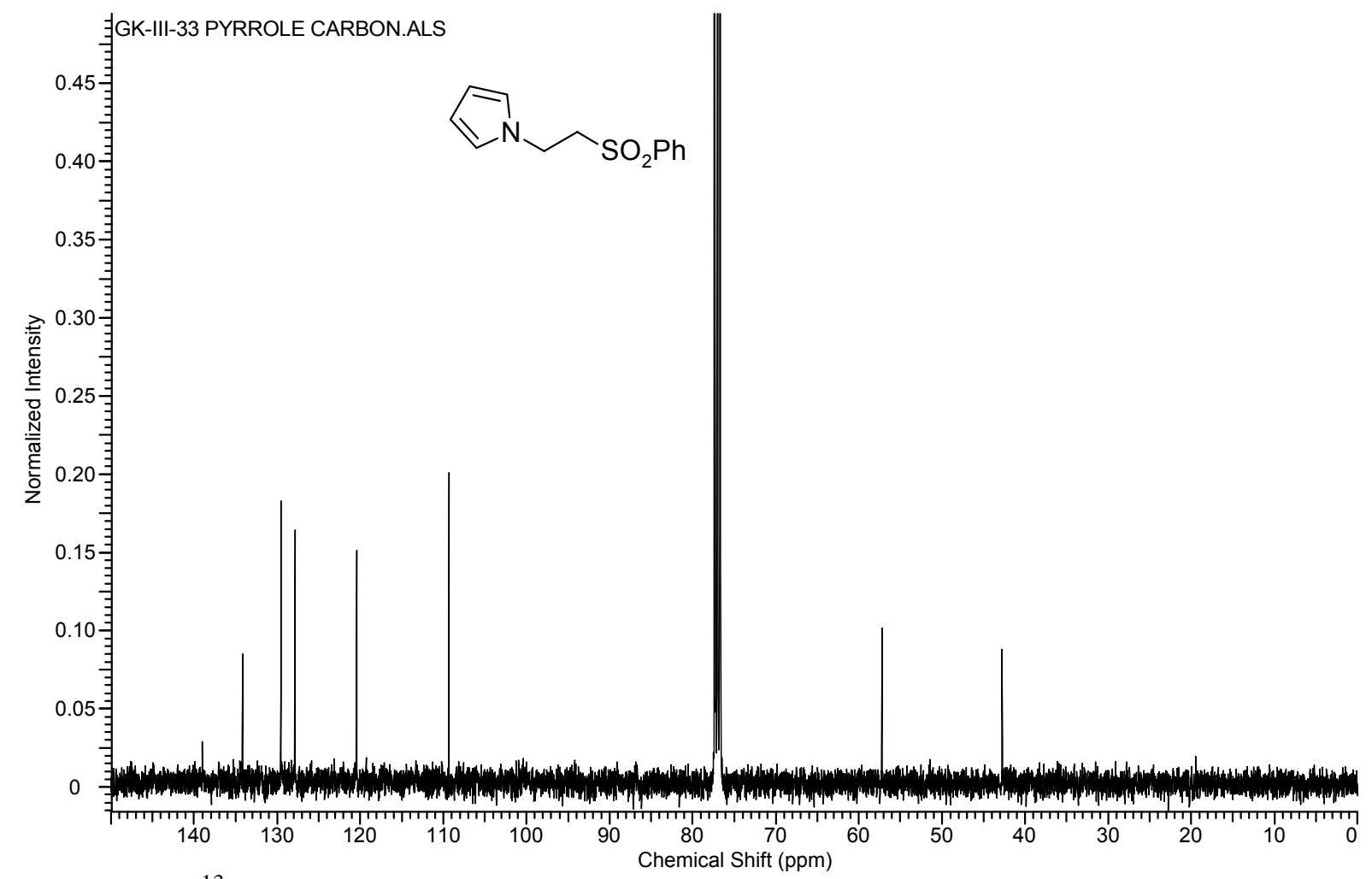

Figure $\mathbf{S 4 2} .{ }^{13} \mathrm{C}$ NMR spectrum of the compound $\mathbf{6 g}$ 


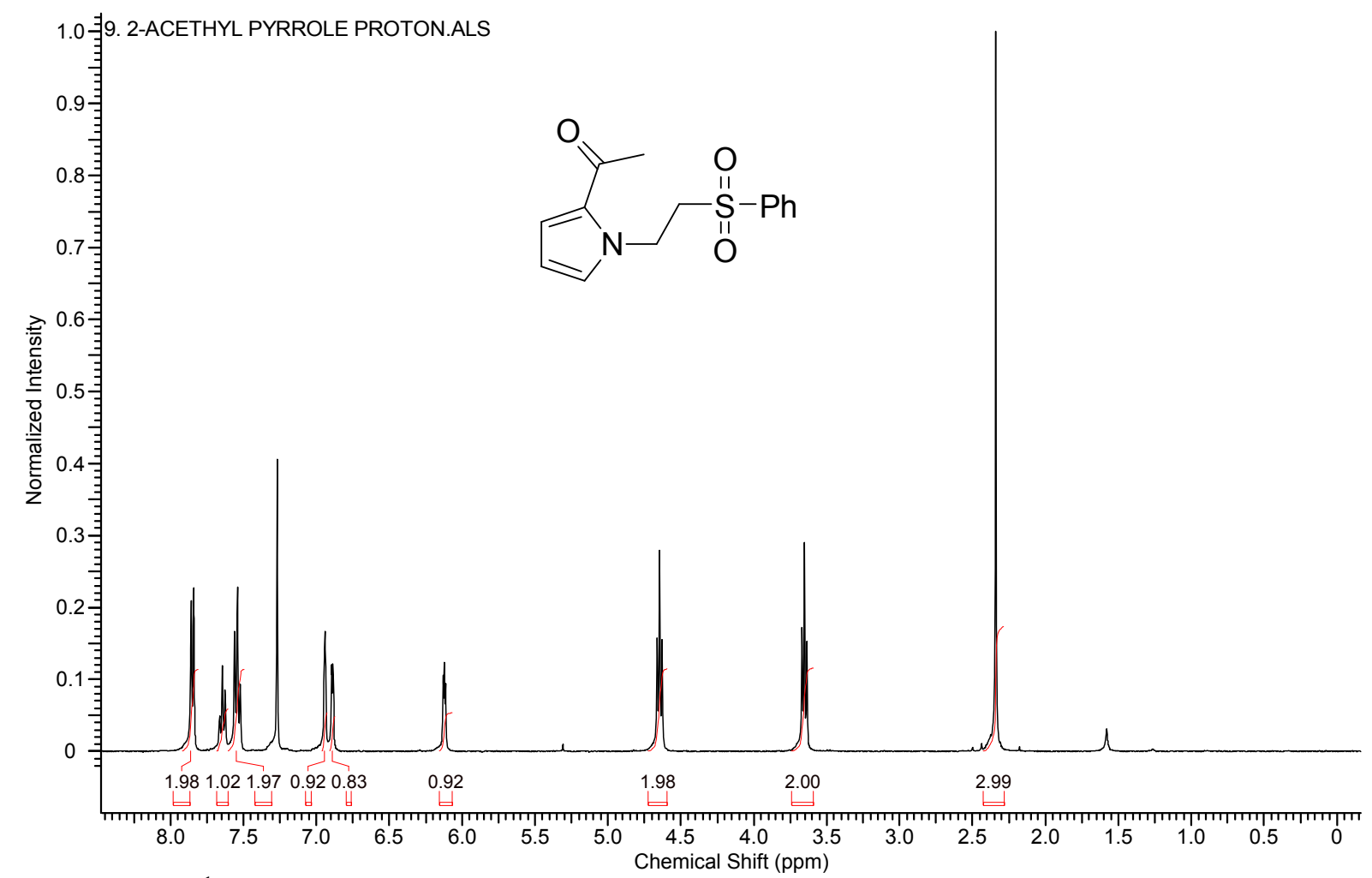

Figure S43. ${ }^{1} \mathrm{H}$ NMR spectrum of the compound $\mathbf{6 h}$

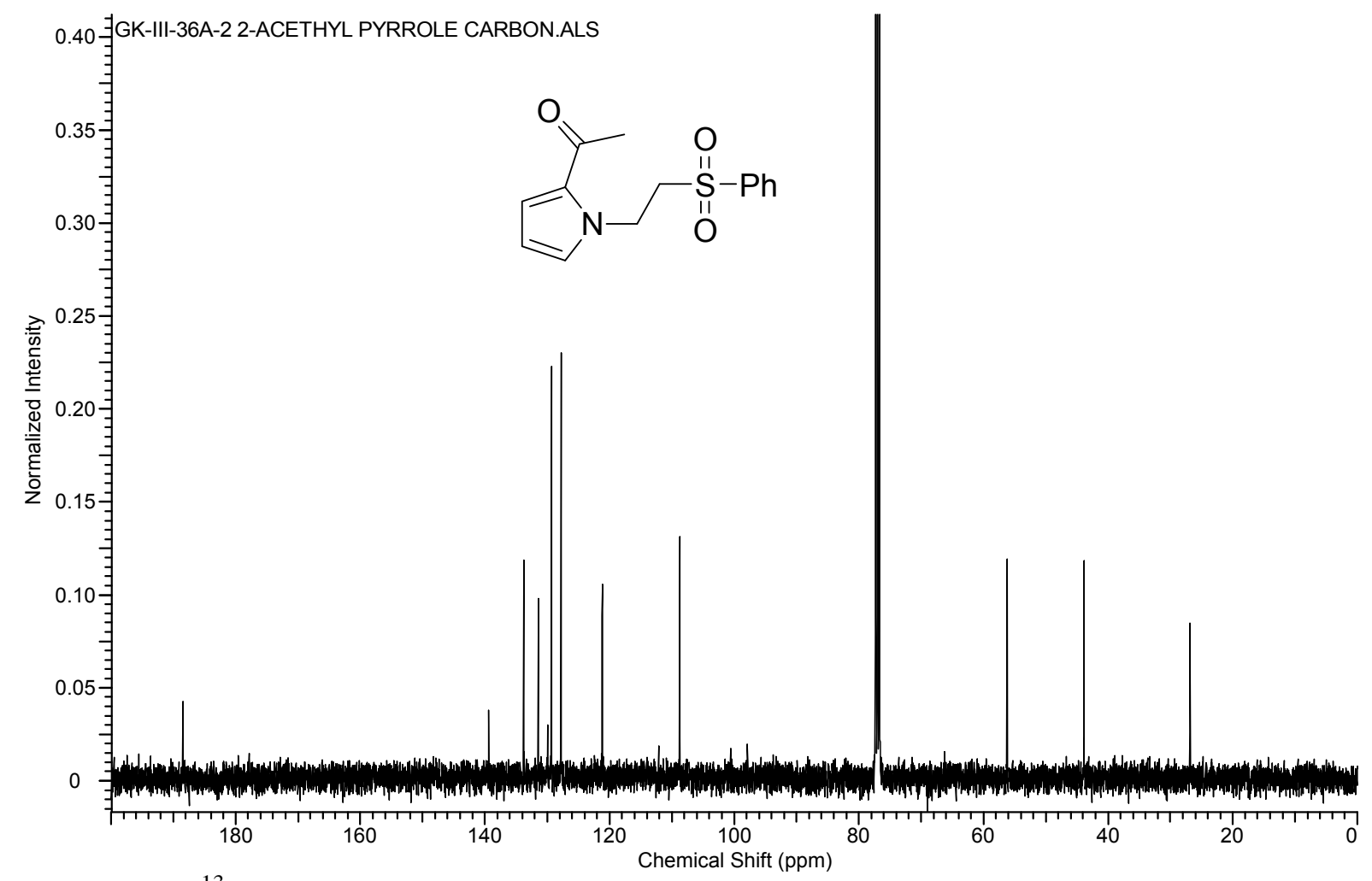

Figure S44. ${ }^{13} \mathrm{C}$ NMR spectrum of the compound $6 \mathbf{h}$ 


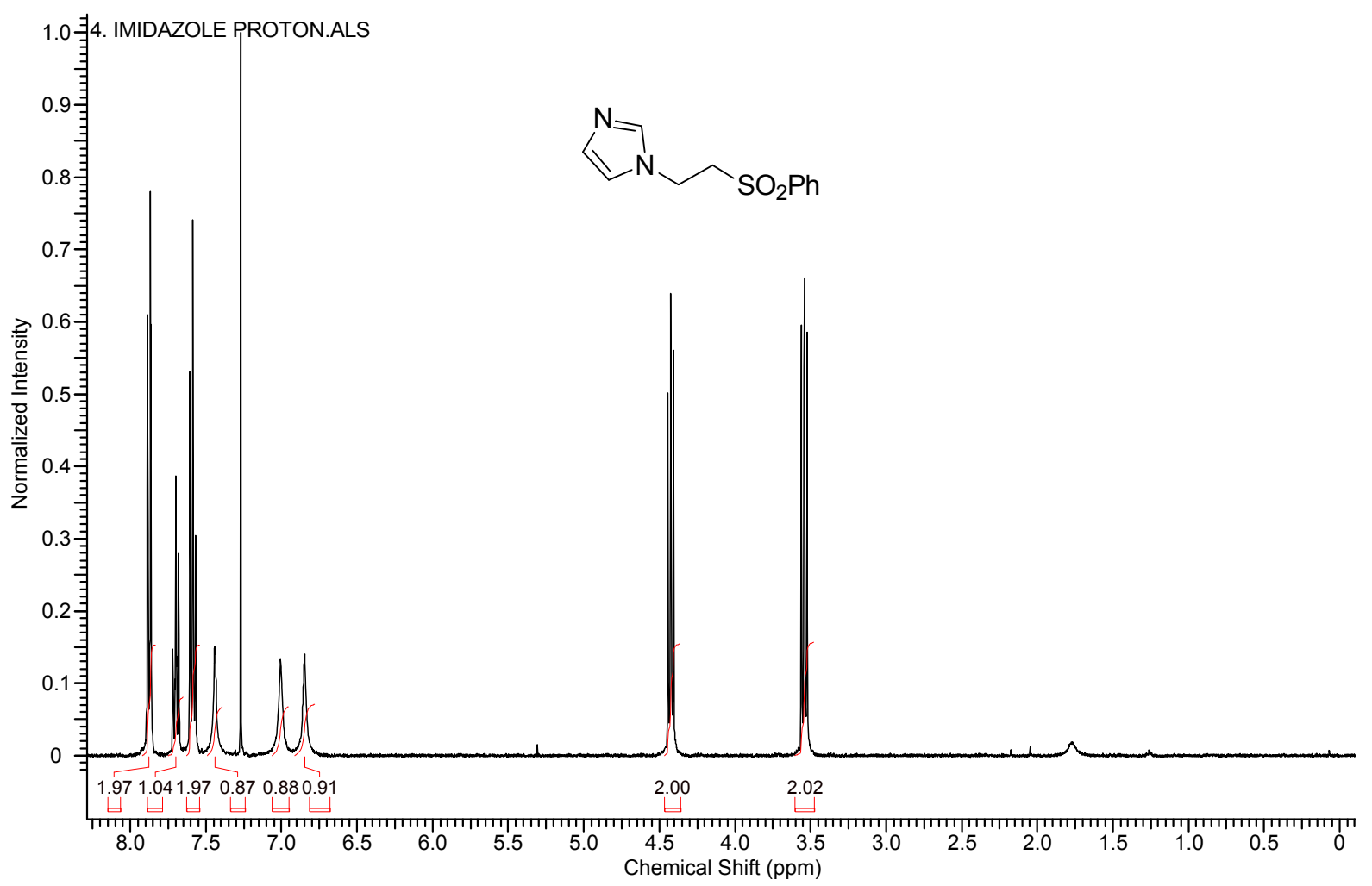

Figure S45. ${ }^{1} \mathrm{H}$ NMR spectrum of the compound $\mathbf{6 i}$

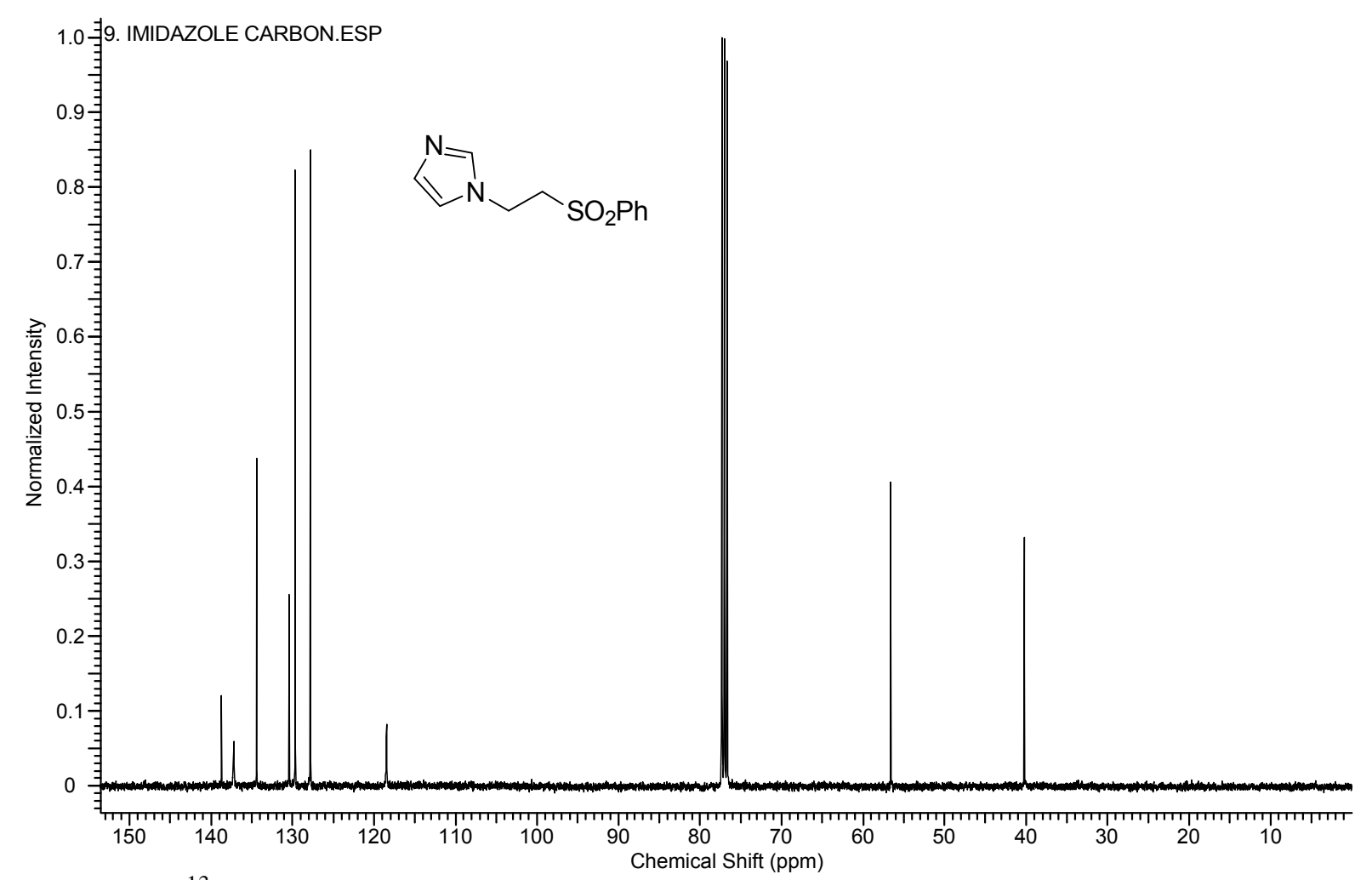

Figure S46. ${ }^{13} \mathrm{C}$ NMR spectrum of the compound $\mathbf{6 i}$ 


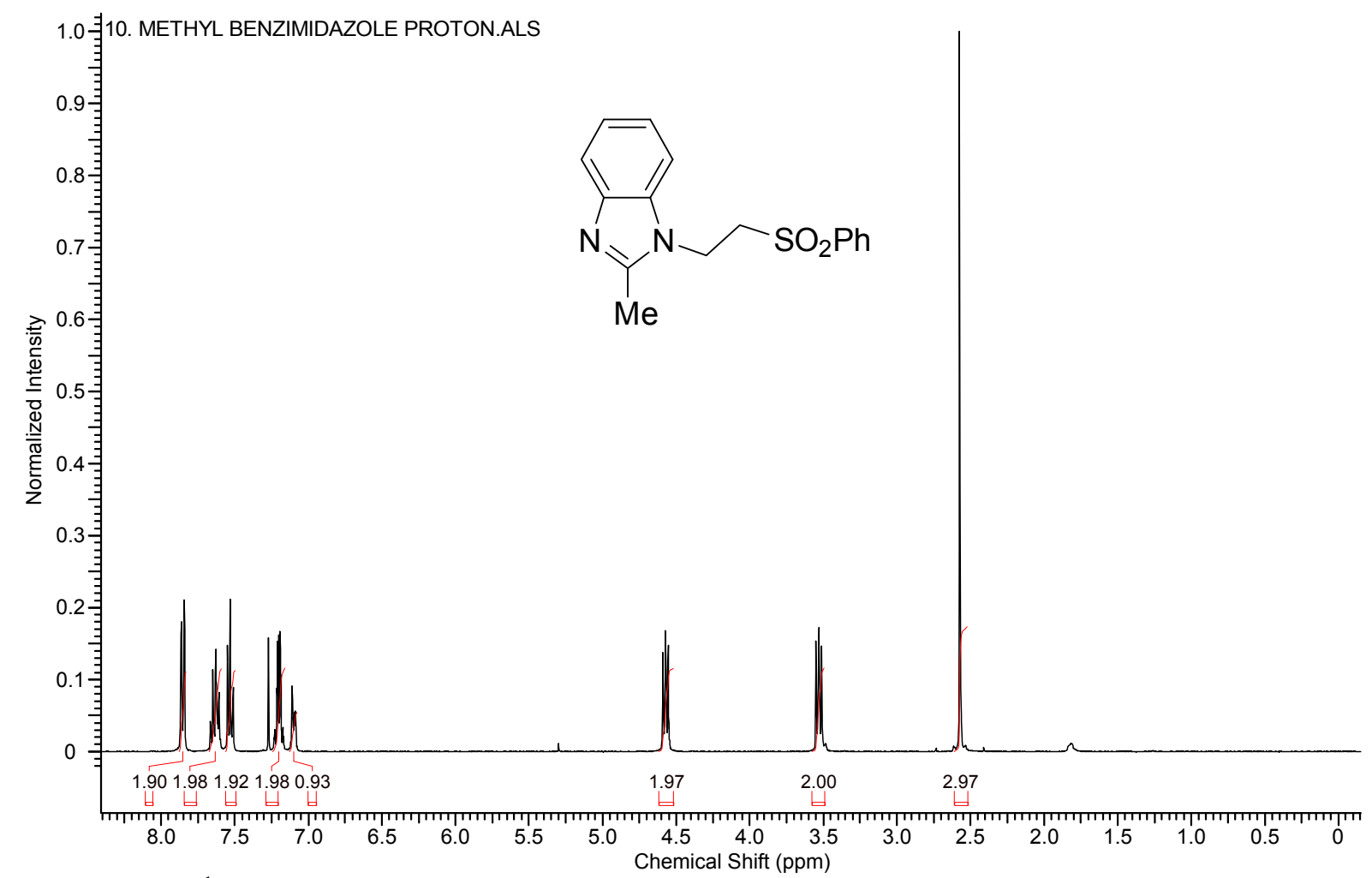

Figure S47. ${ }^{1} \mathrm{H}$ NMR spectrum of the compound $6 \mathbf{j}$

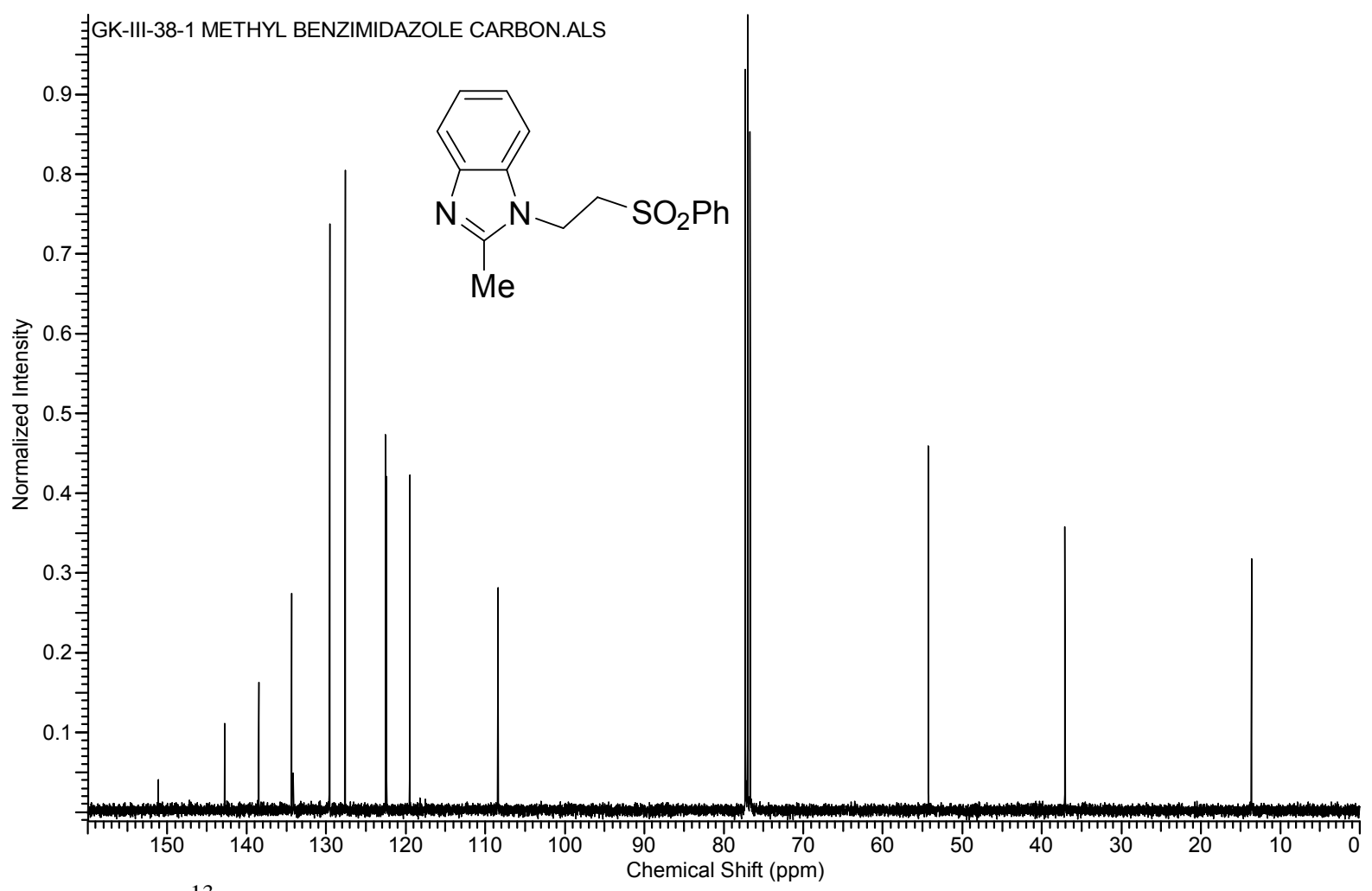

Figure S48. ${ }^{13} \mathrm{C}$ NMR spectrum of the compound $\mathbf{6 j}$ 


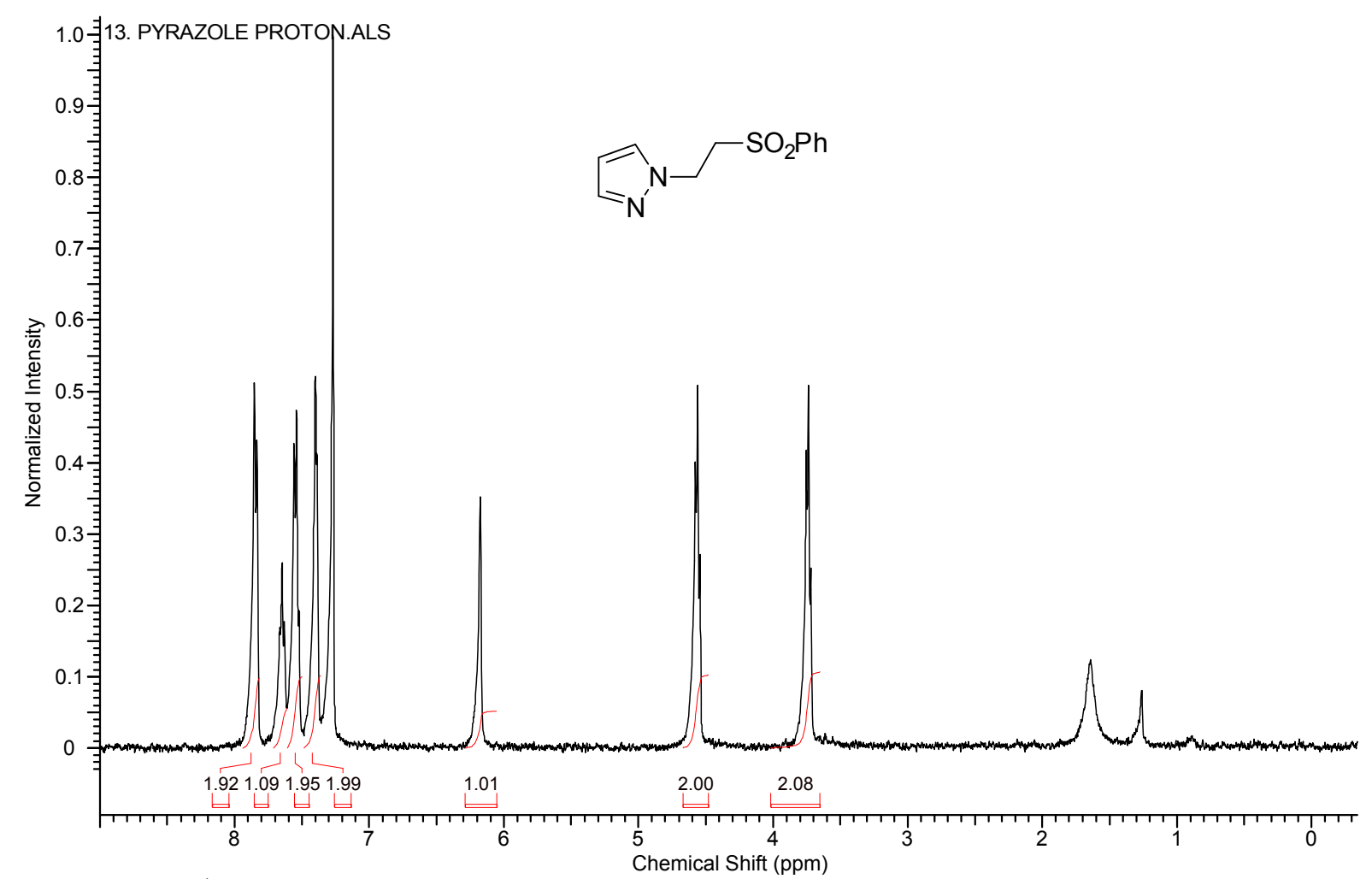

Figure S49. ${ }^{1} \mathrm{H}$ NMR spectrum of the compound $\mathbf{6 k}$

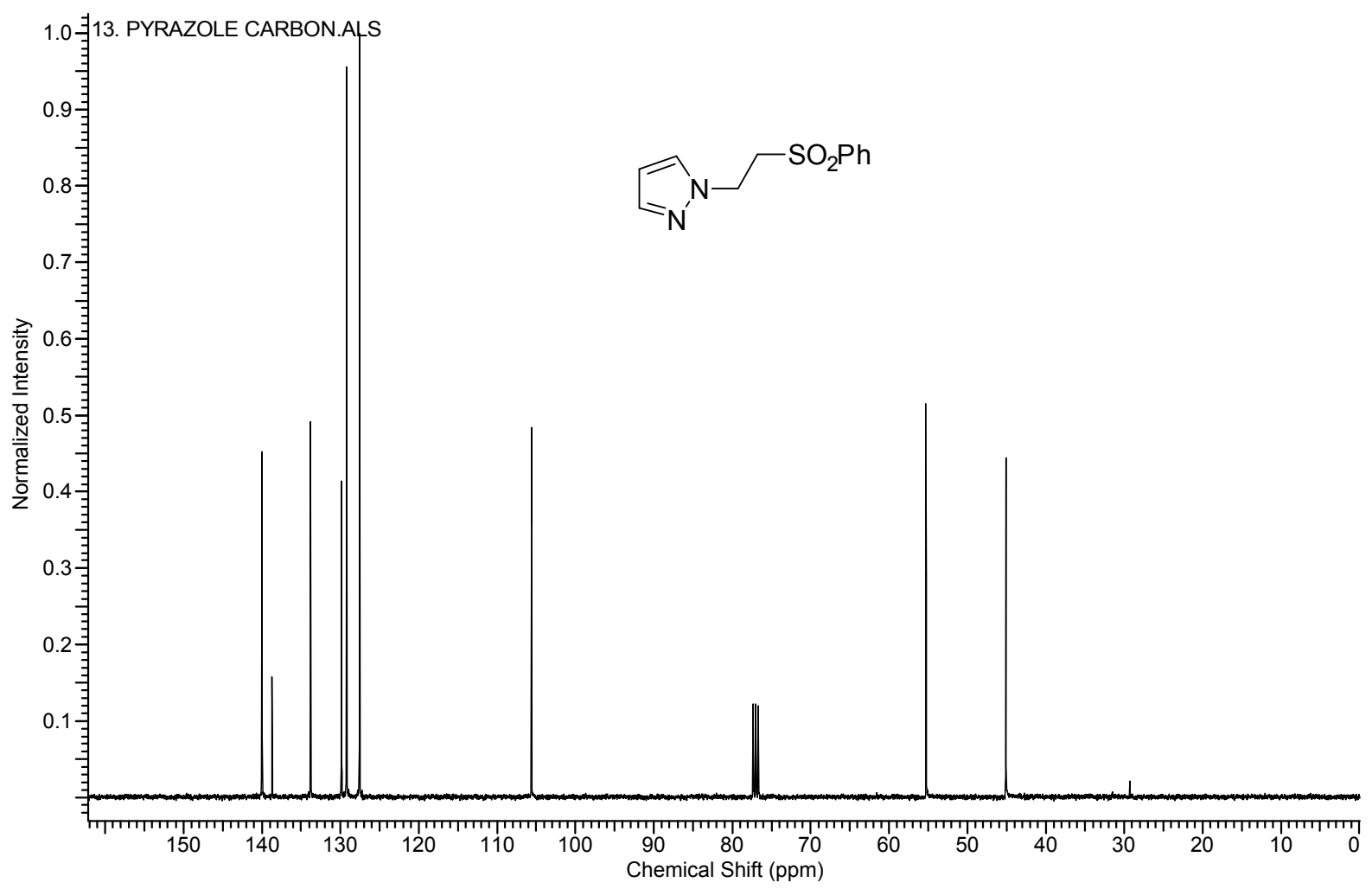

Figure S50. ${ }^{13} \mathrm{C}$ NMR spectrum of the compound $6 \mathbf{k}$ 


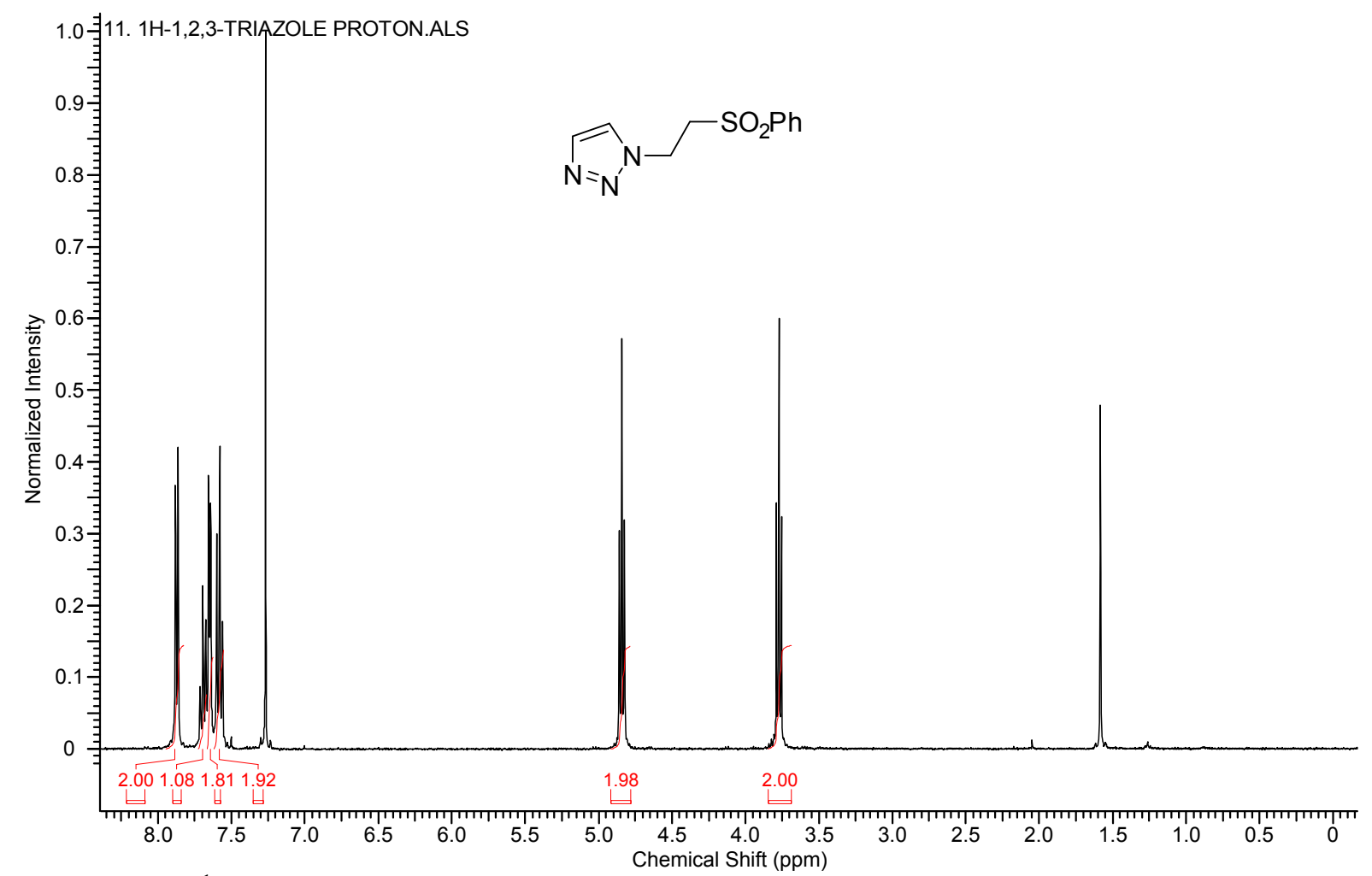

Figure S51. ${ }^{1} \mathrm{H}$ NMR spectrum of the compound $6 \mathbf{1}$

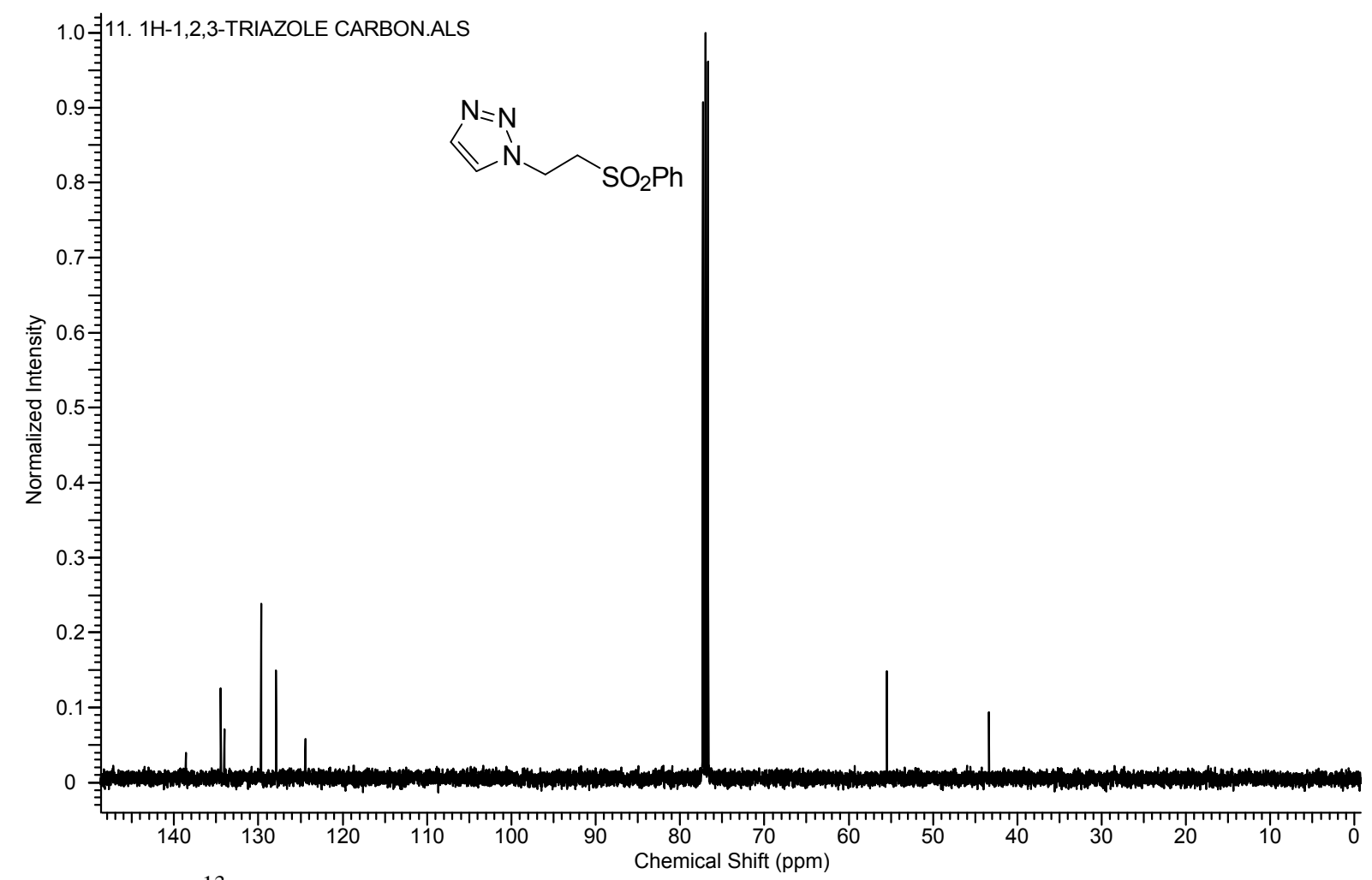

Figure S52. ${ }^{13} \mathrm{C}$ NMR spectrum of the compound $\mathbf{6 l}$ 


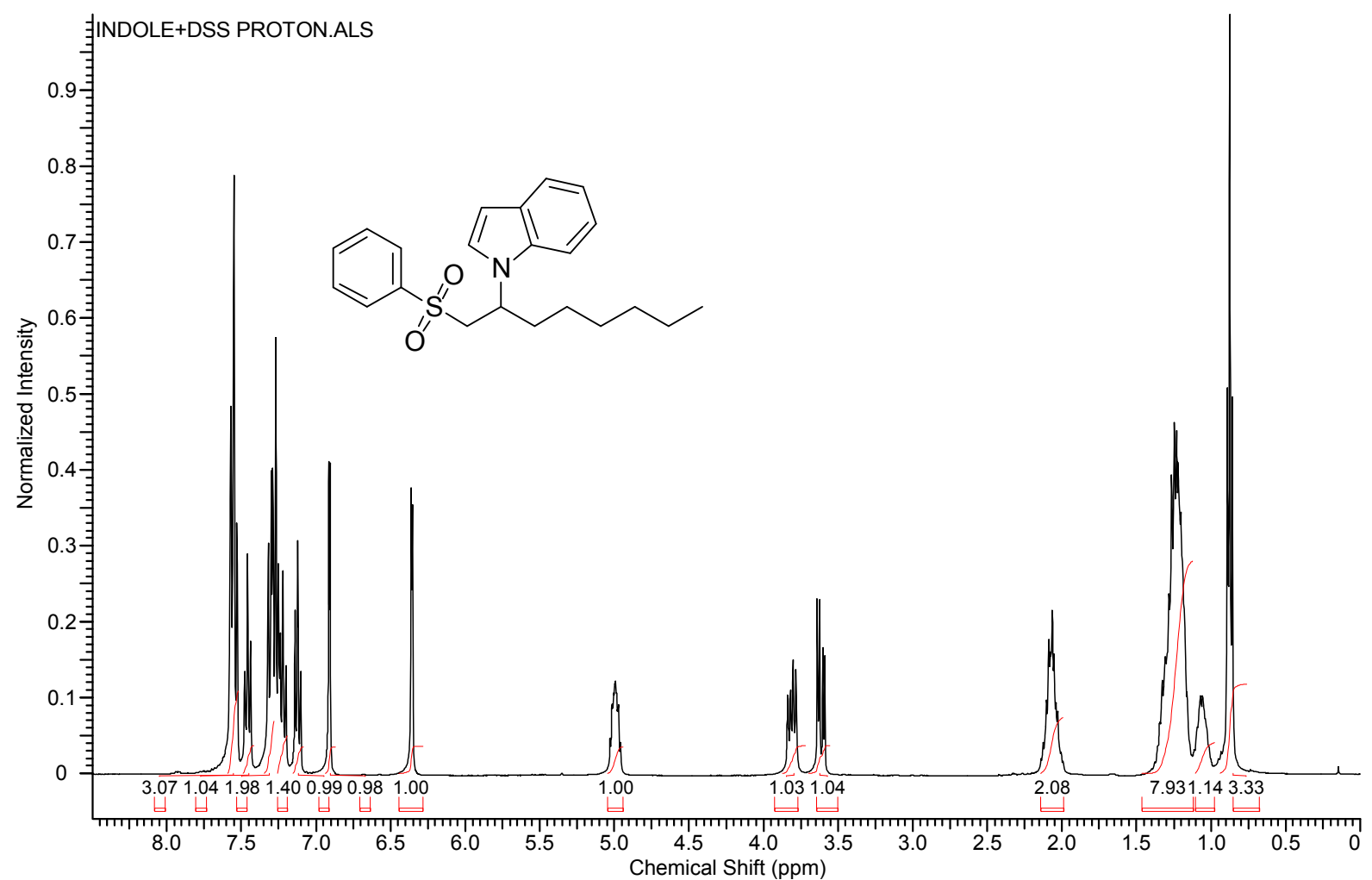

Figure S53. ${ }^{1} \mathrm{H}$ NMR spectrum of the compound $\mathbf{8 a}$

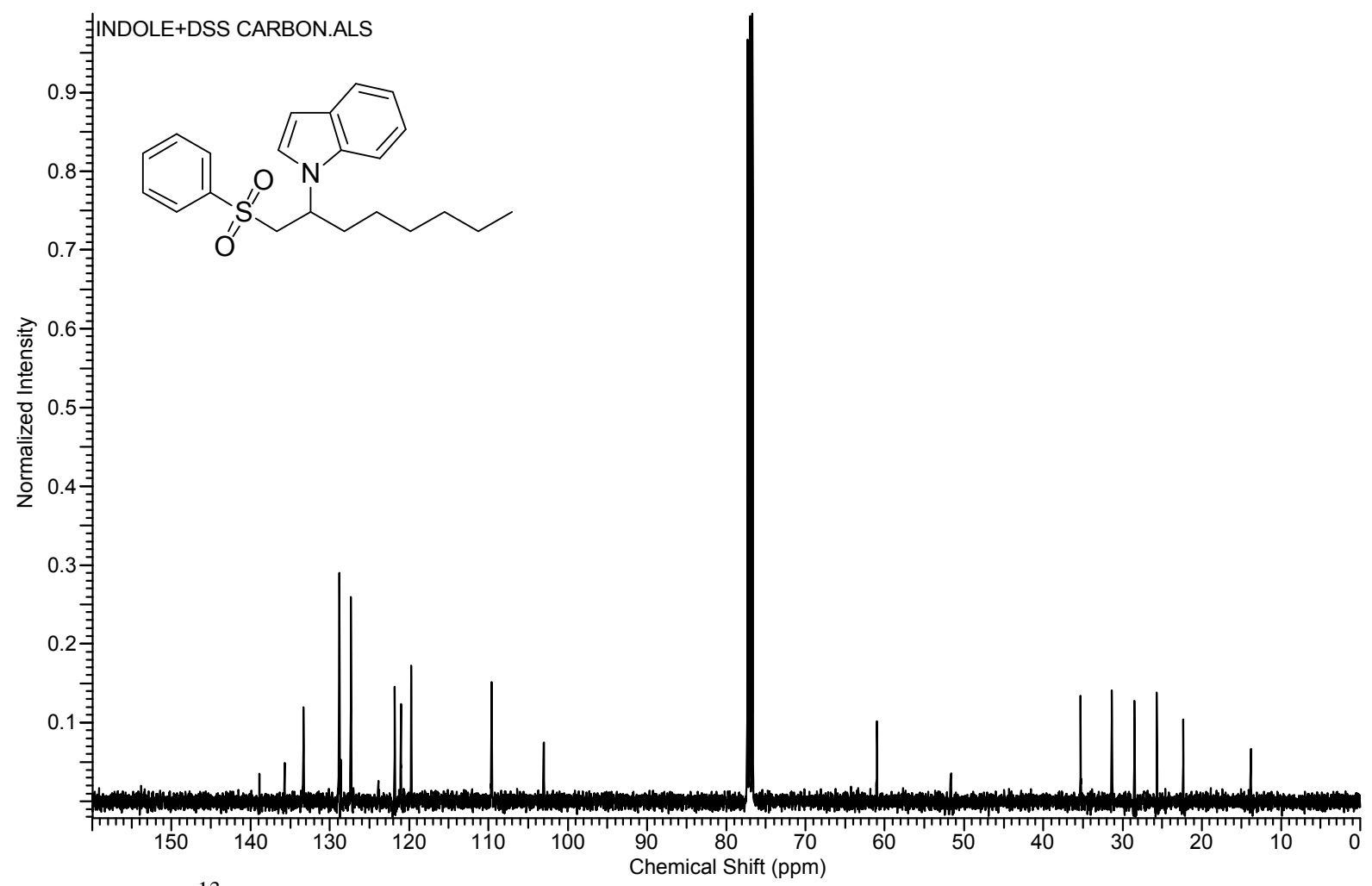

Figure S54. ${ }^{13} \mathrm{C}$ NMR spectrum of the compound $8 \mathbf{a}$

28 


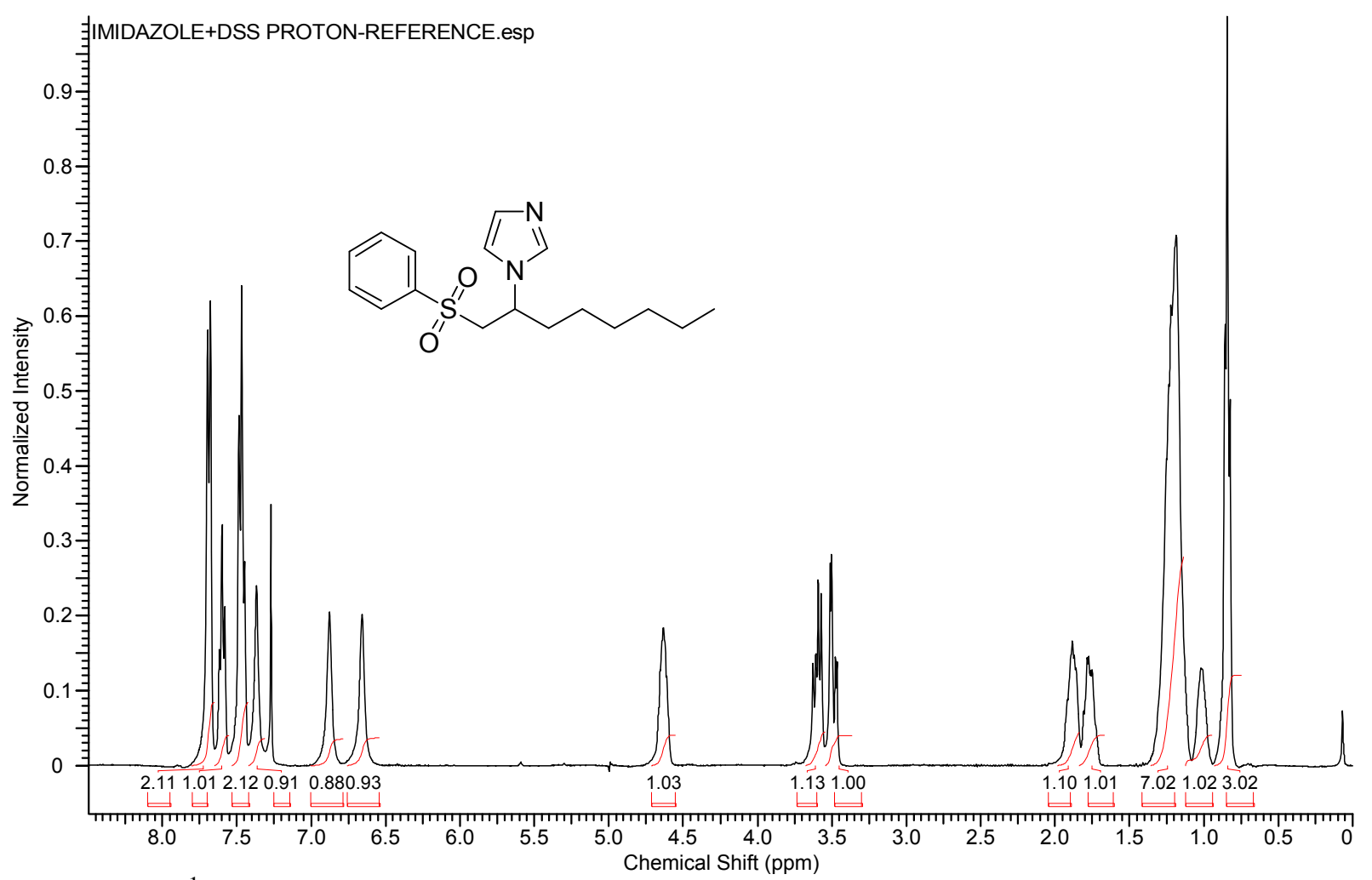

Figure S55. ${ }^{1} \mathrm{H}$ NMR spectrum of the compound $\mathbf{8 b}$

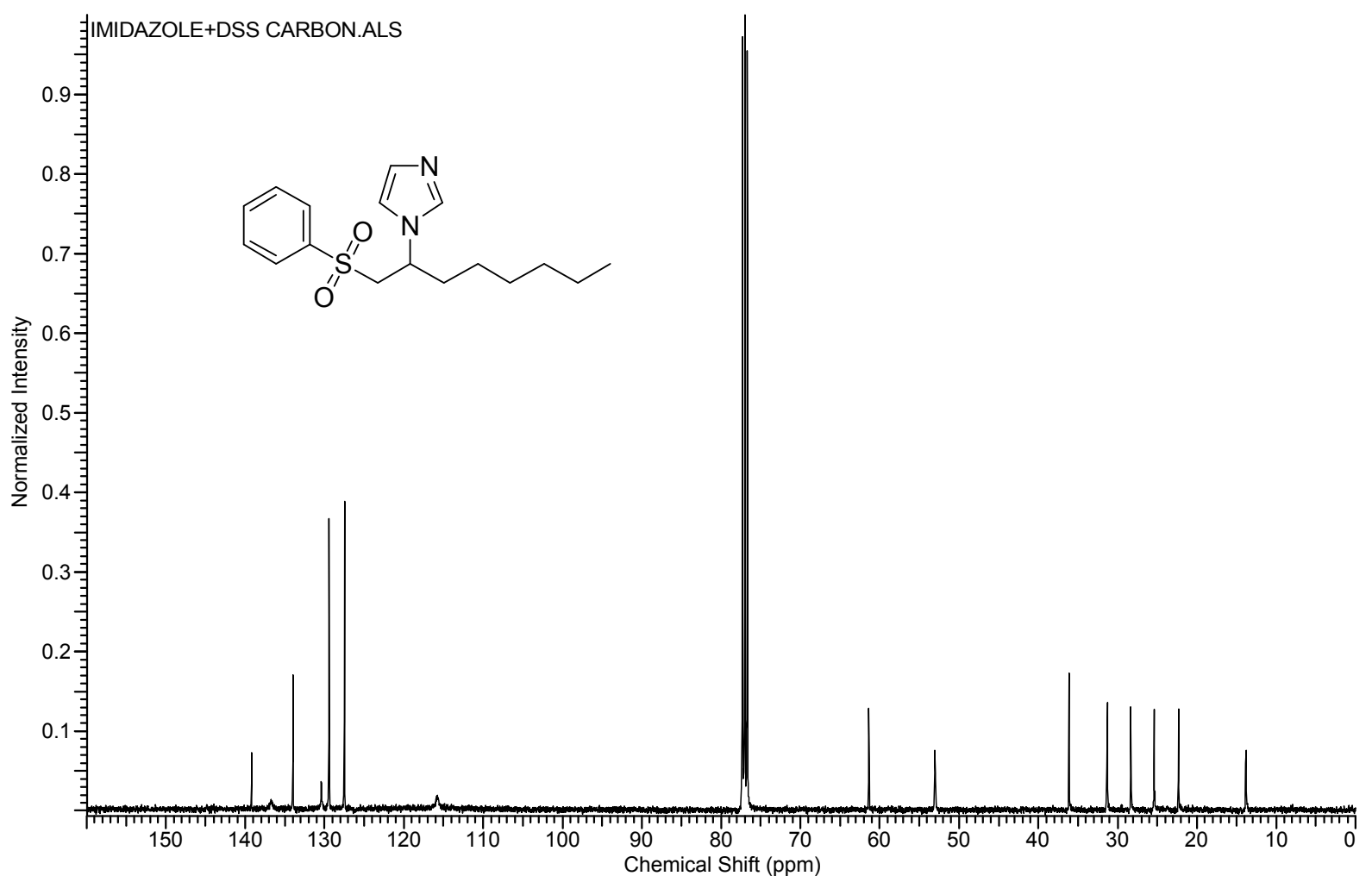

Figure S56. ${ }^{13} \mathrm{C}$ NMR spectrum of the compound $\mathbf{8 b}$ 


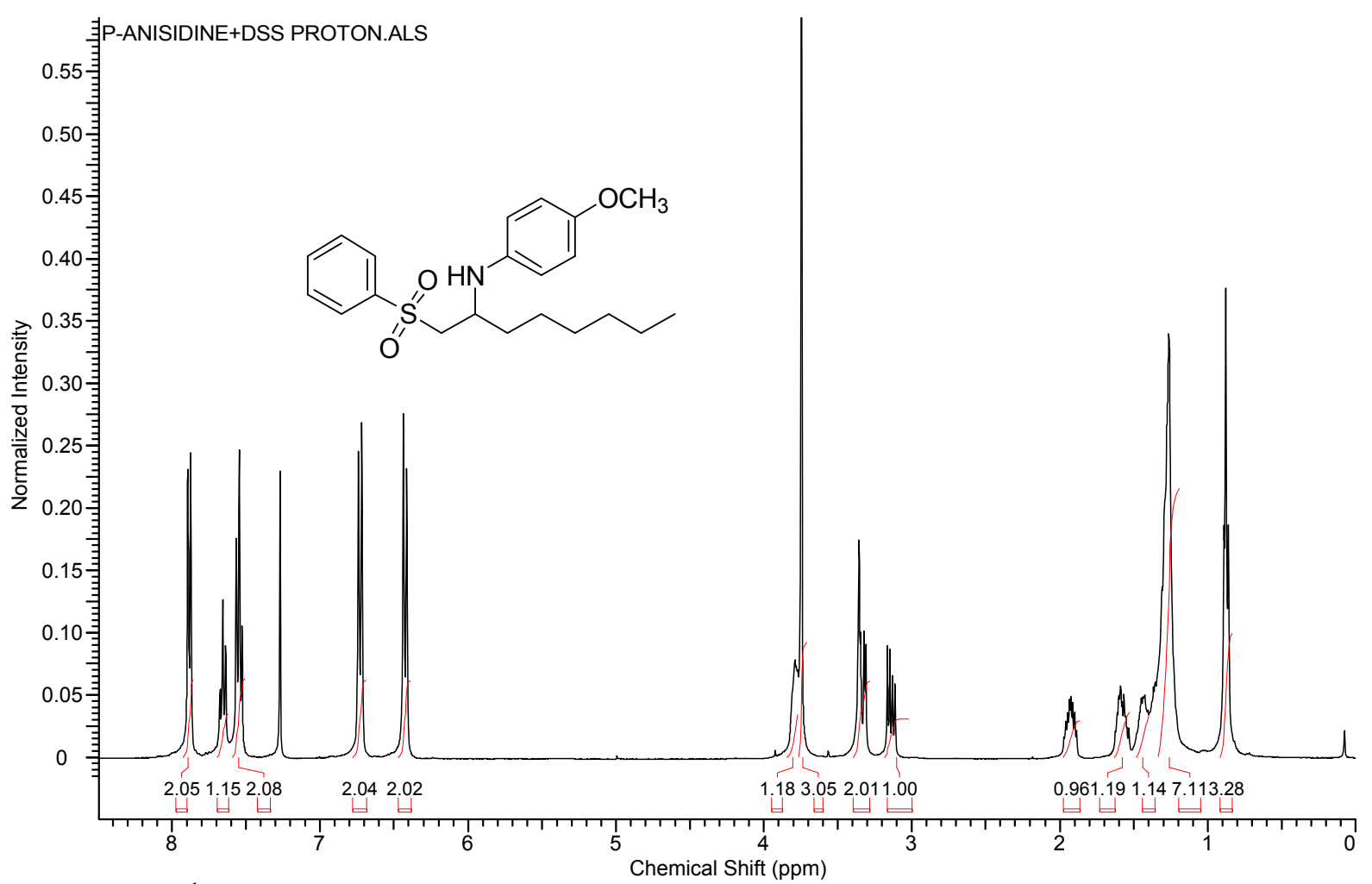

Figure S57. ${ }^{1} \mathrm{H}$ NMR spectrum of the compound $\mathbf{8 c}$

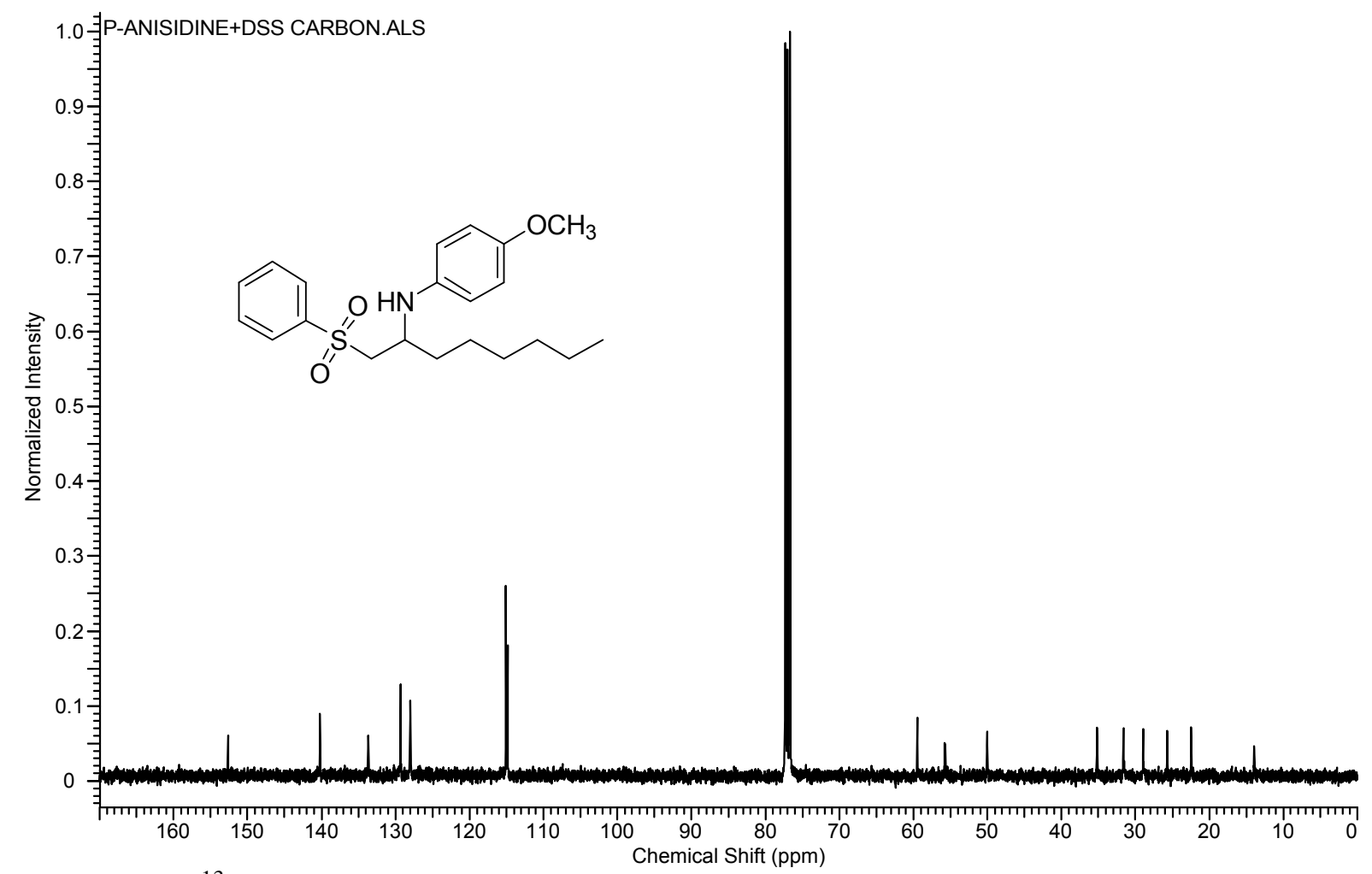

Figure S58. ${ }^{13} \mathrm{C}$ NMR spectrum of the compound $8 \mathrm{c}$ 


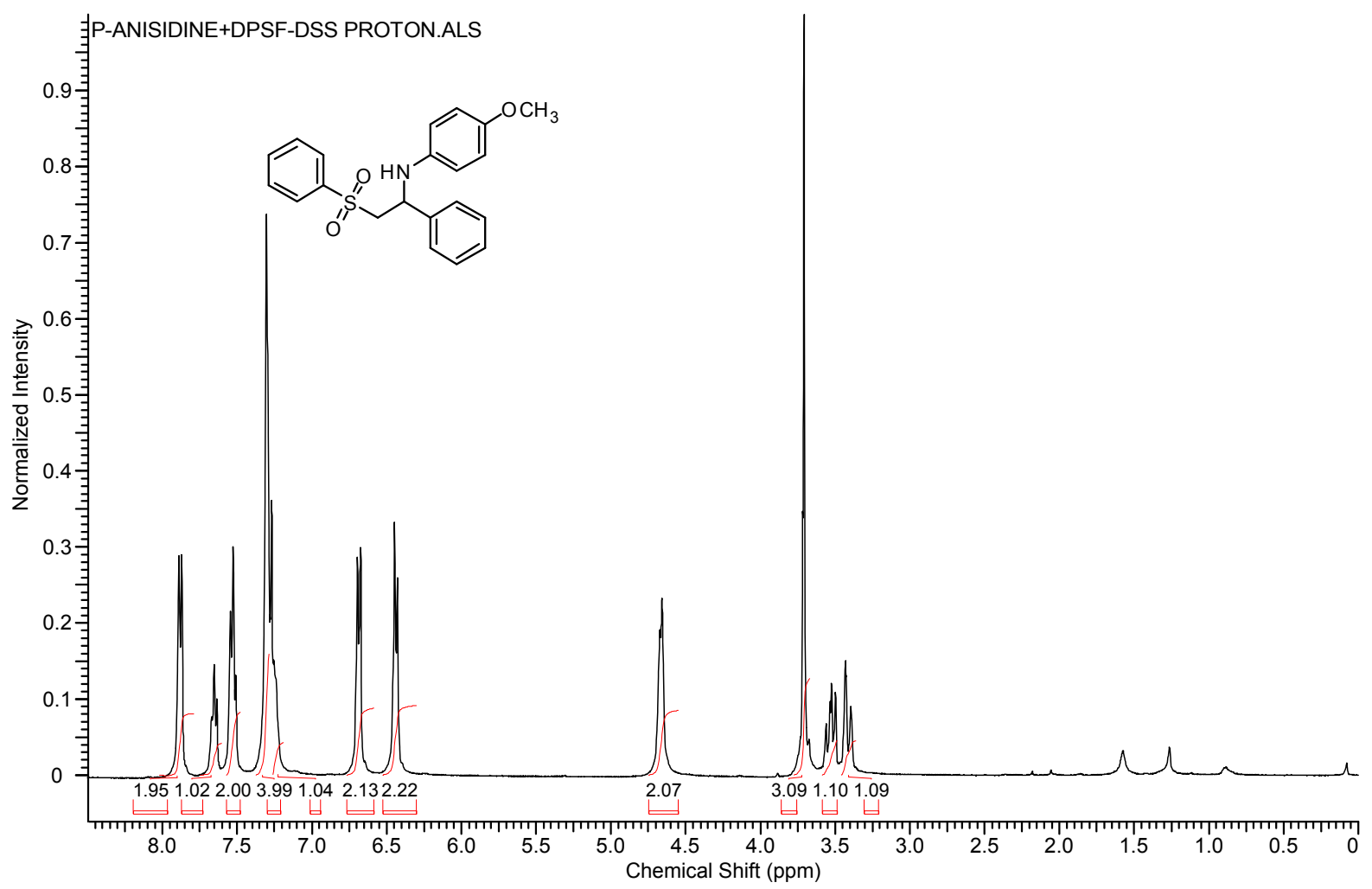

Figure S59. ${ }^{1} \mathrm{H}$ NMR spectrum of the compound $\mathbf{8 d}$

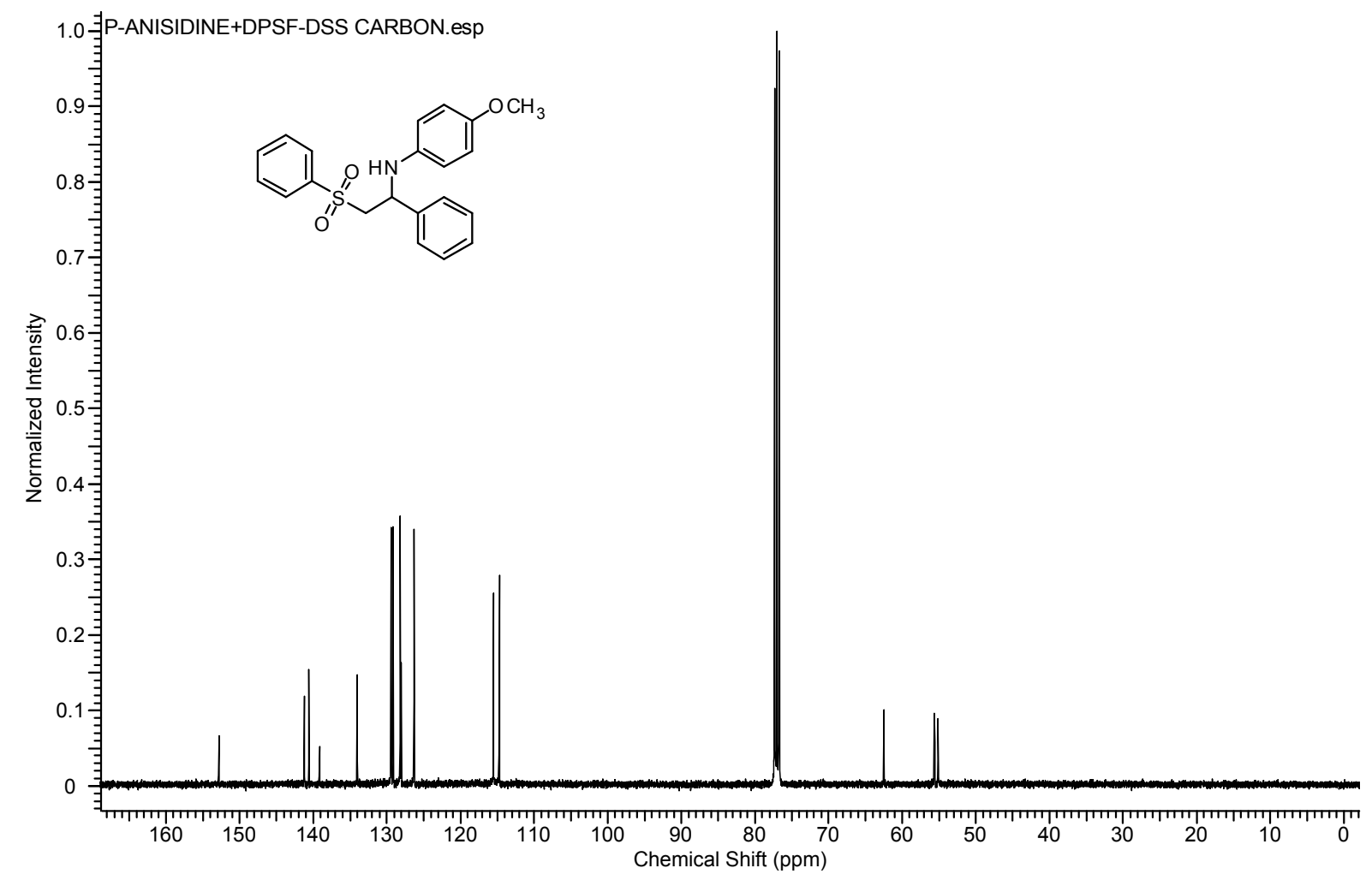

Figure S60. ${ }^{13} \mathrm{C}$ NMR spectrum of the compound $\mathbf{8 d}$ 


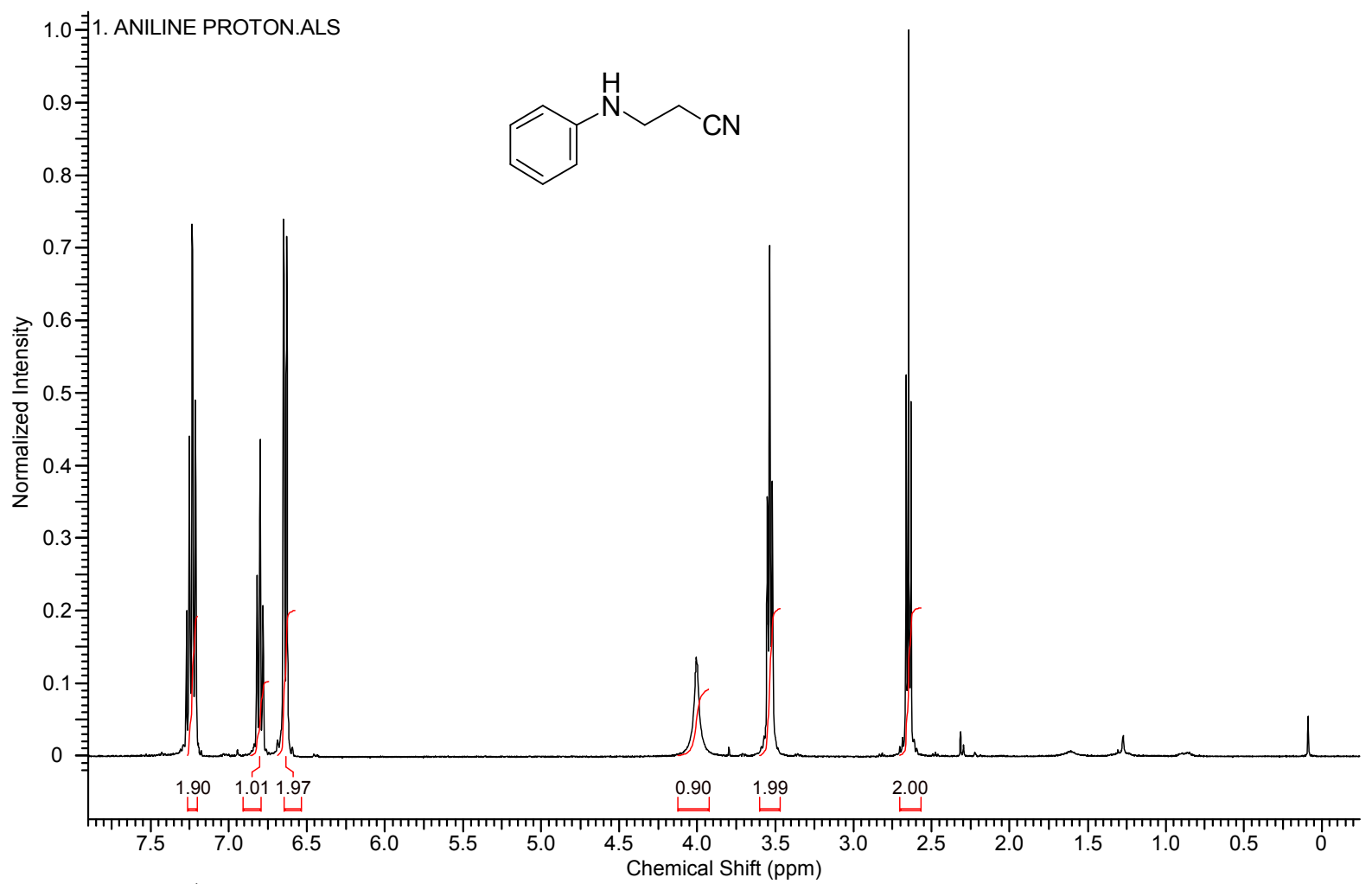

Figure S61. ${ }^{1} \mathrm{H}$ NMR spectrum of the compound 10a

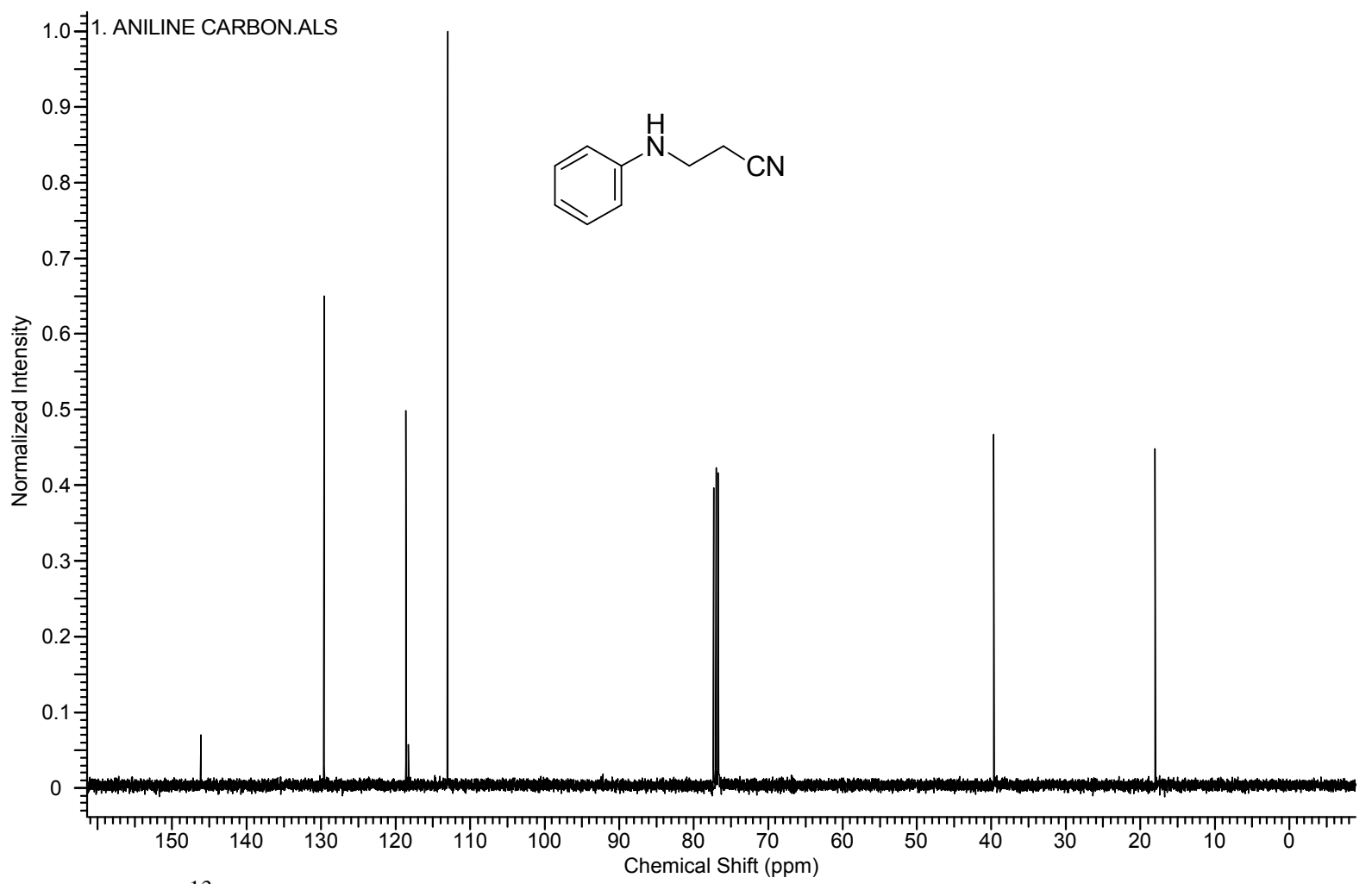

Figure S62. ${ }^{13} \mathrm{C}$ NMR spectrum of the compound 10a 


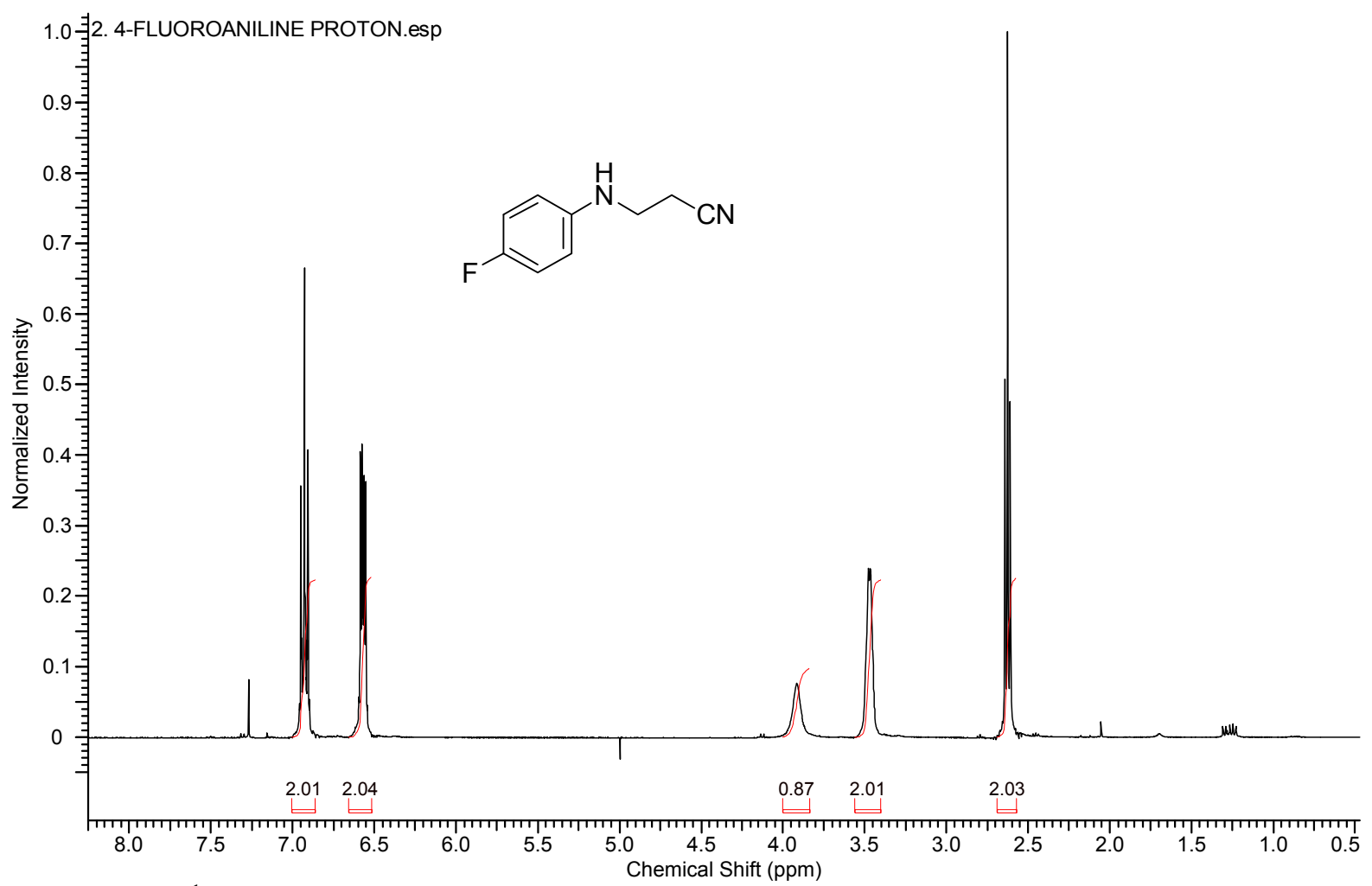

Figure S63. ${ }^{1} \mathrm{H}$ NMR spectrum of the compound 10b

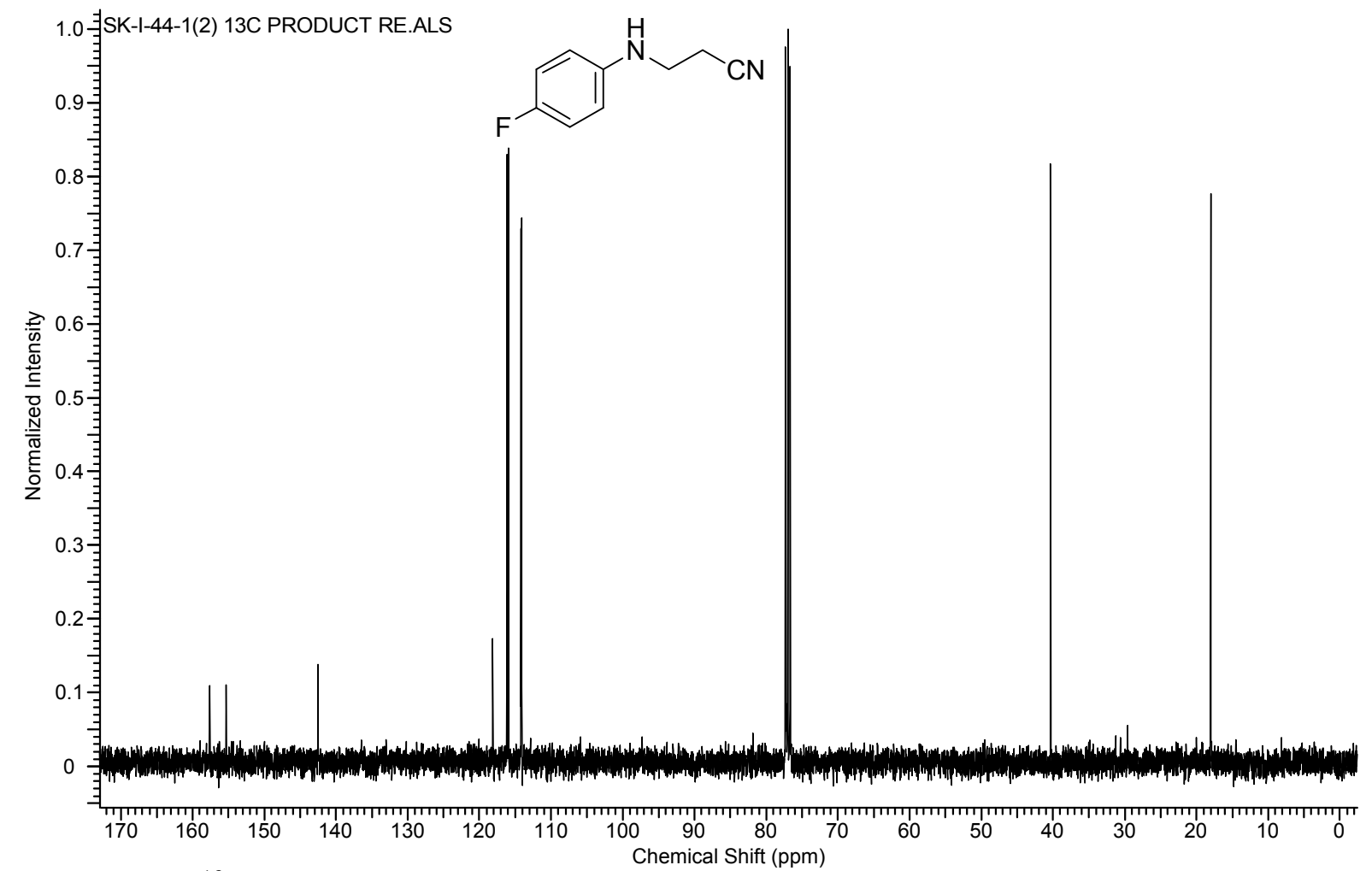

Figure S64. ${ }^{13} \mathrm{C}$ NMR spectrum of the compound $\mathbf{1 0 b}$ 


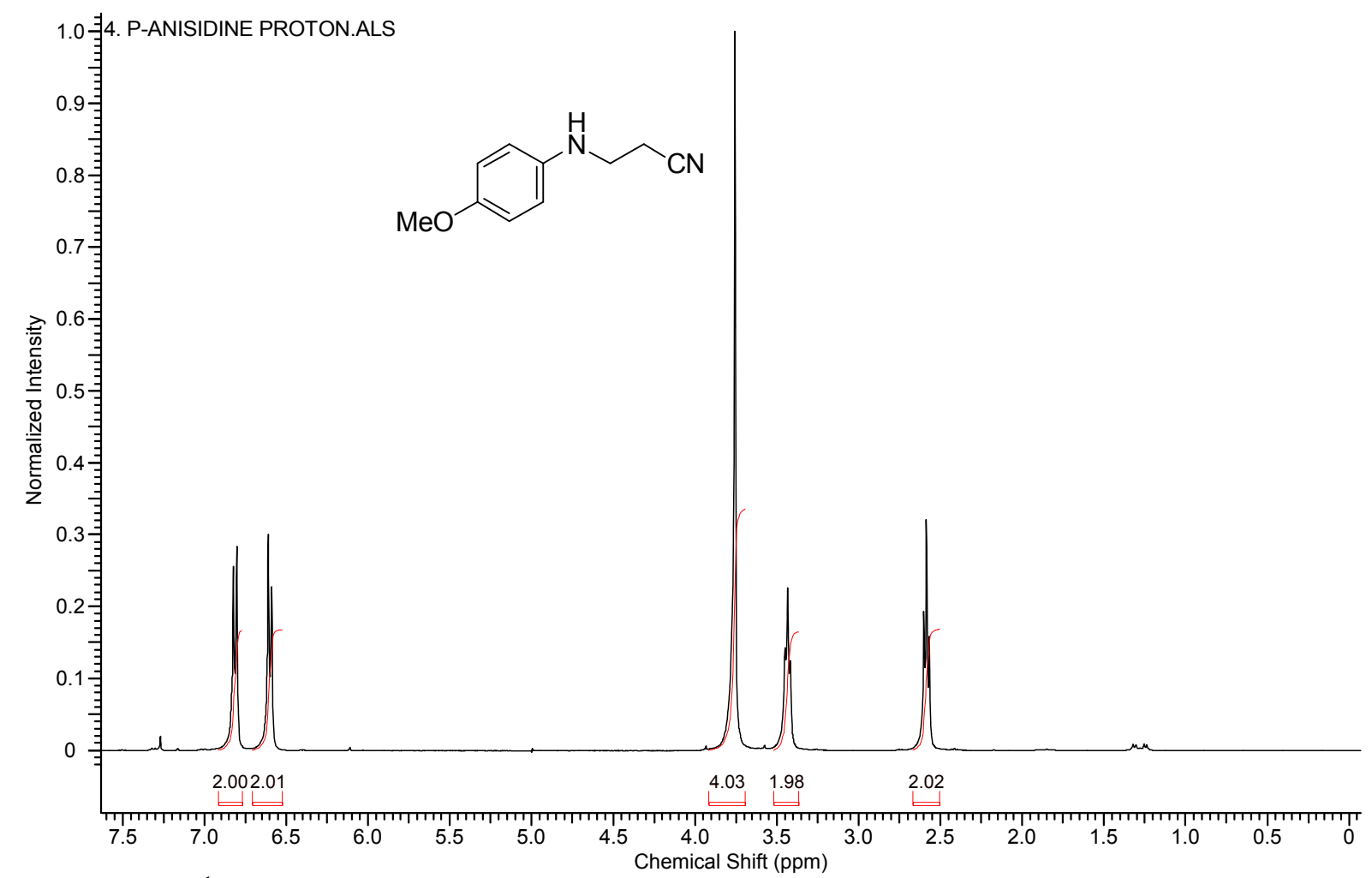

Figure S65. ${ }^{1} \mathrm{H}$ NMR spectrum of the compound 10c

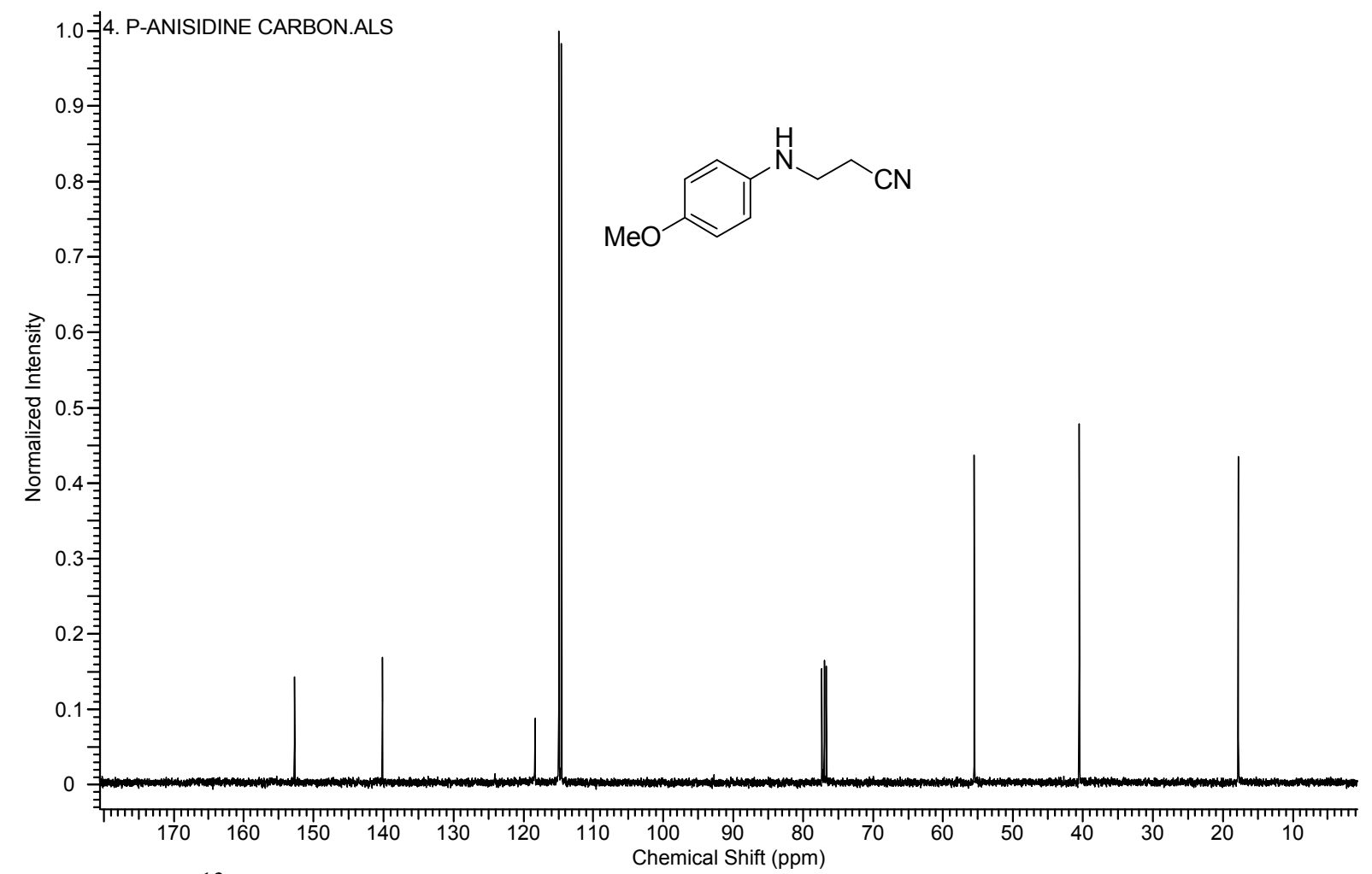

Figure S66. ${ }^{13} \mathrm{C}$ NMR spectrum of the compound 10c 


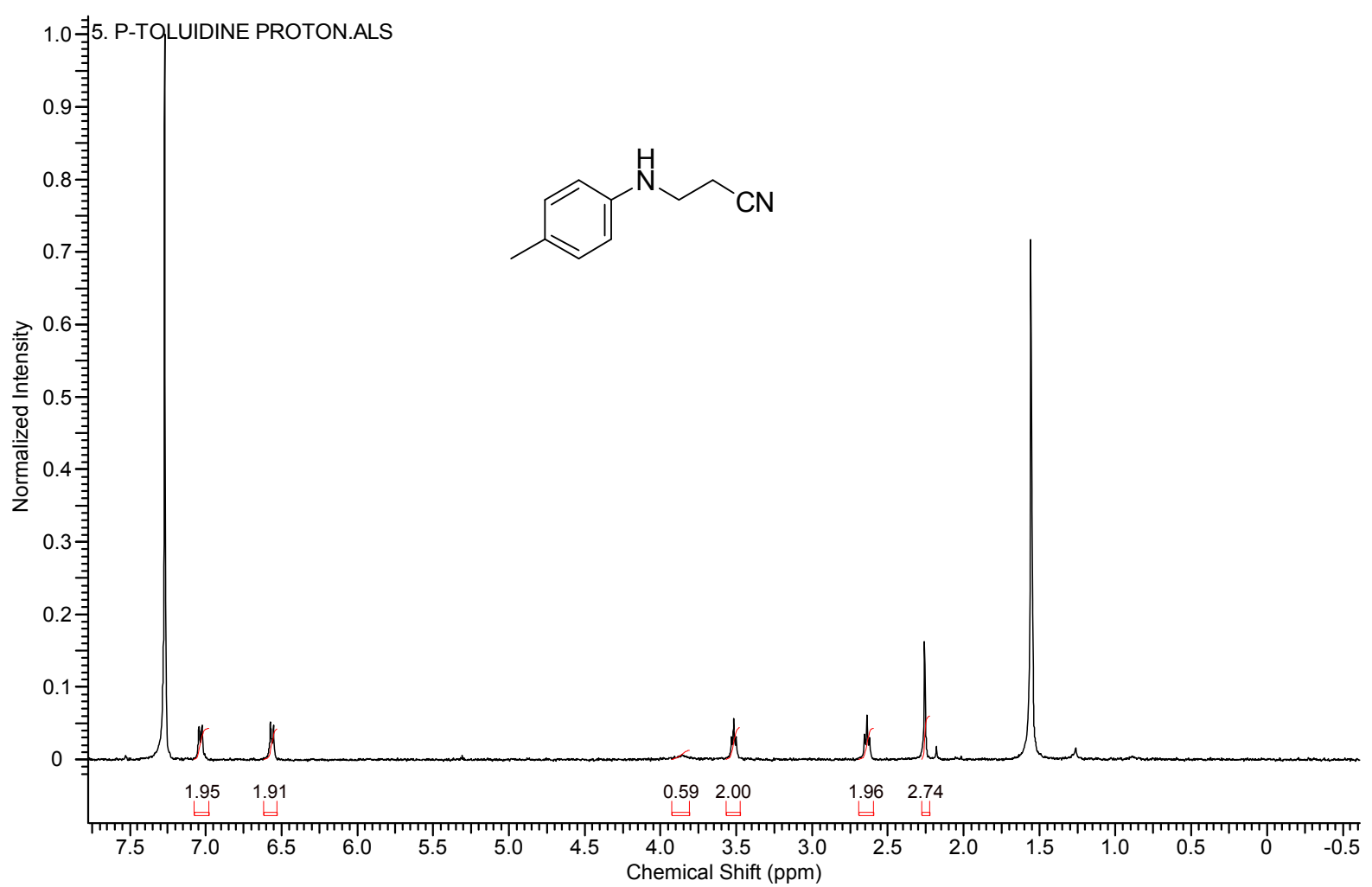

Figure S67. ${ }^{1} \mathrm{H}$ NMR spectrum of the compound 10d

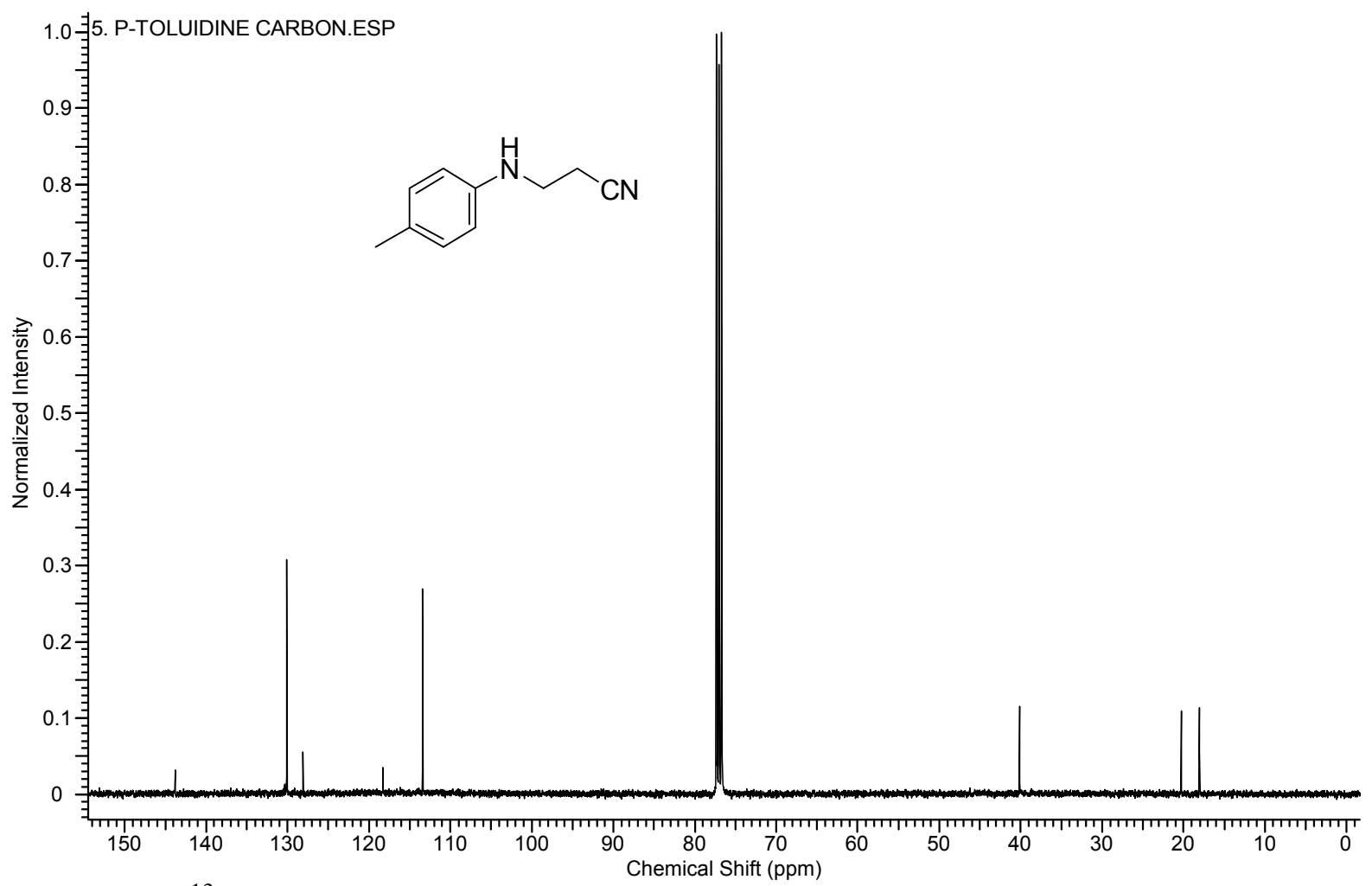

Figure S68. ${ }^{13} \mathrm{C}$ NMR spectrum of the compound 10d 


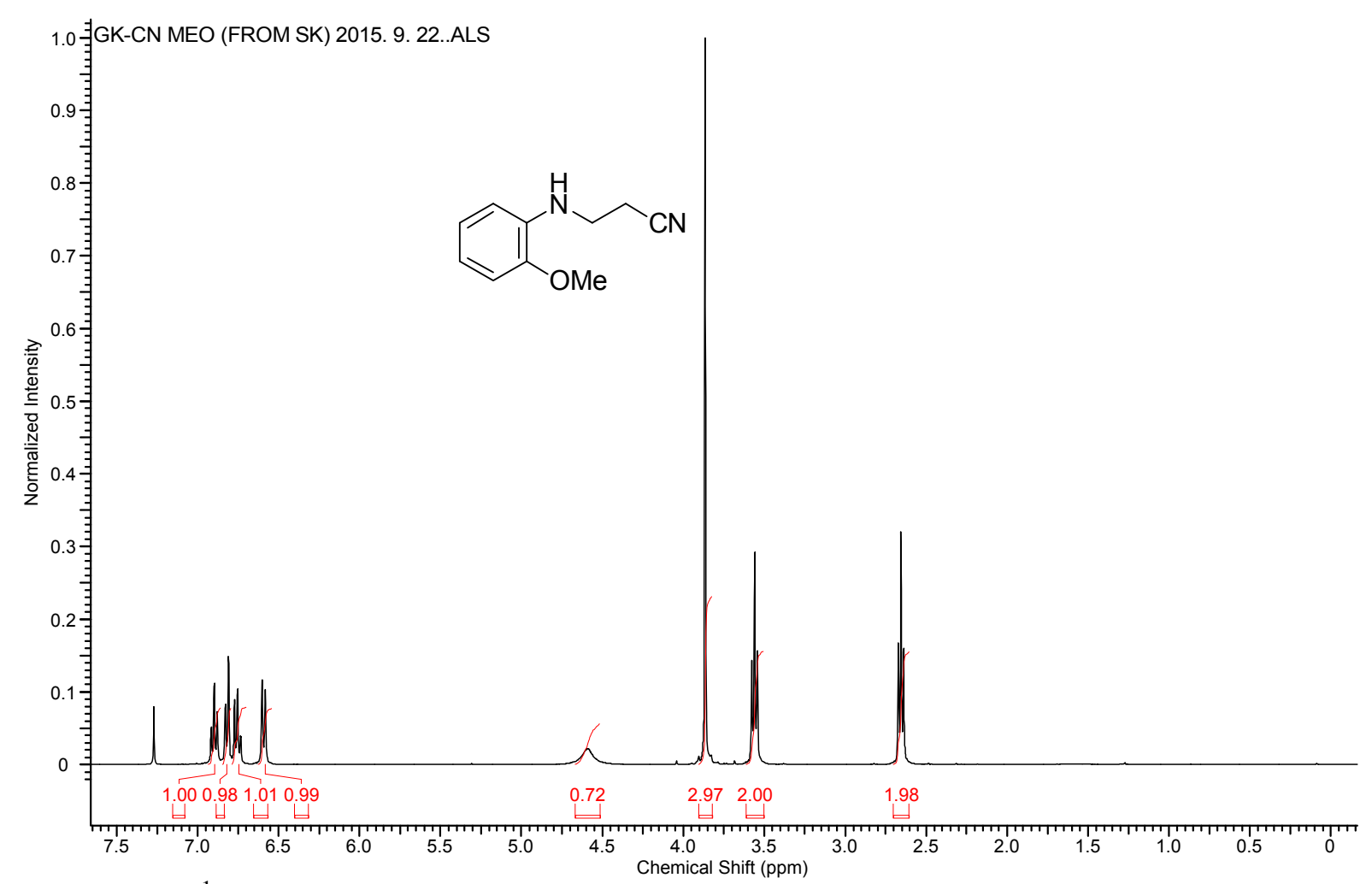

Figure S69. ${ }^{1} \mathrm{H}$ NMR spectrum of the compound 10e

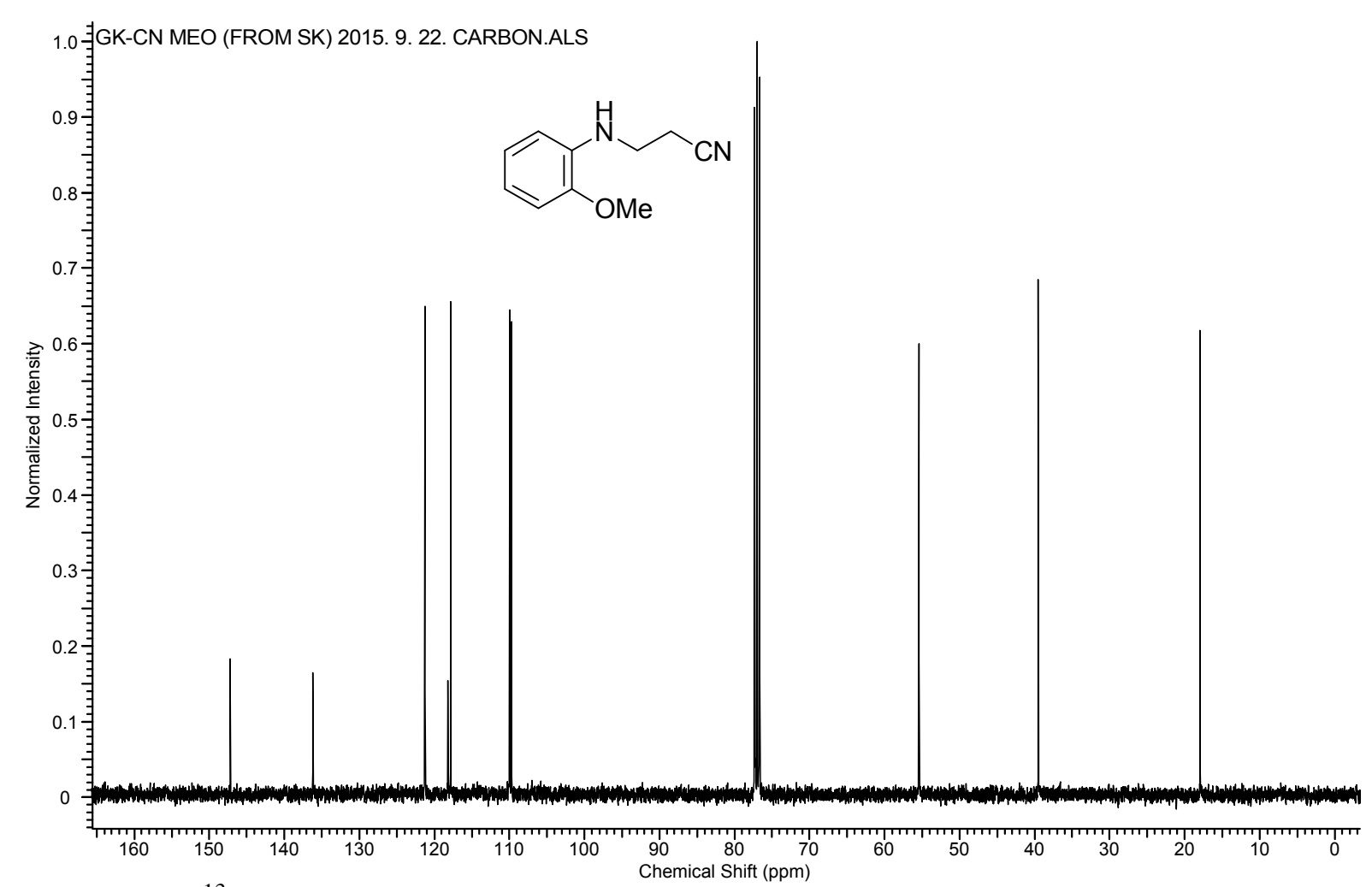

Figure S70. ${ }^{13} \mathrm{C}$ NMR spectrum of the compound 10e 


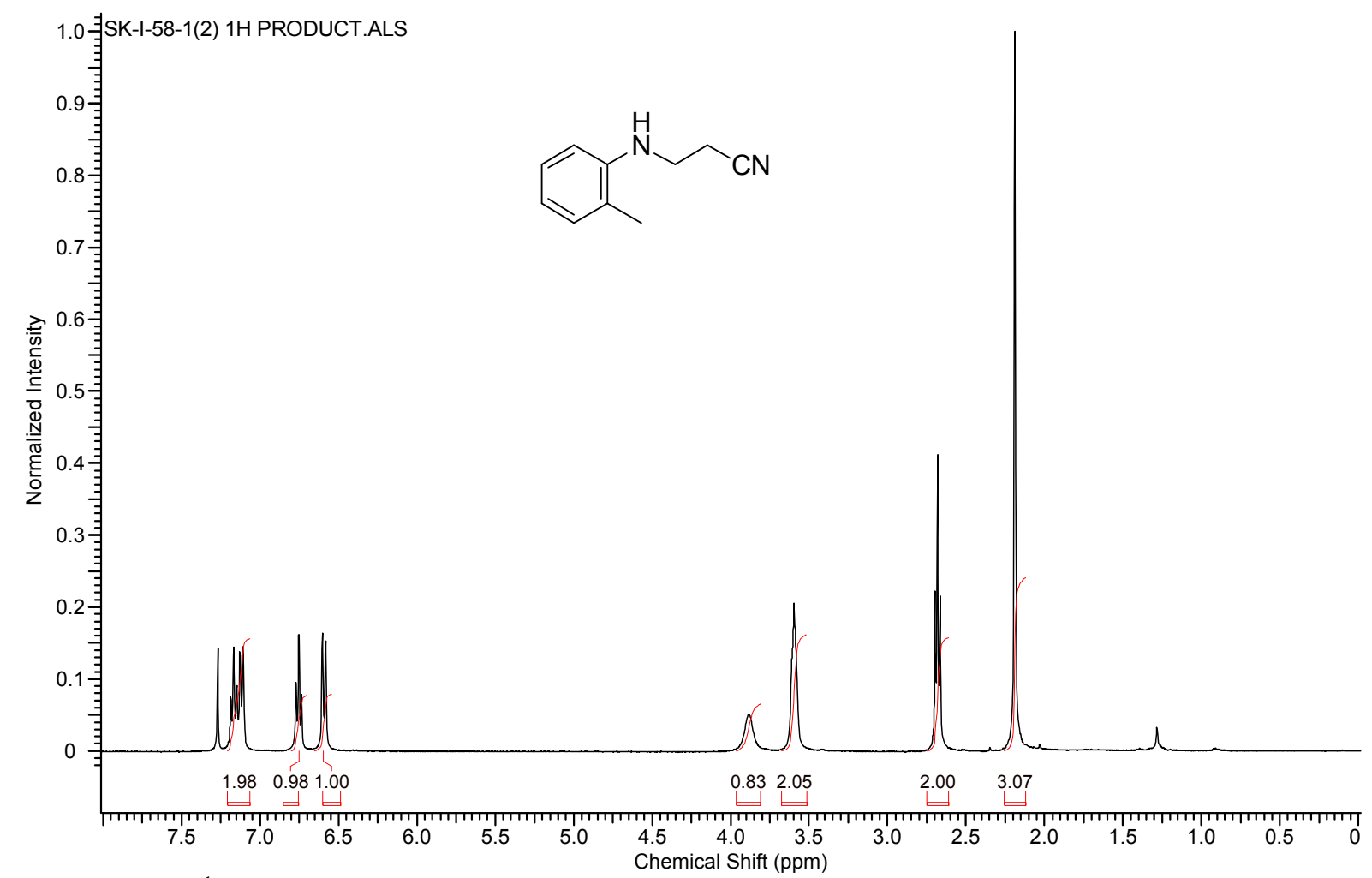

Figure S71. ${ }^{1} \mathrm{H}$ NMR spectrum of the compound 10f

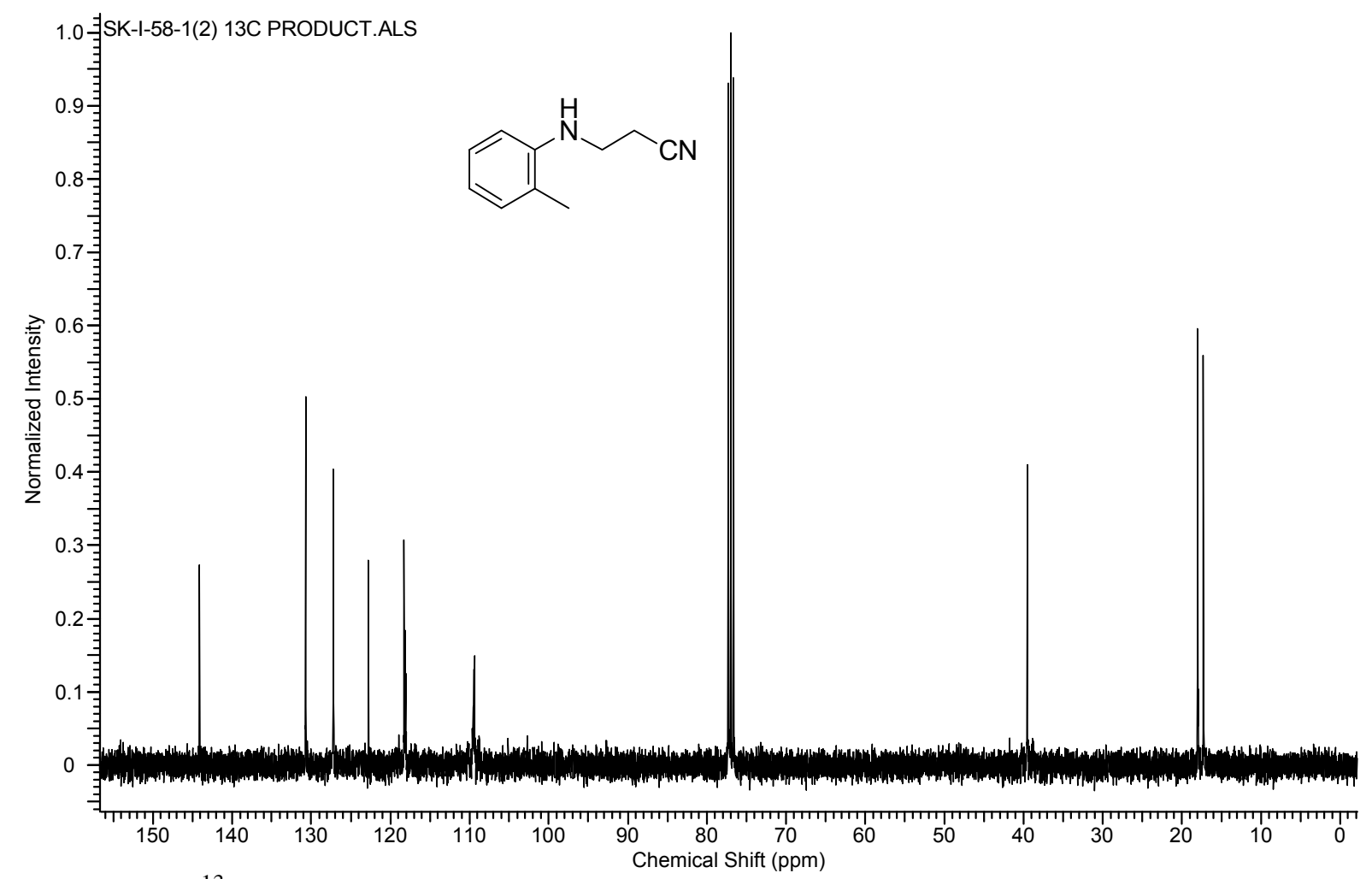

Figure S72. ${ }^{13} \mathrm{C}$ NMR spectrum of the compound $\mathbf{1 0 f}$ 


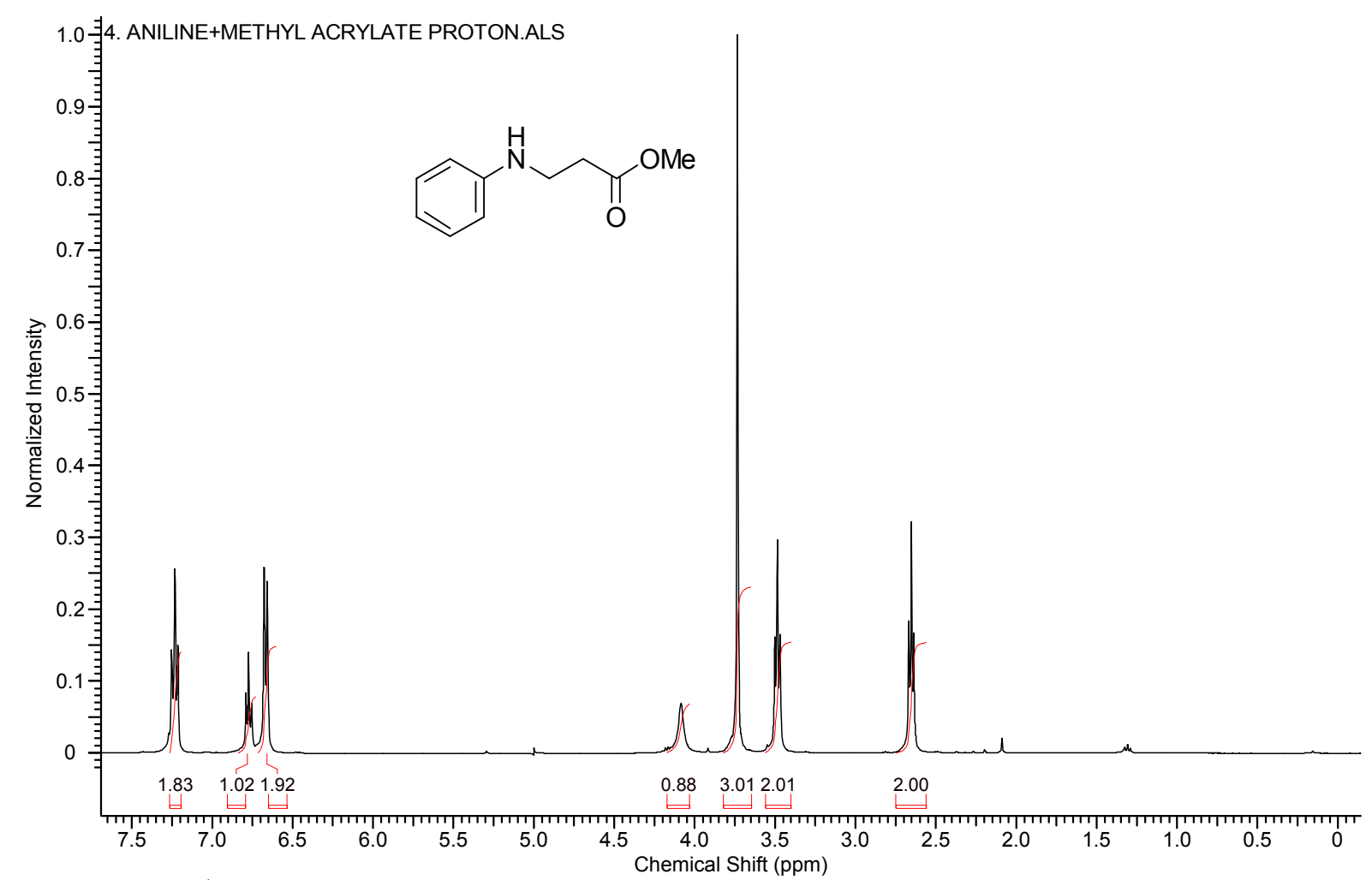

Figure S73. ${ }^{1} \mathrm{H}$ NMR spectrum of the compound $10 \mathrm{~g}$

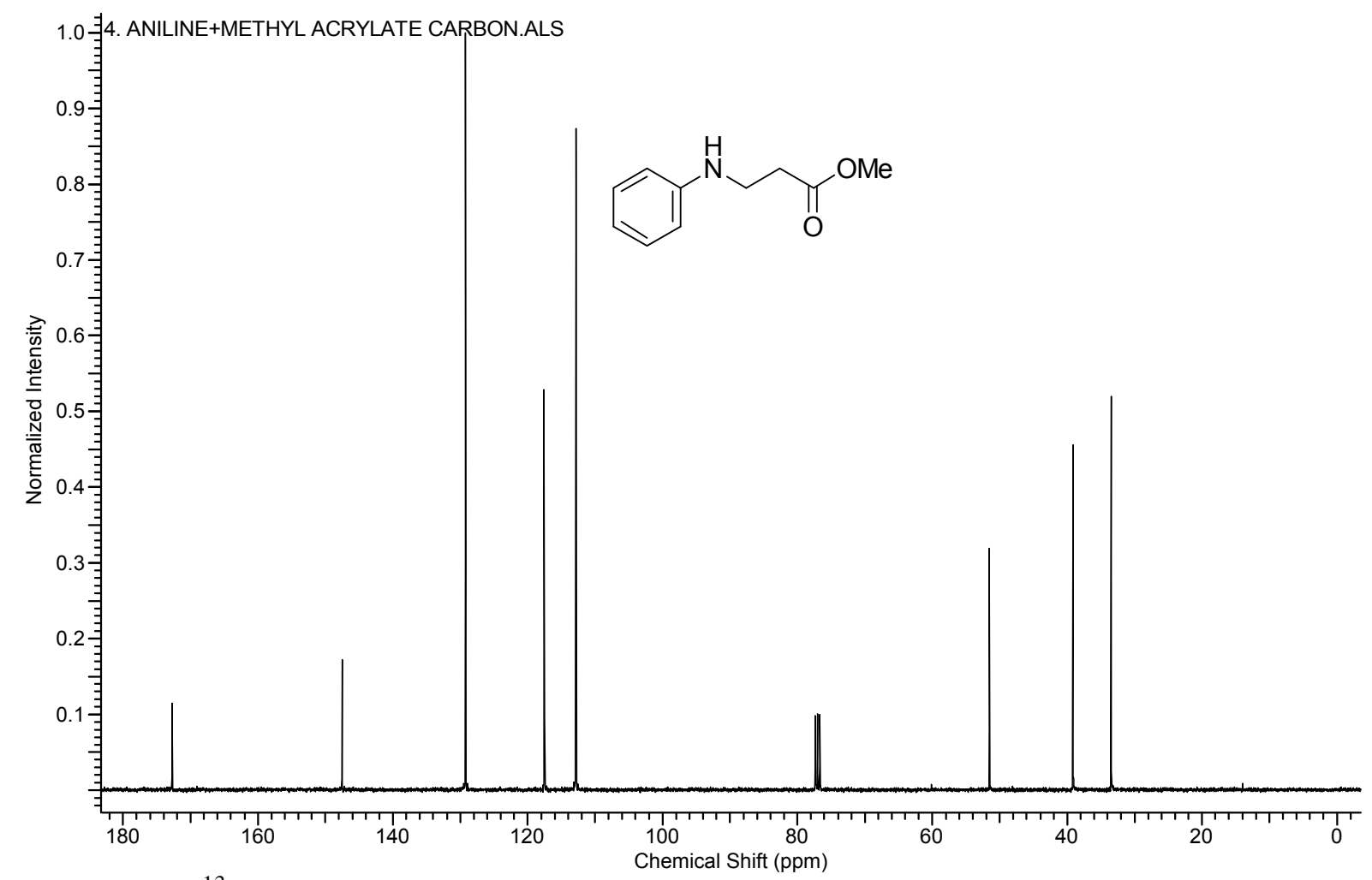

Figure S74. ${ }^{13} \mathrm{C}$ NMR spectrum of the compound $\mathbf{1 0 g}$ 


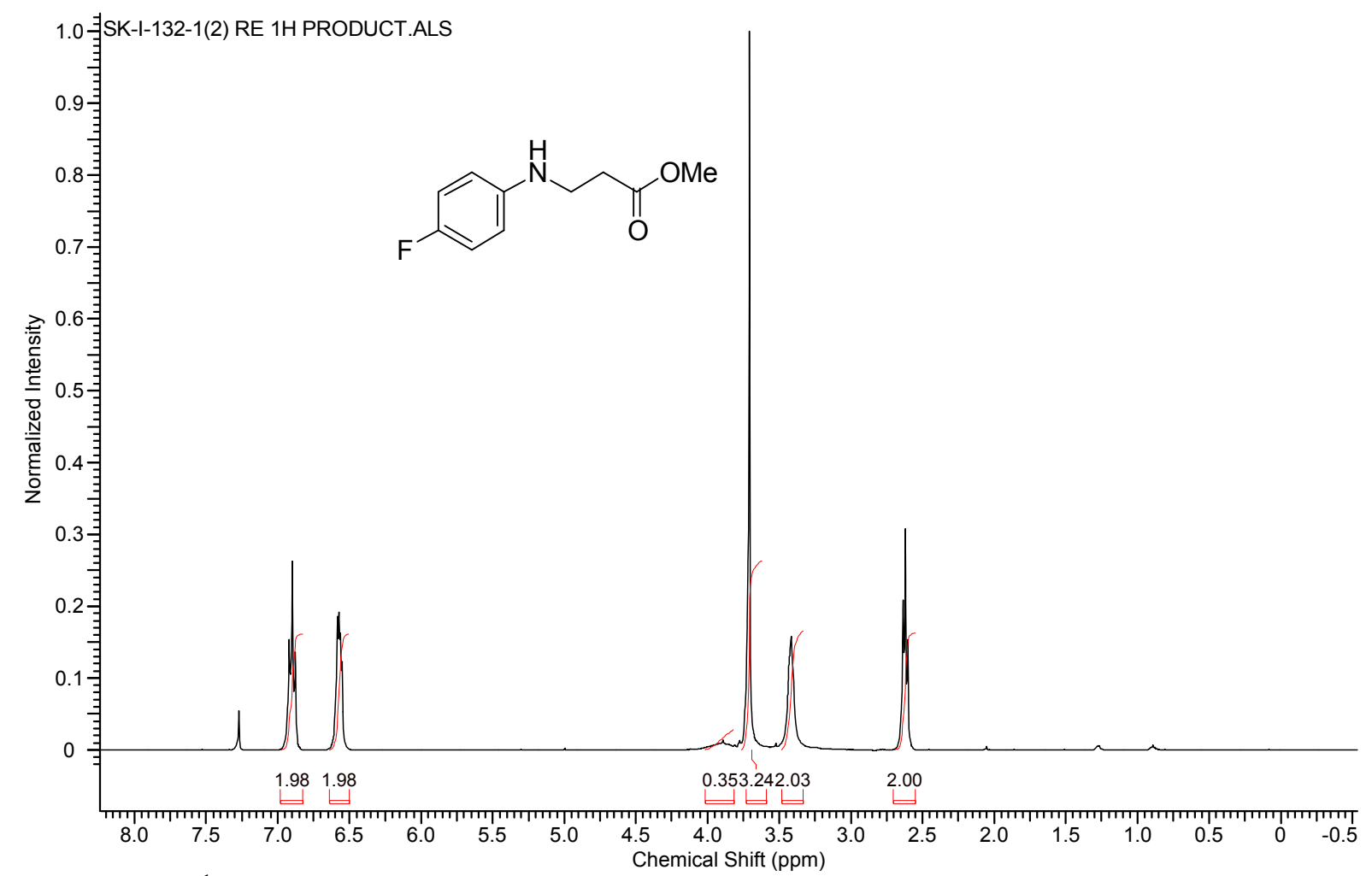

Figure S75. ${ }^{1} \mathrm{H}$ NMR spectrum of the compound $\mathbf{1 0 h}$

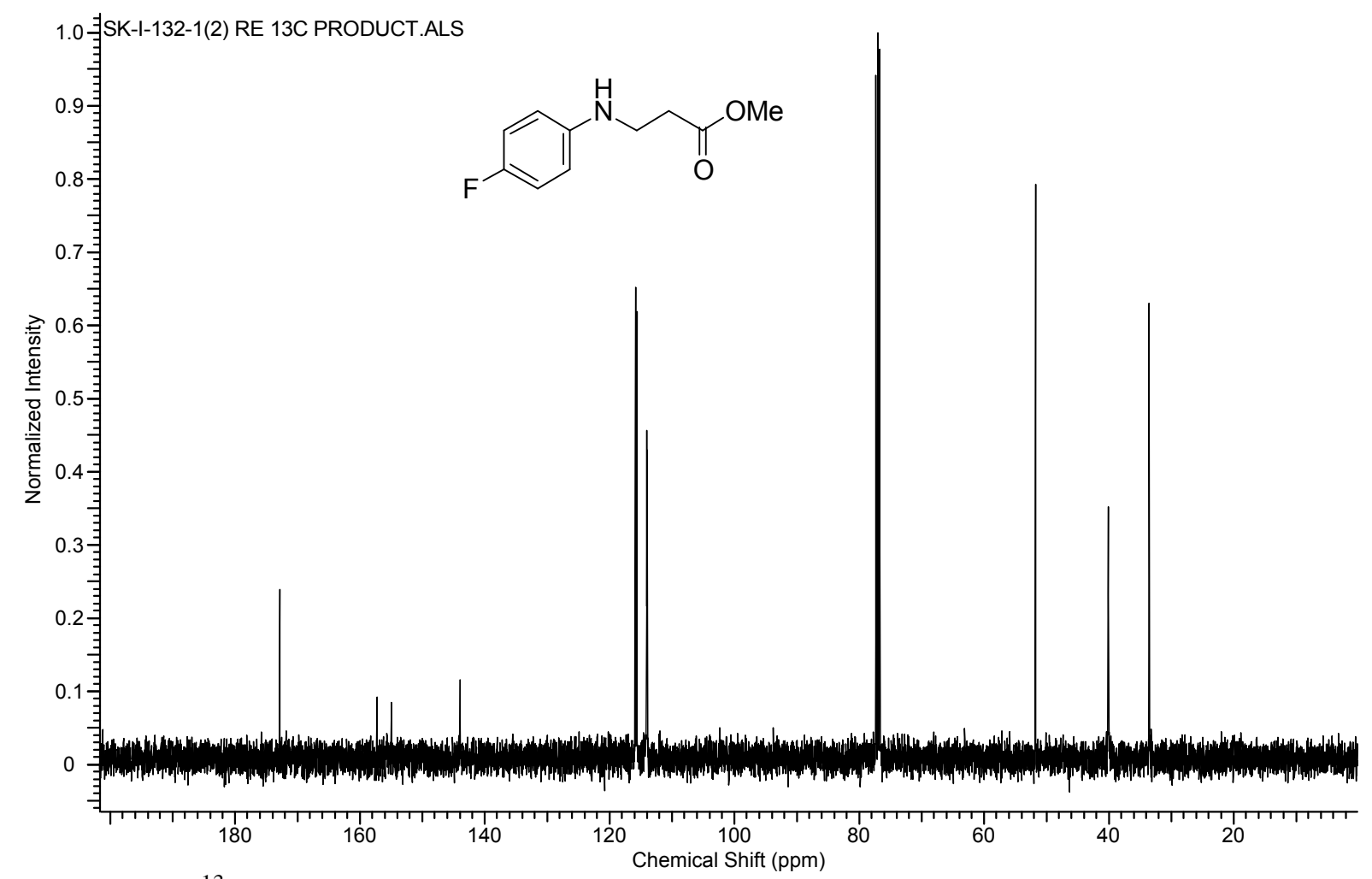

Figure S76. ${ }^{13} \mathrm{C}$ NMR spectrum of the compound $\mathbf{1 0 h}$ 


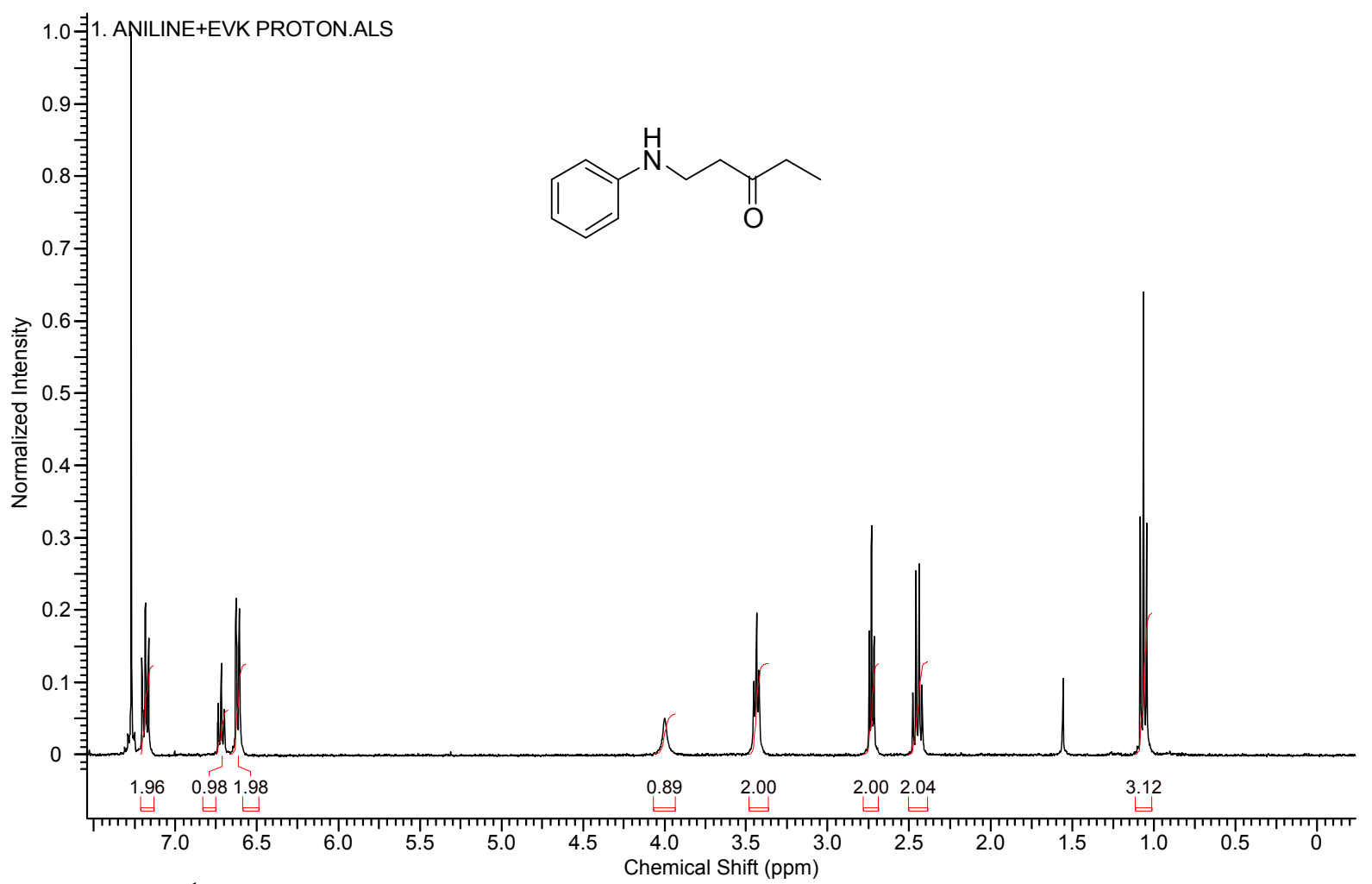

Figure S77. ${ }^{1} \mathrm{H}$ NMR spectrum of the compound $\mathbf{1 0 i}$

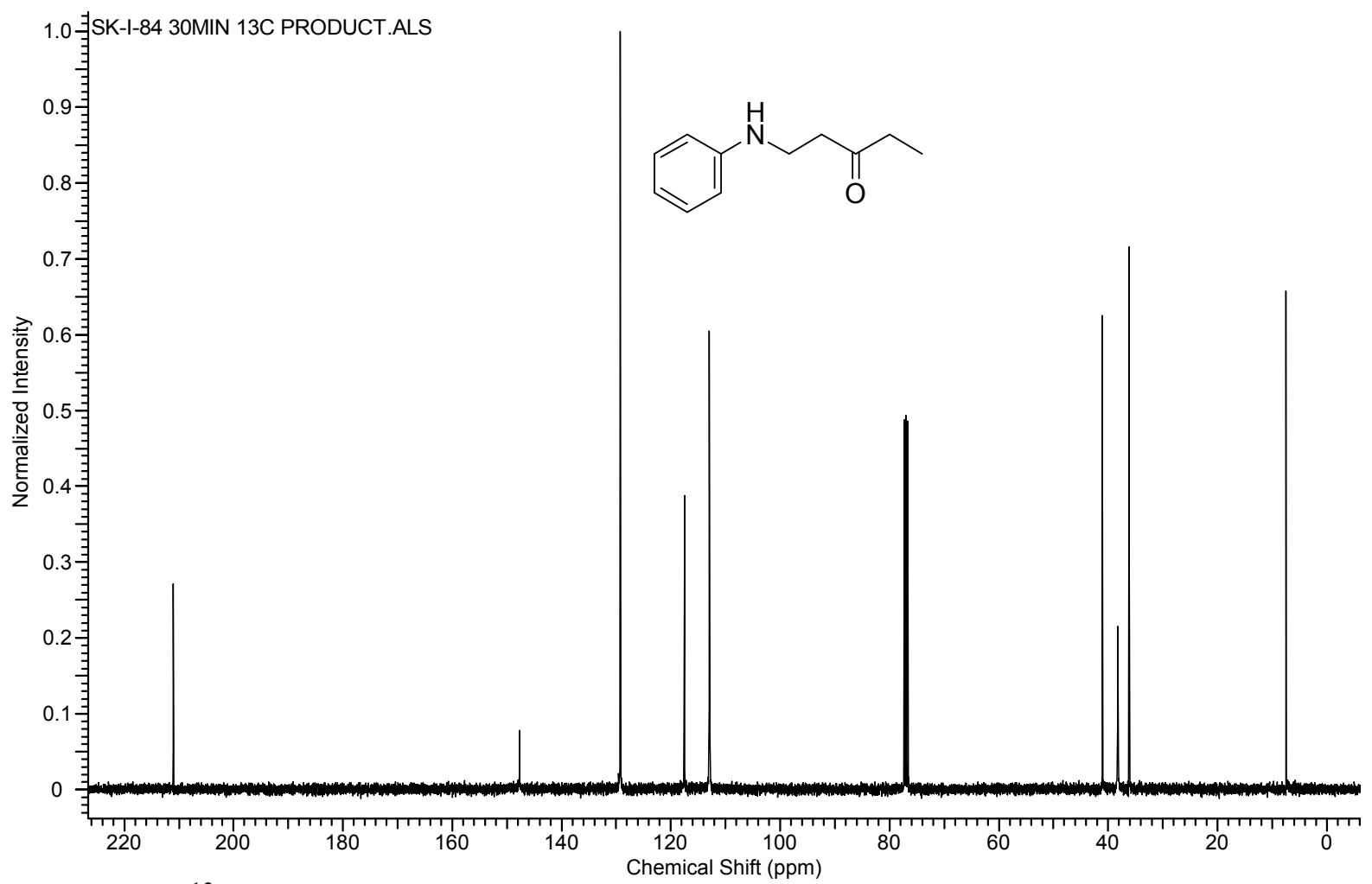

Figure S78. ${ }^{13} \mathrm{C}$ NMR spectrum of the compound $\mathbf{1 0 i}$ 


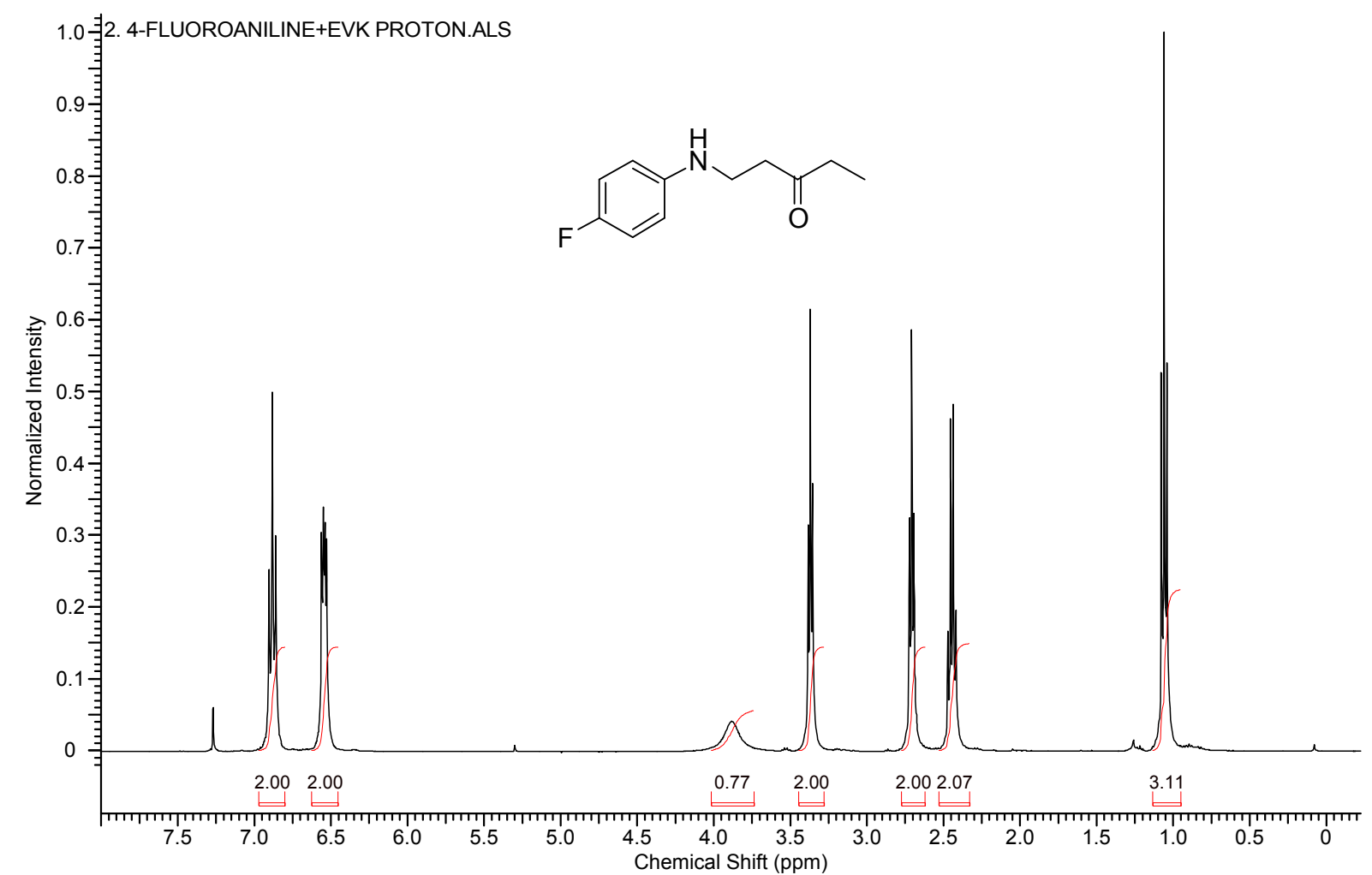

Figure S79. ${ }^{1} \mathrm{H}$ NMR spectrum of the compound $\mathbf{1 0 j}$

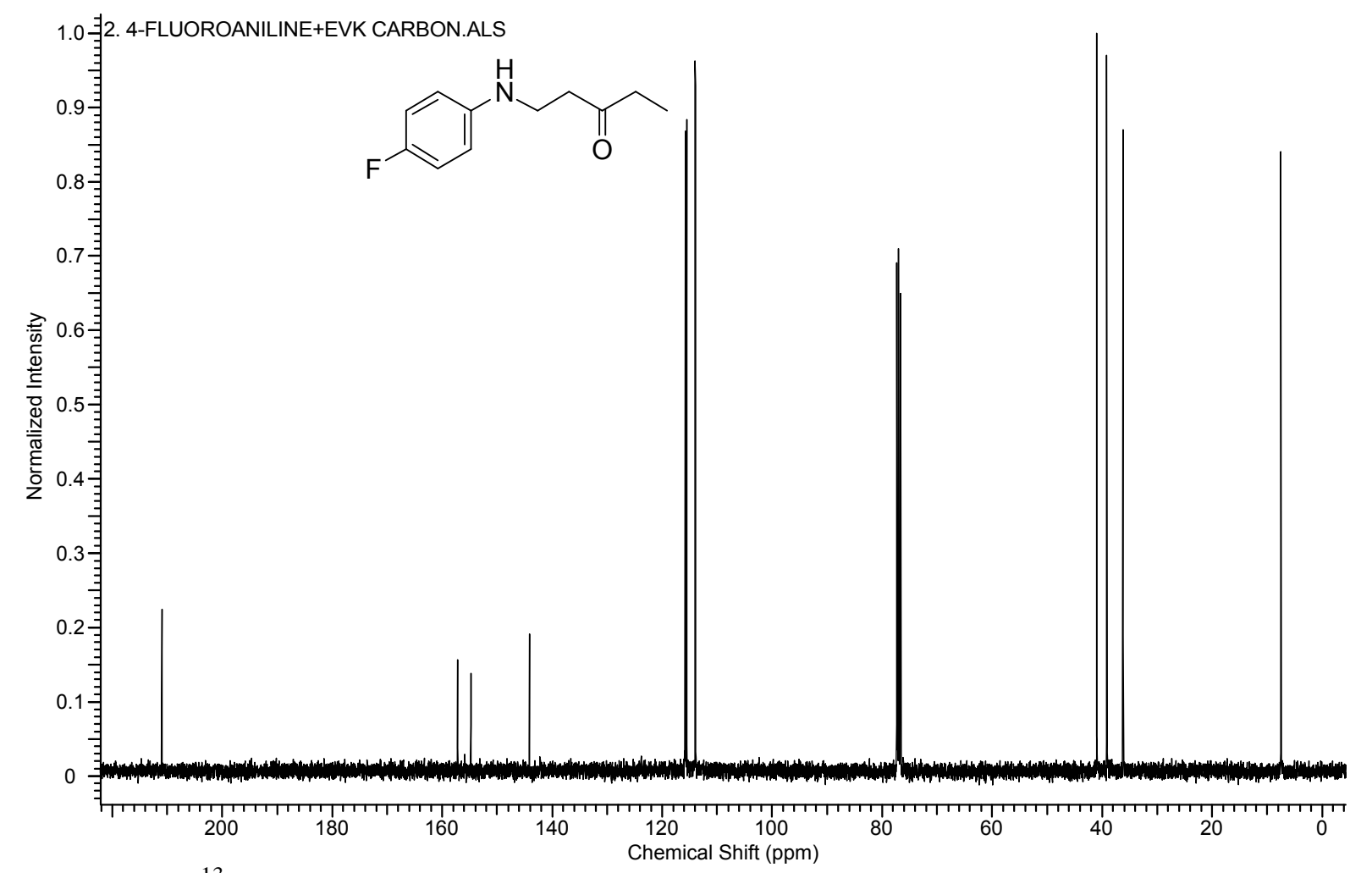

Figure S80. ${ }^{13} \mathrm{C}$ NMR spectrum of the compound $\mathbf{1 0 j}$ 


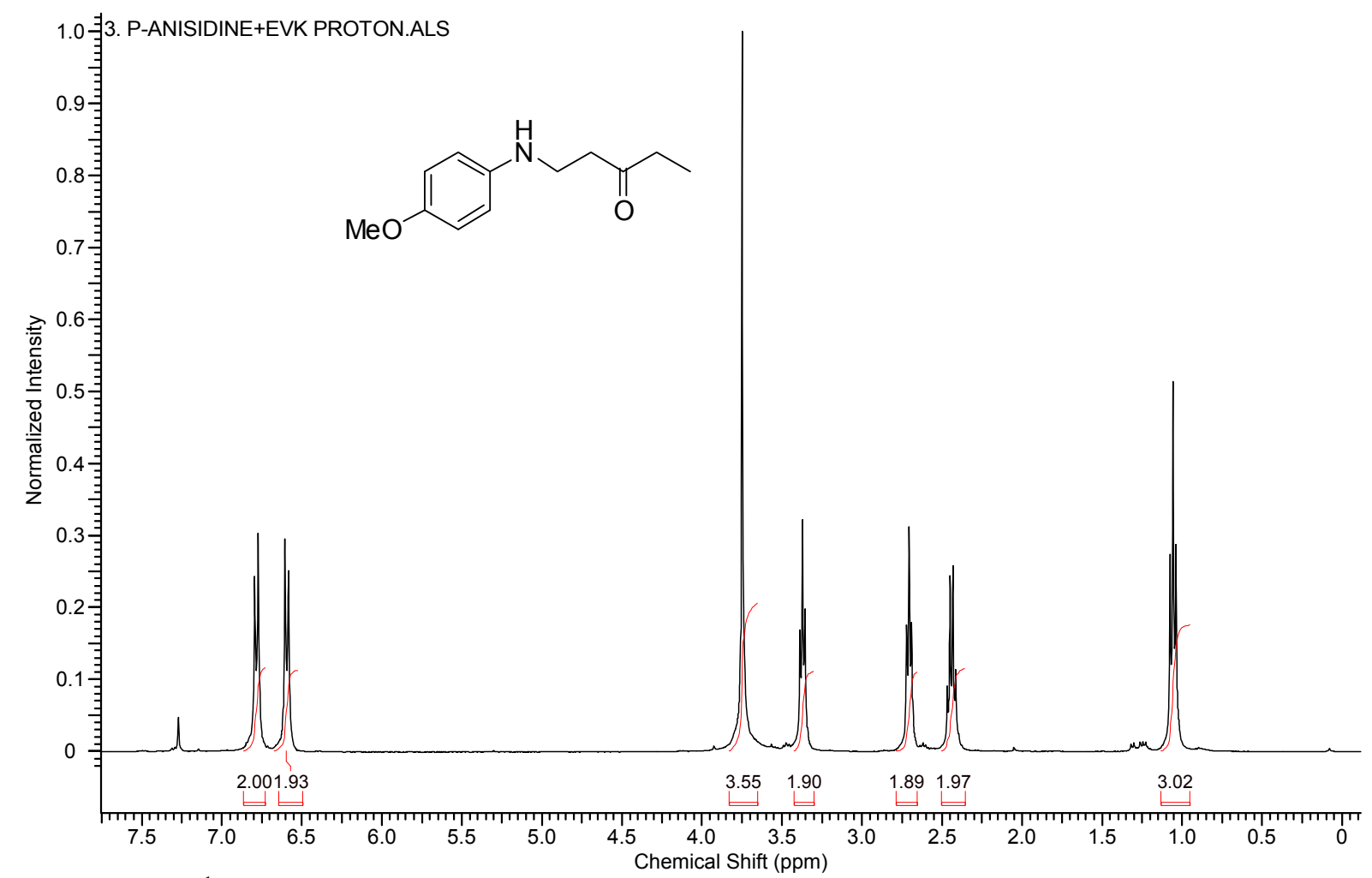

Figure S81. ${ }^{1} \mathrm{H}$ NMR spectrum of the compound 10k

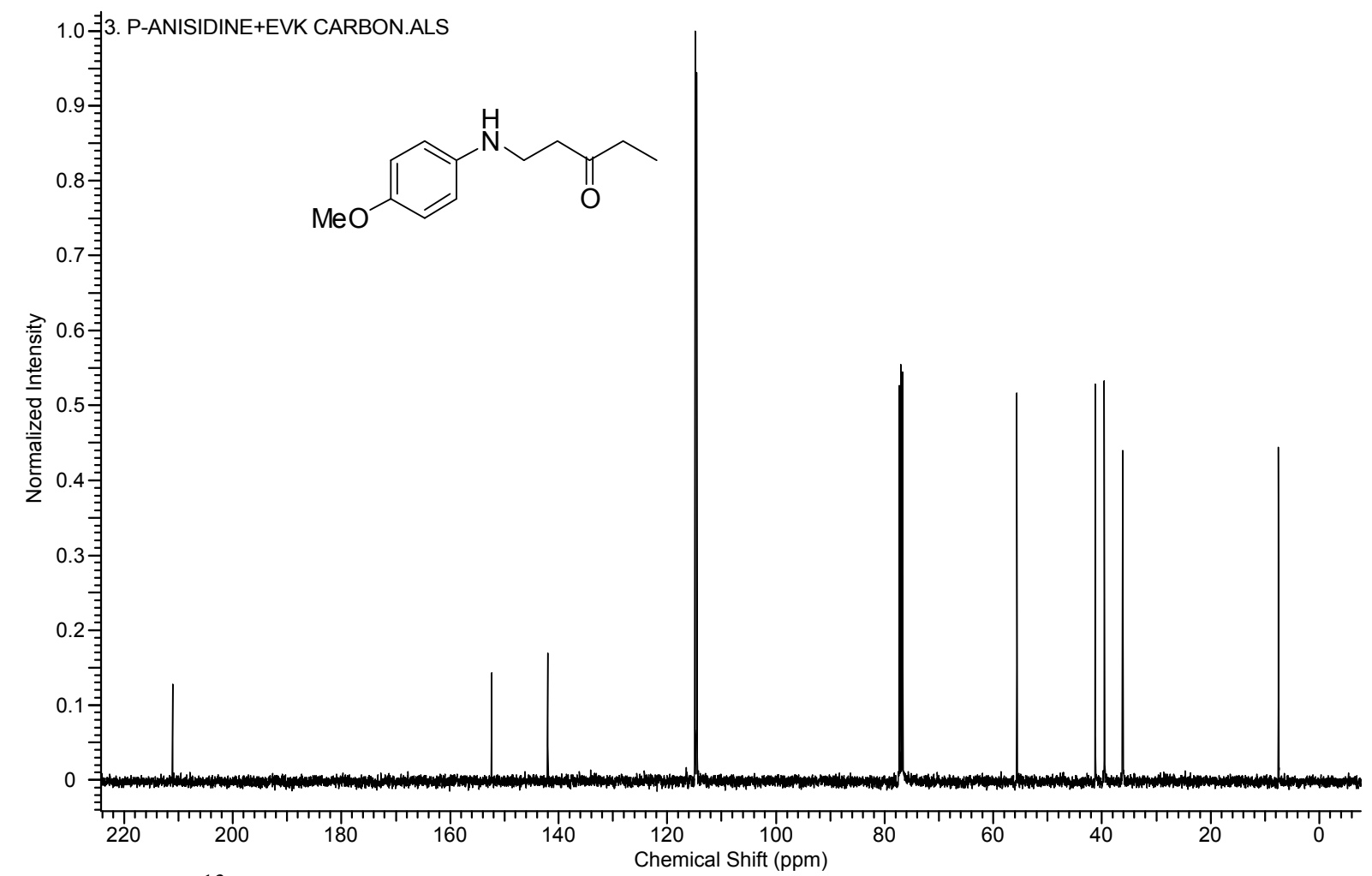

Figure S82. ${ }^{13} \mathrm{C}$ NMR spectrum of the compound 10k 